Supporting Information for

\title{
Construction of Thiazole-Fused Dihydropyrans via Formal [4+2] Cycloaddition Reaction on DNA
}

\author{
Wenting $\mathrm{Wu}^{\dagger}$, Zhen Sun ${ }^{\dagger}$, Xuan Wang ${ }^{\dagger, \ddagger}$, Xiaojie Lu, ${ }^{\ddagger}$, Dongcheng Dai ${ }^{*}{ }^{\dagger}$ \\ †Department of Therapeutic Discovery, Amgen Asia R\&D Center, Amgen Research, 4560 Jinke \\ Road, Pudong, Shanghai 201210, P.R. China \\ $¥$ State Key Laboratory of Drug Research, Shanghai Institute of Materia Medica, Chinese Academy \\ of Science, 501 Haike Road, Zhang Jiang Hi-Tech Park, Pudong, Shanghai 201203, P.R. China
}

E-mail: $\underline{\text { ddai@amgen.com }}$

\section{Table of Contents}

$\begin{array}{ll}\text { 1. General methods } & \text { S2 }\end{array}$

2. Experimental details and characterization data S3-S53

2.1 Preparation of DNA-conjugated 5-alkenyl thiazolone $1 \quad$ S3-S5

2.2 General procedure for aldehydes in formal [4+2] S5 cycloaddition reaction on DNA

$\begin{array}{ll}\text { 2.3 Mass spectra of } 3 & \text { S5-S41 }\end{array}$

2.4 General procedure for ketones in formal [4+2] S41 cycloaddition reaction on DNA

2.5 Mass spectra of 5

2.6 Procedures for enzymatic ligation $\quad$ S53

3. References $\quad$ S54

4. Copies of NMR spectra S55-S56 


\section{General methods}

All reagents were obtained from commercial sources unless otherwise noted. DNA headpiece HP-NH (5'-/5phos/GAGTCA/iSp9/iUniAmM/iSp9/TGACTCCC-3', Figure S1) was purchased from LGC Genomics. All on DNA reactions were performed in PCR tubes or $1.5 \mathrm{~mL}$ eppendorf tubes. On DNA reactions conducted during optimization and extension of substrate scope were analyzed by LCMS. Typically, 1 $\mu \mathrm{L}$ aliquot of the reaction mixture was diluted with $40 \mu \mathrm{L}$ of water and injected into a reverse-phase chromatography column (Xbridge OST C18 column, $1.7 \mu \mathrm{m}, 2.1 * 50 \mathrm{~mm}$ ) from Waters. The samples were eluted as follows: $10-70 \%$ solvent B over $1.5 \mathrm{~min}, 70 \%$ solvent $B$ over $1.5 \mathrm{~min}, 10 \%$ solvent $B$ over $2 \mathrm{~min}, 0.25 \mathrm{~mL} / \mathrm{min}, \lambda=260 \mathrm{~nm}$, solvent $\mathrm{A}: 0.75 \% \mathrm{v} / \mathrm{v}$ hexafluoroisopropanol (HFIP)/0.038\% v/v triethylamine in deionized water, solvent B: $0.75 \% \mathrm{v} / \mathrm{v} \mathrm{HFIP/} 0.038 \%$ triethylamine in methanol/water $=90 / 10$. The effluents were analyzed by a Thermo Scientific LTQ XL Mass Spectrometers in negative ion mode. Mass deconvolution were carried out using BioPharm Finder. NMR spectra were recorded on Bruker Ascend-400M instrument. The following abbreviations are used to designate multiplicities: $\mathrm{s}=$ singlet, $\mathrm{d}=$ doublet, $\mathrm{t}=$ triplet, $\mathrm{q}=$ quartet, $\mathrm{m}=$ multiplet, quint = quintet, $\mathrm{br}=$ broad. Highresolution mass spectra (HRMS) were recorded on a Waters Xevo G2-XS QTof mass spectrometer.

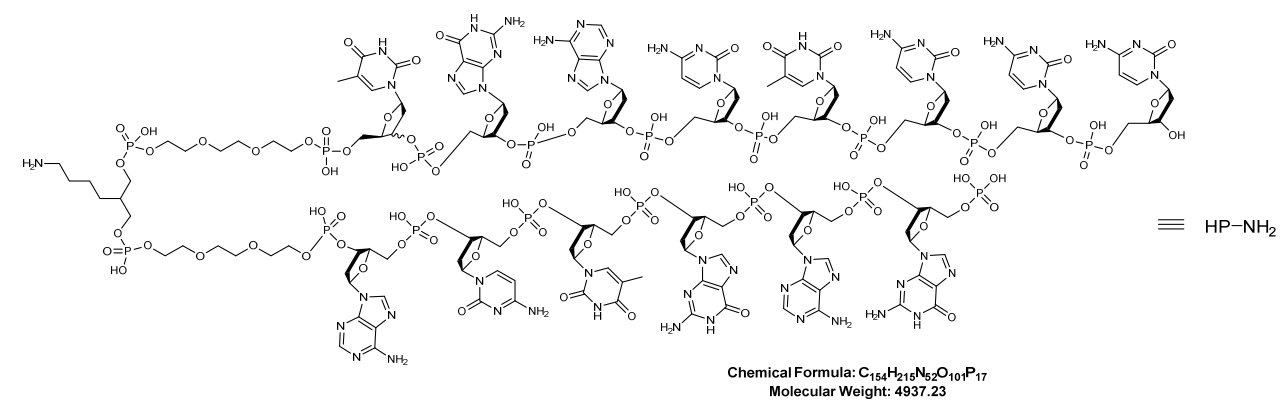

Figure S1. Headpiece (HP-NH 2 ): 5'-/5phos/GAGTCA/iSp9/iUniAmM/iSp9/TGACTCCC-3', MW = 4937.23 


\section{Experimental details and characterization data}

\subsection{Preparation of DNA-conjugated 5-alkenyl thiazolone 1}
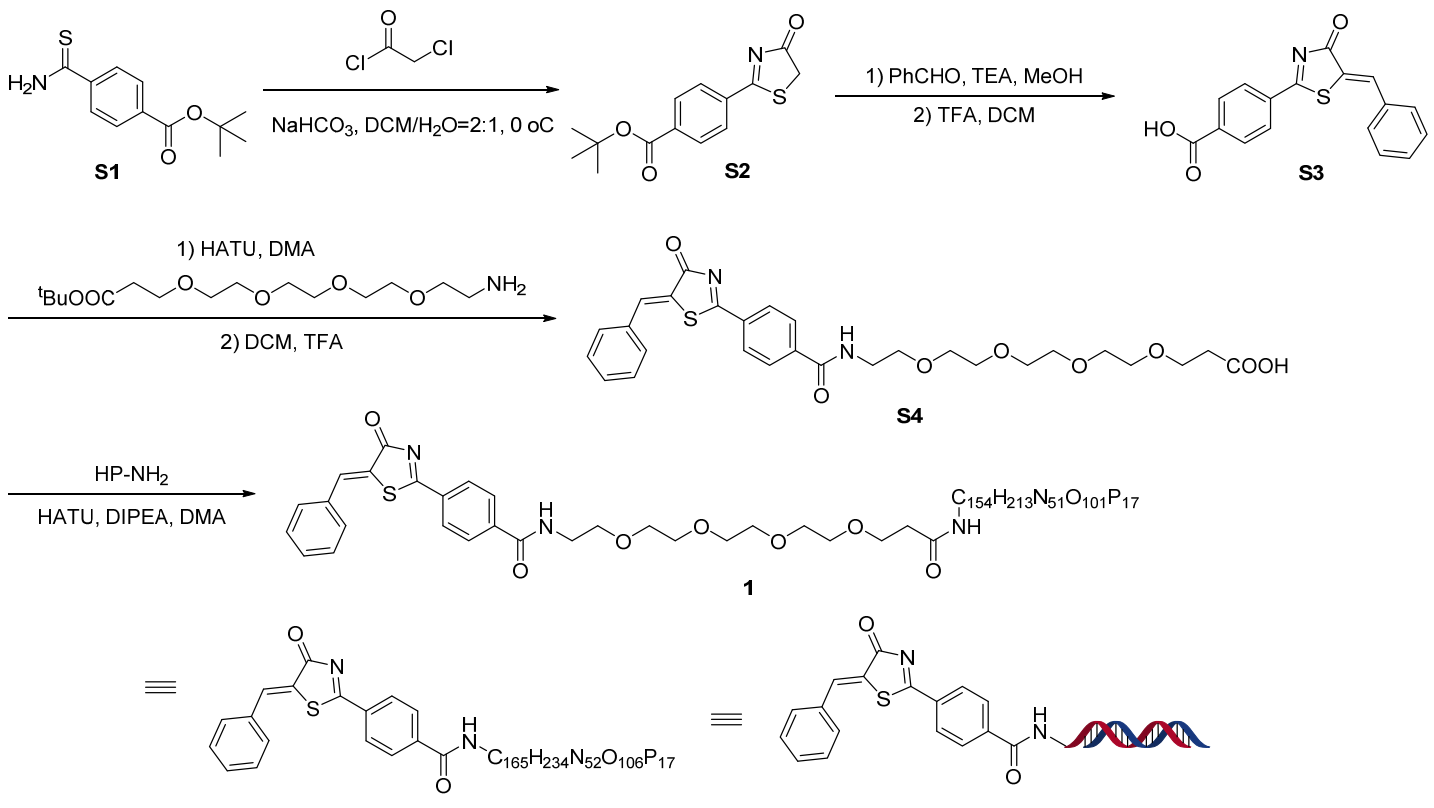

Molecular Weight: 5475.85

Thioamide $\mathbf{S 1}$ was prepared according to known literature. ${ }^{1}$ Compound $\mathbf{S 2}$ and $\mathbf{S 3}$ were prepared via similar routes reported in the literature. ${ }^{2}$

To a solution of $\mathrm{NaHCO}_{3}(115 \mathrm{mg}, 1.369 \mathrm{mmol})$ in water $(3 \mathrm{~mL})$ was added to a solution of thioamide S1 (130 mg, $0.548 \mathrm{mmol})$ in DCM (6 mL). After cooling to $0^{\circ} \mathrm{C}$, 2-chloroacetyl chloride (68.1 mg, 0.603 $\mathrm{mmol}$ ) was added dropwisely to the stirred solution. Then the solution was stirred at $0^{\circ} \mathrm{C}$ for $15 \mathrm{~min}$. The progress of the reaction was monitored by LCMS and TLC. When most matieral was consumed, the organic phase in reaction mixture was separated. The water phase was extracted with DCM (3x $20 \mathrm{~mL}$ ). The combined organic phase was dried over $\mathrm{Na}_{2} \mathrm{SO}_{4}$, filtered and concentrated in vacuo to give the crude material $\mathbf{S 2}$ as a orange oil. $\mathbf{S 2}$ was used immediately without further purification.

To a solution of crude material S2 (120 mg, $0.433 \mathrm{mmol})$ and benzaldehyde $(92 \mathrm{mg}, 0.865 \mathrm{mmol})$ in methanol $(5 \mathrm{~mL})$ was added TEA $(121 \mu \mathrm{l}, 0.865 \mathrm{mmol})$. The reaction was stirred at $75^{\circ} \mathrm{C}$ for $1 \mathrm{~h}$. LCMS and TLC showed the reaction was completed. The crude material was absorbed onto a plug of silica gel and purified by chromatography through a Redi-Sep pre-packed silica gel column (12 g). Eluting with a gradient of $0 \%$ to $20 \%$ EtOAc in hexane, target product $(70 \mathrm{mg}, 0.192 \mathrm{mmol}, 44.3 \%$ yield) was obtained as yellow solid. To a solution of above product $(70 \mathrm{mg}, 0.192 \mathrm{mmol}$ ) in DCM ( $3 \mathrm{~mL}$ ) was added TFA ( $1 \mathrm{~mL}, 12.98 \mathrm{mmol})$. The reaction was stirred at room temperature for $16 \mathrm{~h}$. LCMS and TLC showed the reaction was completed. The solution was concentrated in vacuo to give the crude material $\mathbf{S} \mathbf{3}$ as a yellow solid.

To a solution of compound S3 $(50 \mathrm{mg}, 0.162 \mathrm{mmol})$ and HATU $(73.8 \mathrm{mg}, 0.194 \mathrm{mmol})$ in N, Ndimethylacetamide ( $4 \mathrm{~mL}$ ) was added tert-butyl 1-amino-3,6,9,12-tetraoxapentadecan-15-oate (156 $\mathrm{mg}, 0.485 \mathrm{mmol}$ ). The reaction was stirred at room temperature for $3 \mathrm{~h}$. LCMS and TLC showed the 
reaction was completed. The reaction mixture was diluted with water $(15 \mathrm{~mL})$ and extracted with EtOAc $(3 \times 20 \mathrm{~mL})$. The organic extract was washed with brine $(3 \times 10 \mathrm{~mL})$ and dried over $\mathrm{Na}_{2} \mathrm{SO}_{4}$. The solution was filtered and concentrated in vacuo to give the crude material .The crude material was absorbed onto a plug of silica gel and purified by chromatography through a Redi-Sep pre-packed silica gel column (12 g), eluting with a gradient of $0 \%$ to $100 \%$ EtOAc in hexane, to provide target compound ( $70 \mathrm{mg}, 0.114 \mathrm{mmol}, 70.7 \%$ yield) as green solid. To a solution of above compound (70 $\mathrm{mg}, 0.114 \mathrm{mmol})$ in dichloromethane $(5 \mathrm{~mL})$ was added TFA $(8.80 \mu \mathrm{l}, 0.114 \mathrm{mmol})$. The reaction was stirred at room temperature for $16 \mathrm{~h}$. LCMS and TLC showed the reaction was completed. The solution was concentrated in vacuo to give the crude material .Then the crude material was purified by PrepHPLC to give compound $\mathbf{S} 4$ (30 mg, $0.052 \mathrm{mmol}, 45.6 \%$ yield) as green solid.

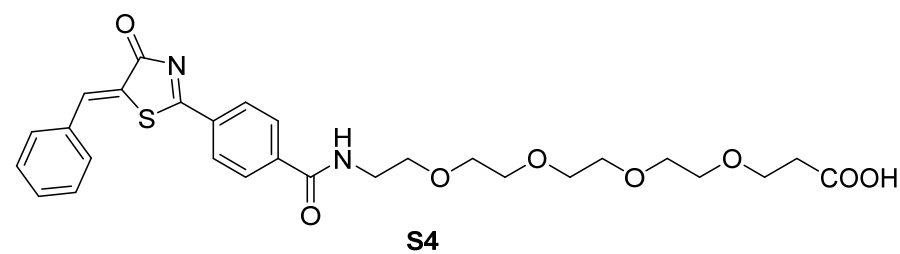

S4: green solid, $30 \mathrm{mg}$, 46\% yield. ${ }^{1} \mathrm{H}$ NMR (400 MHz, $\left.\mathrm{CDCl}_{3}\right) \delta 8.23(\mathrm{~d}, J=8.4 \mathrm{~Hz}, 2 \mathrm{H}), 8.09-8.07$ (m, 3H), 7.98 (t, $J=4.8 \mathrm{~Hz}, 1 \mathrm{H}), 7.68$ (d, $J=6.4 \mathrm{~Hz}, 2 \mathrm{H}), 7.51$ (d, $J=7.6 \mathrm{~Hz}, 2 \mathrm{H}), 5.33$ (brs, 2H), 3.75$3.72(\mathrm{~m}, 4 \mathrm{H}), 3.71-3.67(\mathrm{~m}, 4 \mathrm{H}), 3.65-3.64(\mathrm{~m}, 3 \mathrm{H}), 3.61-3.58(\mathrm{~m}, 7 \mathrm{H}), 2.55(\mathrm{t}, J=6.0 \mathrm{~Hz}, 2 \mathrm{H}) .{ }^{13} \mathrm{C}$ NMR (101 MHz, $\left.\mathrm{CDCl}_{3}\right) \delta 186.7,183.0,175.0,166.4,140.3,139.4,133.8,133.6,131.4,130.8,129.4$, $128.8,128.3,126.1,70.41,70.37,70.3,70.1,69.9,66.9,40.0,35.5$. HRMS (ESI-QTOF) m/z: [M + H] ${ }^{+}$ Calcd for $\mathrm{C}_{28} \mathrm{H}_{33} \mathrm{~N}_{2} \mathrm{O}_{8} \mathrm{~S} 557.1952$; Found 557.1959.

To a solution of compound S4 (100 uL, $50 \mathrm{mM}$ in DMA, $5000 \mathrm{nmol})$ was added [dimethylamino(triazolo[4,5-b]pyridin-3-yloxy)methylidene]-dimethylazanium (HATU) (25 uL, 200 $\mathrm{mM}$ in DMA, $5000 \mathrm{nmol}$ ) and N,N-diisopropylethylamine (DIPEA) (25 uL, $200 \mathrm{mM}$ in DMA, $5000 \mathrm{nmol}$ ). To a solution of DNA headpiece ( $25 \mathrm{uL}, 1 \mathrm{mM}, 50 \mathrm{nmol}$ ) in $\mathrm{pH}=9.4$ borate buffer was added above DMA solution. The resultant mixture was vortexed and stood at $20^{\circ} \mathrm{C}$ for $15 \mathrm{~min}$. Aqueous $\mathrm{NaCl}(20$ $\mu \mathrm{L}, 5.0 \mathrm{M})$ and cold ethanol $(0.5 \mathrm{~mL})$ were sequentially added and the resultant mixture was stored at $-80{ }^{\circ} \mathrm{C}$ for $2 \mathrm{~h}$. The mixture was centrifuged at $4{ }^{\circ} \mathrm{C}$ for $30 \mathrm{~min}$ at $10000 \mathrm{rpm}$ before the resultant supernatant was removed. The pellet was dissolved in deionized water, cooled and lyophilized to obtain the DNA-conjugated 5-alkenyl thiazolone 1 which was used without further purification.

\section{Mass spectrum of 1}

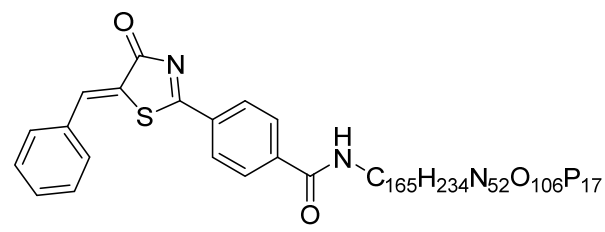

Molecular Weight: 5475.85 
wwt-0506-1

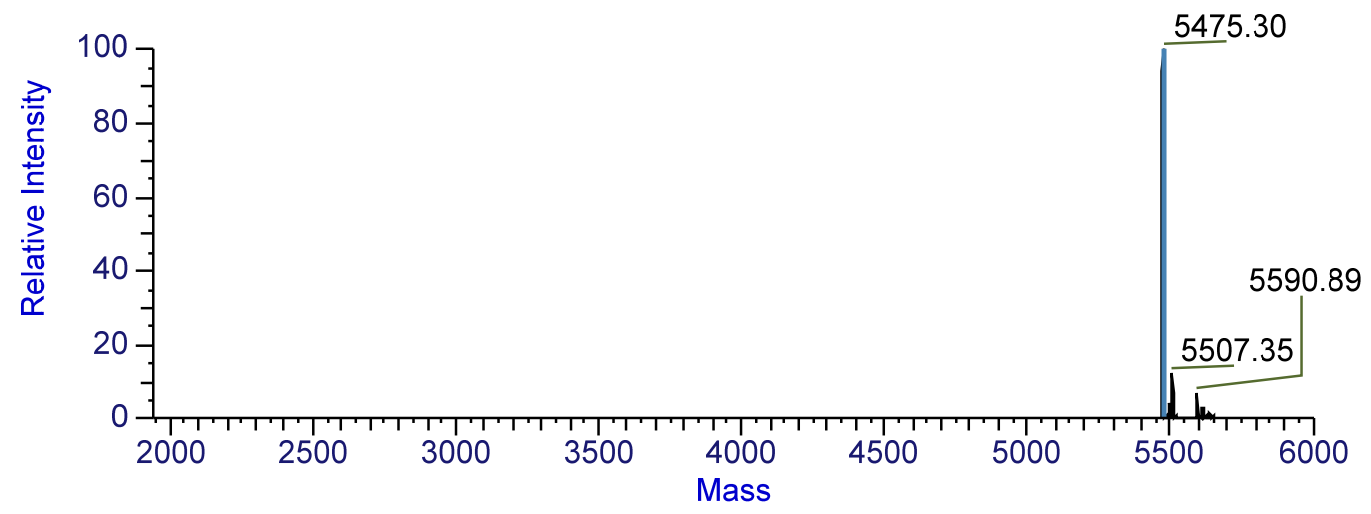

\begin{tabular}{|r|r|r|r|}
\hline Average Mass & Intensity & Relative Abundance & Fractional Abundance \\
\hline 5475.30 & $4.52 \mathrm{E}+05$ & 100.00 & 79.55 \\
\hline 5507.35 & $5.38 \mathrm{E}+04$ & 11.90 & 9.46 \\
\hline 5590.89 & $2.95 \mathrm{E}+04$ & 6.52 & 5.19 \\
\hline 5497.05 & $1.66 \mathrm{E}+04$ & 3.67 & 2.92 \\
\hline 5614.60 & $1.00 \mathrm{E}+04$ & 2.22 & 1.77 \\
\hline 5637.10 & $3.98 \mathrm{E}+03$ & 0.88 & 0.70 \\
\hline 5605.25 & $2.36 \mathrm{E}+03$ & 0.52 & 0.42 \\
\hline
\end{tabular}

\subsection{General procedure for aldehydes in formal [4+2] cycloaddition reaction on DNA}<smiles>O=C(COc1ccccc1)NC(=O)c1ccc(C2=NC(=O)C(=Cc3ccccc3)S2)cc1</smiles><smiles>[R]CC=O</smiles>

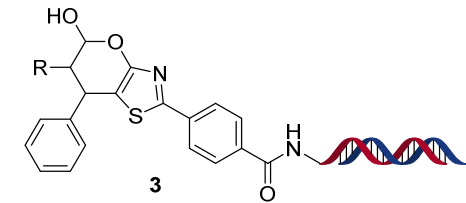

To a solution of DNA-linked 1 ( $5 \mathrm{nmol}, 1$ equiv) in water $(5 \mu \mathrm{L})$ was added a solution of aldehyde 2 (1000 nmol, 200 equiv, 200 mM in DMSO, 5 uL), pyrrolidine (200 nmol, 40 equiv, 200 mM in DMSO, $1 \mathrm{uL})$, and benzoic acid ( $\mathrm{BzOH})(200 \mathrm{nmol}, 40$ equiv, $200 \mathrm{mM}$ in DMSO, $1 \mathrm{uL})$. The resultant mixture was vortexed and stood at room temperature for overnight. When LTQ-LCMS showed that reaction was completed, aqueous $\mathrm{NaCl}(2.0 \mu \mathrm{L}, 5.0 \mathrm{M})$ and cold ethanol $(60 \mu \mathrm{L})$ were sequentially added and the resultant mixture was stored at $-80{ }^{\circ} \mathrm{C}$ for $2 \mathrm{~h}$. The mixture was centrifuged at $4{ }^{\circ} \mathrm{C}$ for $30 \mathrm{~min}$ at $10000 \mathrm{rpm}$ before the resultant supernatant was removed. The pellet was dissolved in deionized water and analyzed by fractional abundance LTQ-LCMS to determine the yield of the formal [4+2] cycloaddition reaction.

\subsection{Mass spectra of 3}

Note: Information of top 10 ions, if existed, were listed in the table. Information of desired product was highlighted in yellow, while information of starting material remained, if any, was highlighted in green. 


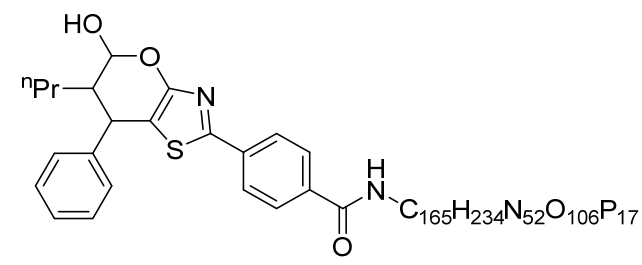

Molecular Weight: 5561.98

wwt-0508-overnight-2

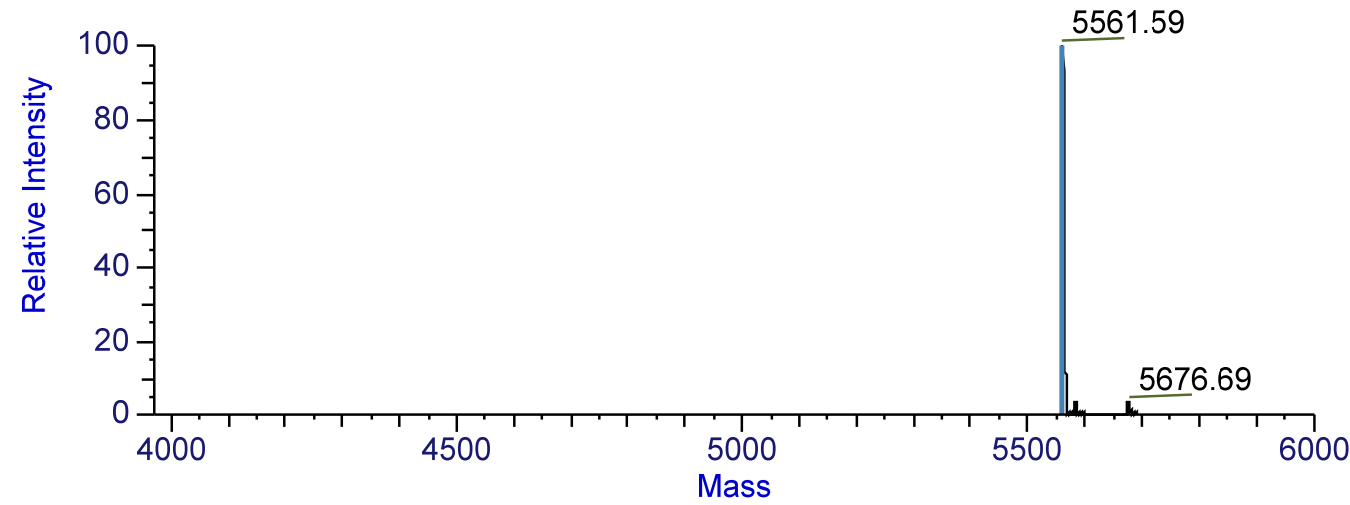

\begin{tabular}{|r|l|r|r|}
\hline Average Mass & Intensity & Relative Abundance & Fractional Abundance \\
\hline 5561.59 & $5.72 \mathrm{E}+05$ & 100.00 & 94.24 \\
\hline 5676.69 & $1.82 \mathrm{E}+04$ & 3.18 & 3.00 \\
\hline 5583.50 & $1.68 \mathrm{E}+04$ & 2.94 & 2.77 \\
\hline
\end{tabular}

$3 b$

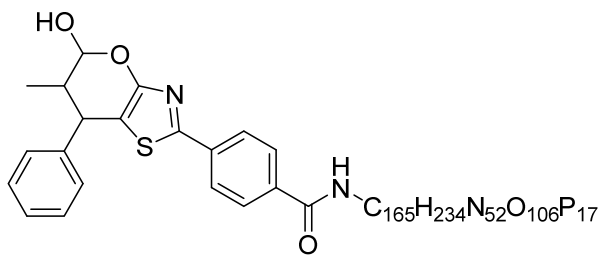

Molecular Weight: 5533.93

wwt-0508-overnight-3

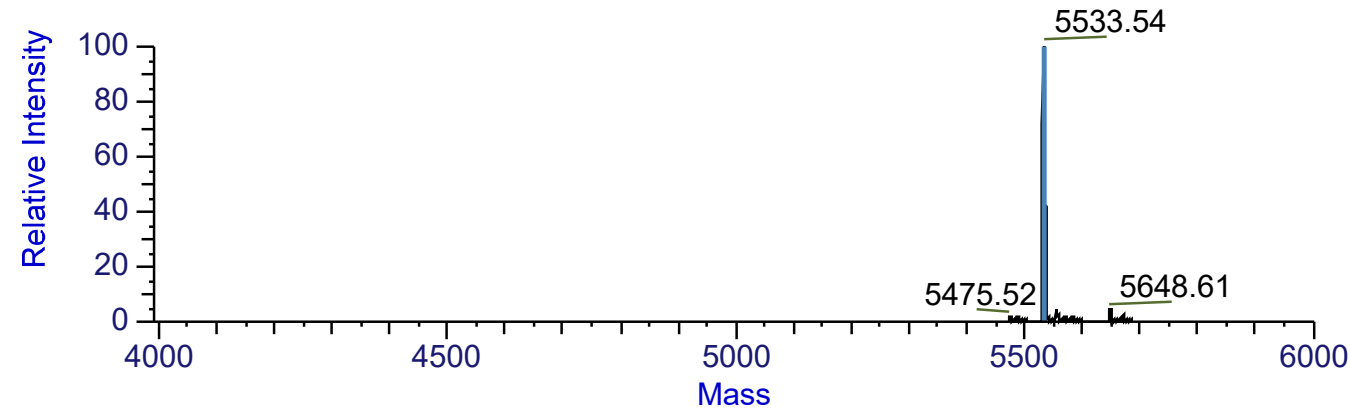




\begin{tabular}{|r|l|r|r|}
\hline Average Mass & Intensity & Relative Abundance & Fractional Abundance \\
\hline 5533.54 & $6.79 \mathrm{E}+05$ & 100.00 & 86.80 \\
\hline 5648.61 & $2.65 \mathrm{E}+04$ & 3.90 & 3.39 \\
\hline 5555.58 & $2.65 \mathrm{E}+04$ & 3.89 & 3.38 \\
\hline 5671.92 & $1.49 \mathrm{E}+04$ & 2.20 & 1.91 \\
\hline 5572.24 & $1.02 \mathrm{E}+04$ & 1.51 & 1.31 \\
\hline 5475.52 & $8.57 \mathrm{E}+03$ & 1.26 & 1.09 \\
\hline 5490.02 & $8.50 \mathrm{E}+03$ & 1.25 & 1.09 \\
\hline 5585.04 & $8.11 \mathrm{E}+03$ & 1.19 & 1.04 \\
\hline
\end{tabular}

3c

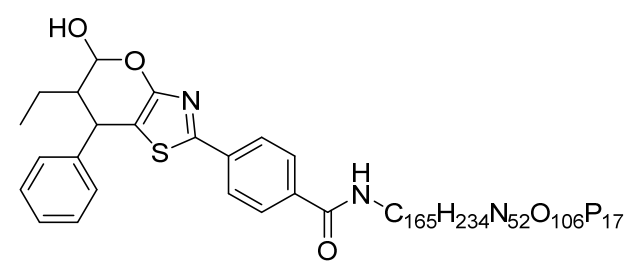

Molecular Weight: 5547.95

wwt-0508-overnight-9

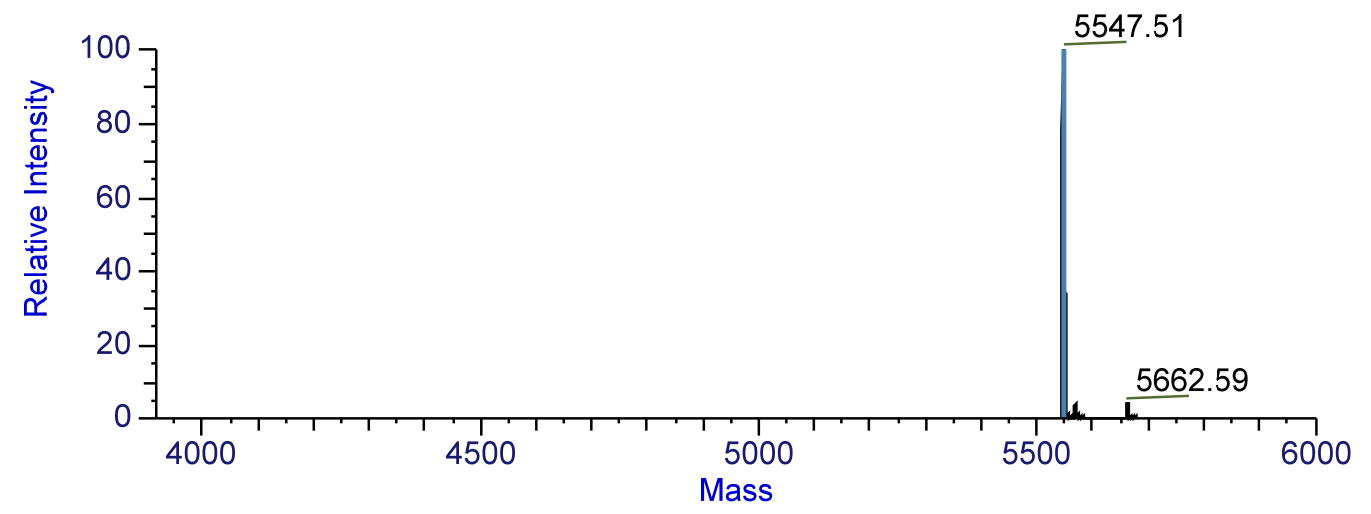

\begin{tabular}{|r|l|r|r|}
\hline Average Mass & Intensity & Relative Abundance & Fractional Abundance \\
\hline 5547.51 & $4.29 \mathrm{E}+05$ & 100.00 & 93.29 \\
\hline 5662.59 & $1.58 \mathrm{E}+04$ & 3.67 & 3.43 \\
\hline 5569.41 & $1.51 \mathrm{E}+04$ & 3.51 & 3.28 \\
\hline
\end{tabular}




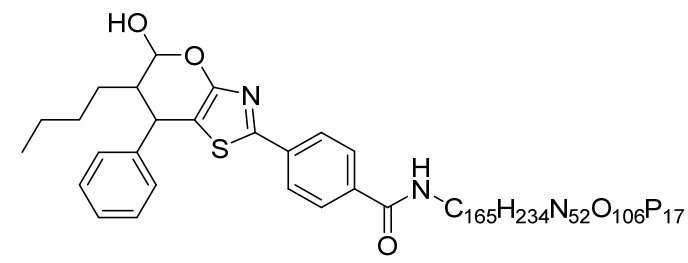

Molecular Weight: 5576.01

wwt-0508-overnight-5

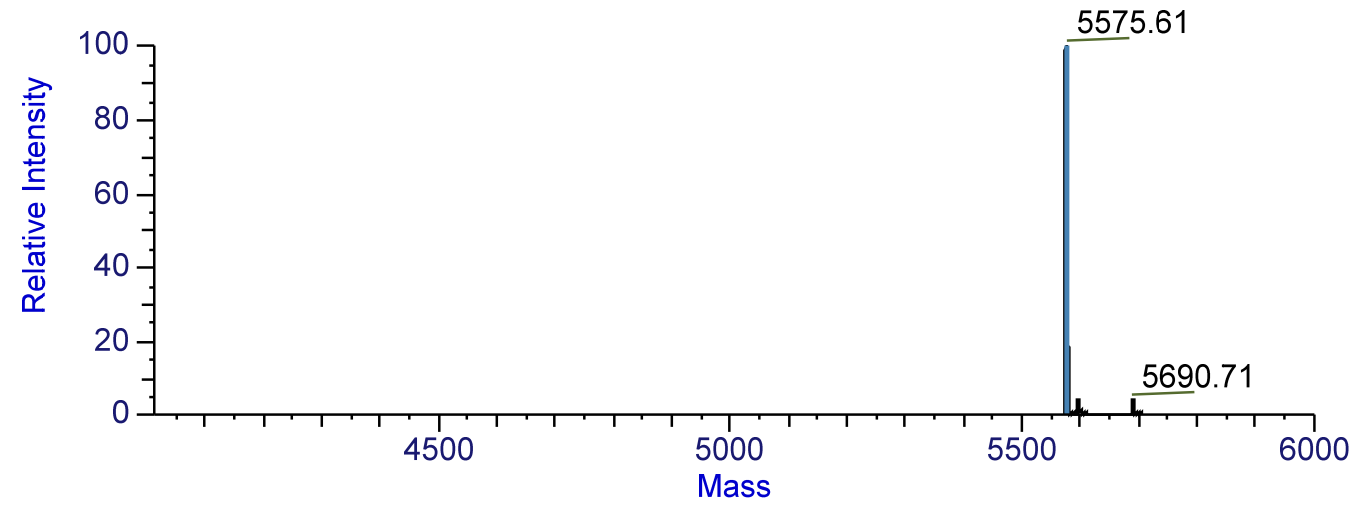

\begin{tabular}{|r|l|r|r|}
\hline Average Mass & Intensity & Relative Abundance & Fractional Abundance \\
\hline 5575.61 & $7.61 \mathrm{E}+05$ & 100.00 & 92.95 \\
\hline 5690.71 & $2.91 \mathrm{E}+04$ & 3.82 & 3.55 \\
\hline 5597.47 & $2.86 \mathrm{E}+04$ & 3.76 & 3.50 \\
\hline
\end{tabular}

$3 e$

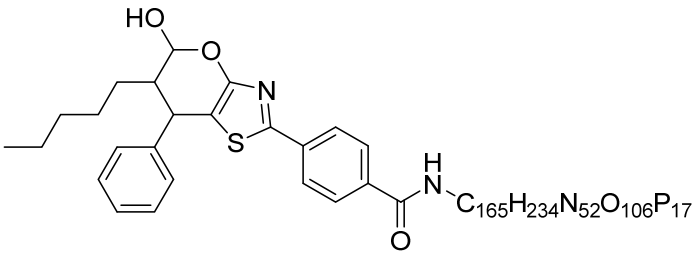

Molecular Weight: 5590.03 


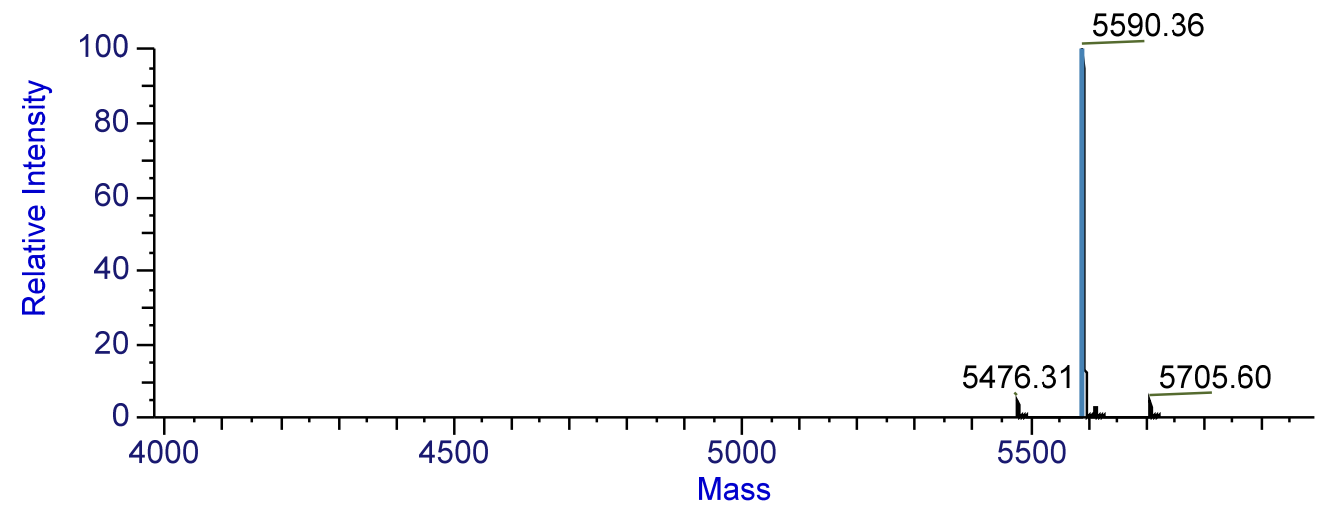

\begin{tabular}{|r|l|r|r|}
\hline Average Mass & Intensity & Relative Abundance & Fractional Abundance \\
\hline 5590.36 & $2.79 \mathrm{E}+05$ & 100.00 & 89.76 \\
\hline 5476.31 & $1.23 \mathrm{E}+04$ & 4.40 & 3.95 \\
\hline 5705.60 & $1.21 \mathrm{E}+04$ & 4.34 & 3.90 \\
\hline 5612.23 & $7.43 \mathrm{E}+03$ & 2.66 & 2.39 \\
\hline
\end{tabular}

\section{$3 f$}

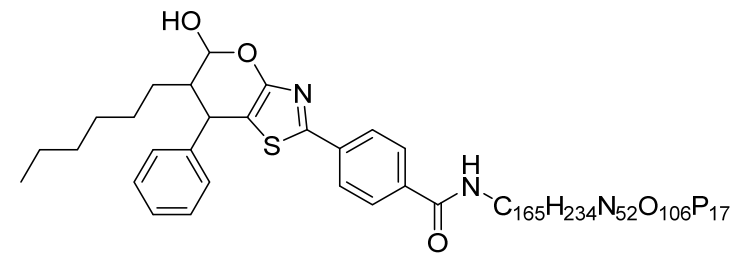

Molecular Weight: 5604.06

wwt-8-28-24h-51

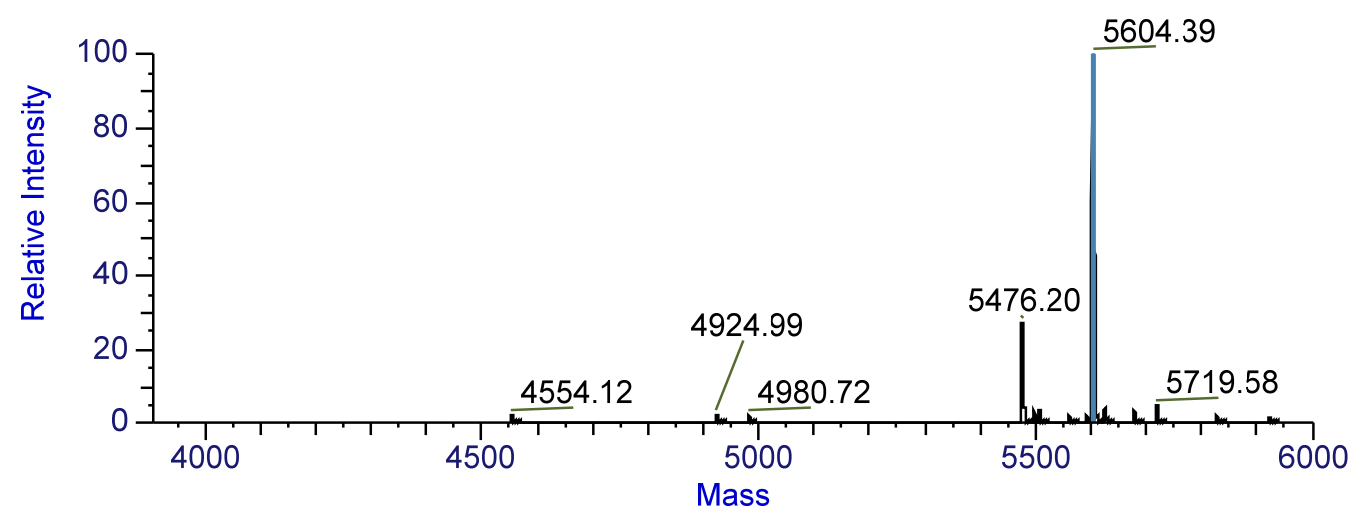

\begin{tabular}{|r|l|r|r|}
\hline Average Mass & Intensity & Relative Abundance & Fractional Abundance \\
\hline 5604.39 & $1.96 \mathrm{E}+05$ & 100.00 & 64.81 \\
\hline 5476.20 & $5.29 \mathrm{E}+04$ & 26.94 & 17.46 \\
\hline 5719.58 & $8.64 \mathrm{E}+03$ & 4.40 & 2.85 \\
\hline 5626.30 & $7.63 \mathrm{E}+03$ & 3.88 & 2.52 \\
\hline
\end{tabular}




\begin{tabular}{|l|l|l|l|}
\hline 5496.32 & $5.78 \mathrm{E}+03$ & 2.94 & 1.91 \\
\hline 5677.58 & $5.72 \mathrm{E}+03$ & 2.91 & 1.89 \\
\hline 5508.37 & $5.72 \mathrm{E}+03$ & 2.91 & 1.89 \\
\hline 5591.25 & $3.31 \mathrm{E}+03$ & 1.68 & 1.09 \\
\hline 5826.06 & $3.24 \mathrm{E}+03$ & 1.65 & 1.07 \\
\hline 4980.72 & $3.15 \mathrm{E}+03$ & 1.61 & 1.04 \\
\hline
\end{tabular}

\section{$3 g$}

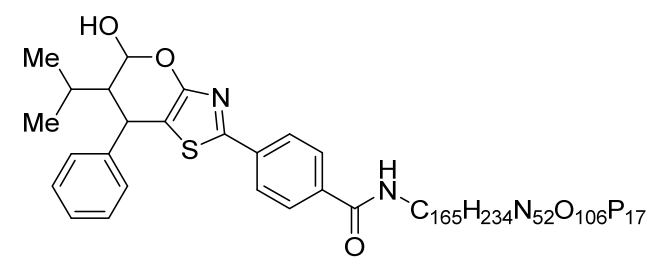

Molecular Weight: 5561.98

wwt-0508-overnight-4

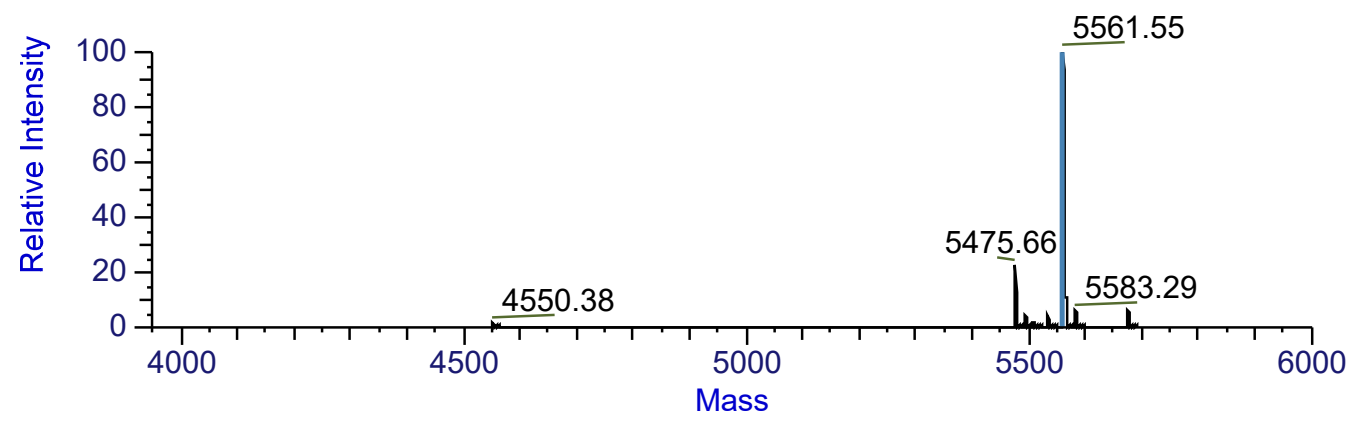

\begin{tabular}{|r|r|r|r|}
\hline Average Mass & Intensity & Relative Abundance & Fractional Abundance \\
\hline 5561.55 & $3.64 \mathrm{E}+05$ & 100.00 & 68.88 \\
\hline 5475.66 & $8.26 \mathrm{E}+04$ & 22.69 & 15.63 \\
\hline 5583.29 & $2.08 \mathrm{E}+04$ & 5.70 & 3.93 \\
\hline 5676.62 & $2.02 \mathrm{E}+04$ & 5.53 & 3.81 \\
\hline 5533.39 & $1.58 \mathrm{E}+04$ & 4.33 & 2.99 \\
\hline 5494.16 & $1.53 \mathrm{E}+04$ & 4.21 & 2.90 \\
\hline 5507.45 & $6.09 \mathrm{E}+03$ & 1.67 & 1.15 \\
\hline 4550.38 & $3.74 \mathrm{E}+03$ & 1.03 & 0.71 \\
\hline
\end{tabular}

3h

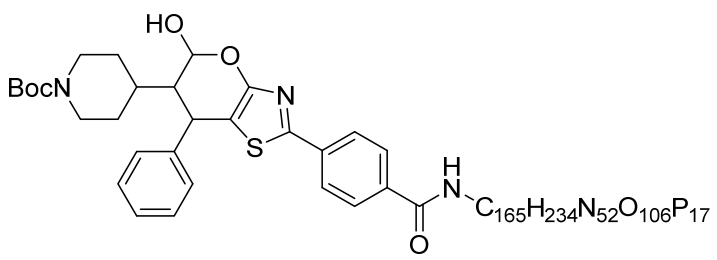

Molecular Weight: 5703.15 
wwt-0508-overnight-7

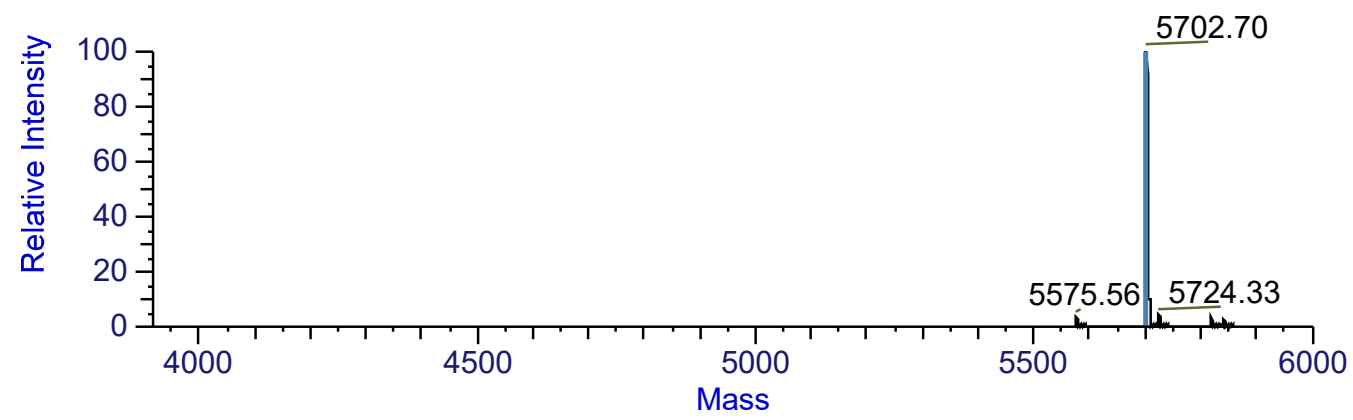

\begin{tabular}{|r|r|r|r|}
\hline Average Mass & Intensity & Relative Abundance & Fractional Abundance \\
\hline 5702.70 & $5.00 \mathrm{E}+05$ & 100.00 & 88.42 \\
\hline 5724.33 & $2.26 \mathrm{E}+04$ & 4.52 & 4.00 \\
\hline 5575.56 & $1.75 \mathrm{E}+04$ & 3.49 & 3.09 \\
\hline 5817.82 & $1.56 \mathrm{E}+04$ & 3.11 & 2.75 \\
\hline 5841.32 & $9.88 \mathrm{E}+03$ & 1.97 & 1.75 \\
\hline
\end{tabular}

3i

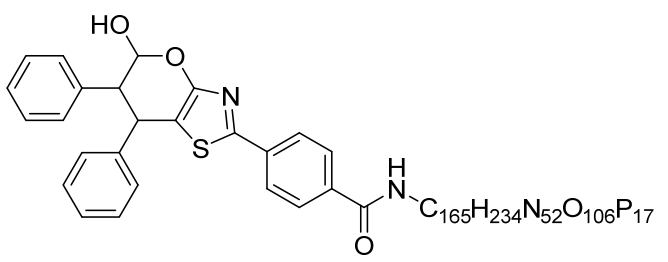

Molecular Weight: 5596.00

wwt-0508-overnight-15

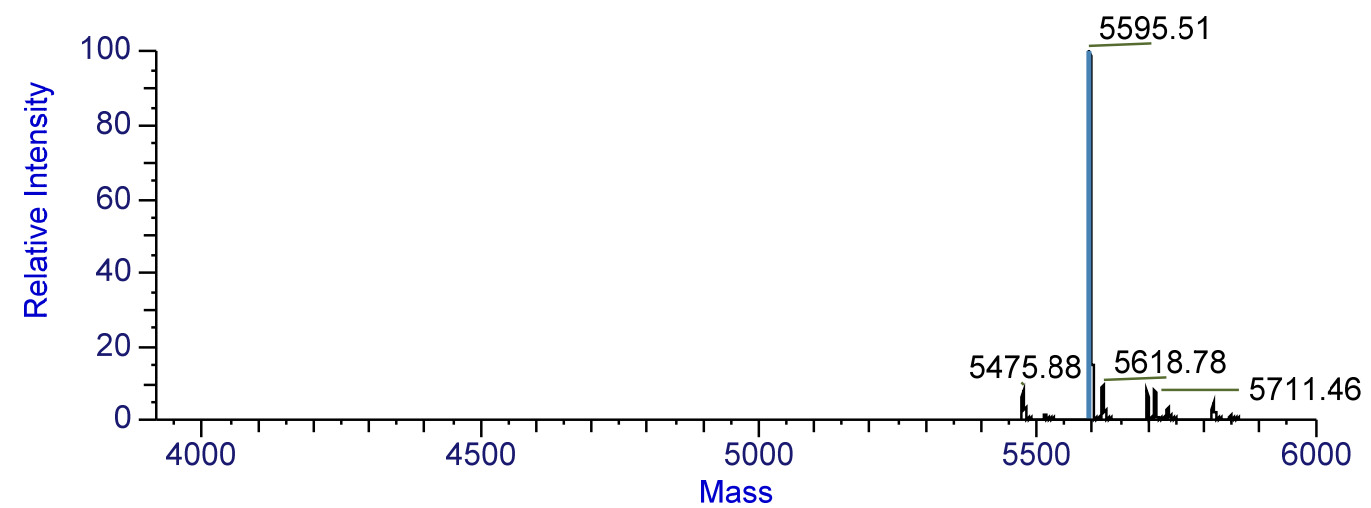

\begin{tabular}{|r|r|r|r|}
\hline Average Mass & Intensity & Relative Abundance & Fractional Abundance \\
\hline 5595.51 & $3.96 \mathrm{E}+05$ & 100.00 & 70.48 \\
\hline 5618.78 & $3.61 \mathrm{E}+04$ & 9.12 & 6.43 \\
\hline 5711.46 & $3.16 \mathrm{E}+04$ & 7.97 & 5.62 \\
\hline 5475.88 & $3.15 \mathrm{E}+04$ & 7.95 & 5.60 \\
\hline 5697.50 & $3.08 \mathrm{E}+04$ & 7.79 & 5.49 \\
\hline
\end{tabular}




\begin{tabular}{|r|r|r|r|}
\hline 5817.45 & $1.62 \mathrm{E}+04$ & 4.09 & 2.88 \\
\hline 5735.84 & $1.21 \mathrm{E}+04$ & 3.06 & 2.16 \\
\hline 5515.49 & $4.73 \mathrm{E}+03$ & 1.19 & 0.84 \\
\hline 5848.48 & $2.77 \mathrm{E}+03$ & 0.70 & 0.49 \\
\hline
\end{tabular}

3j

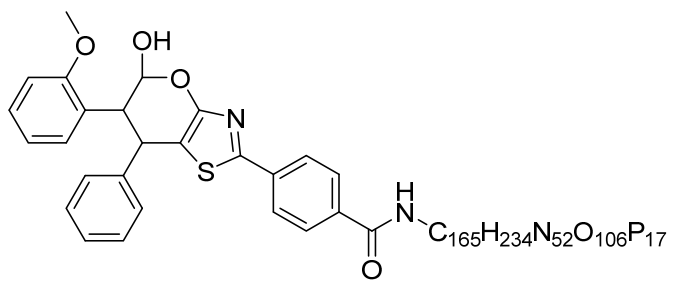

Molecular Weight: 5626.02

wwt-8-28-24h-60

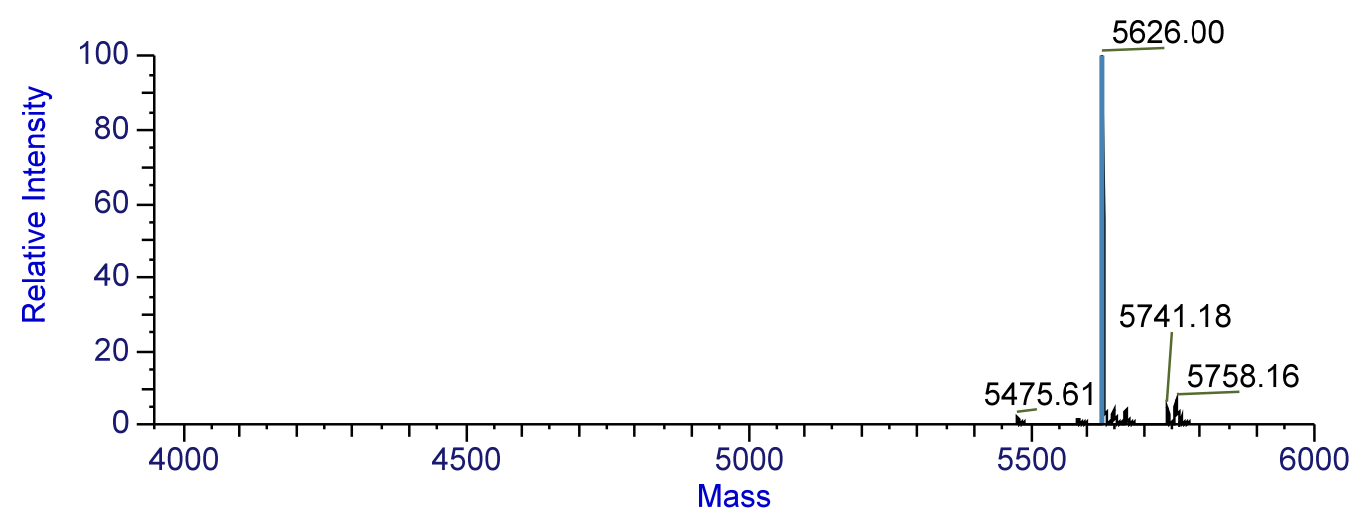

\begin{tabular}{|r|l|r|r|}
\hline Average Mass & Intensity & Relative Abundance & Fractional Abundance \\
\hline 5626.00 & $5.63 \mathrm{E}+05$ & 100.00 & 81.13 \\
\hline 5758.16 & $3.80 \mathrm{E}+04$ & 6.75 & 5.48 \\
\hline 5741.18 & $2.48 \mathrm{E}+04$ & 4.40 & 3.57 \\
\hline 5647.86 & $2.12 \mathrm{E}+04$ & 3.76 & 3.05 \\
\hline 5669.16 & $2.00 \mathrm{E}+04$ & 3.55 & 2.88 \\
\hline 5475.61 & $1.13 \mathrm{E}+04$ & 2.00 & 1.63 \\
\hline 5765.88 & $8.16 \mathrm{E}+03$ & 1.45 & 1.18 \\
\hline 5581.91 & $7.54 \mathrm{E}+03$ & 1.34 & 1.09 \\
\hline
\end{tabular}




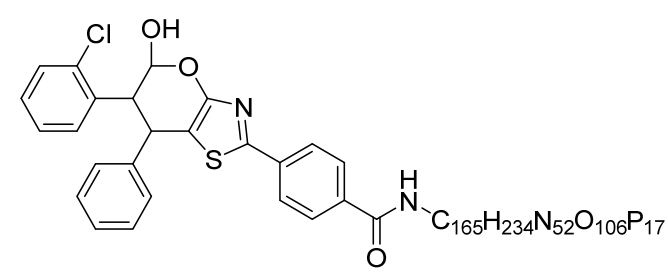

Molecular Weight: 5630.44

wwt-8-28-24h-62

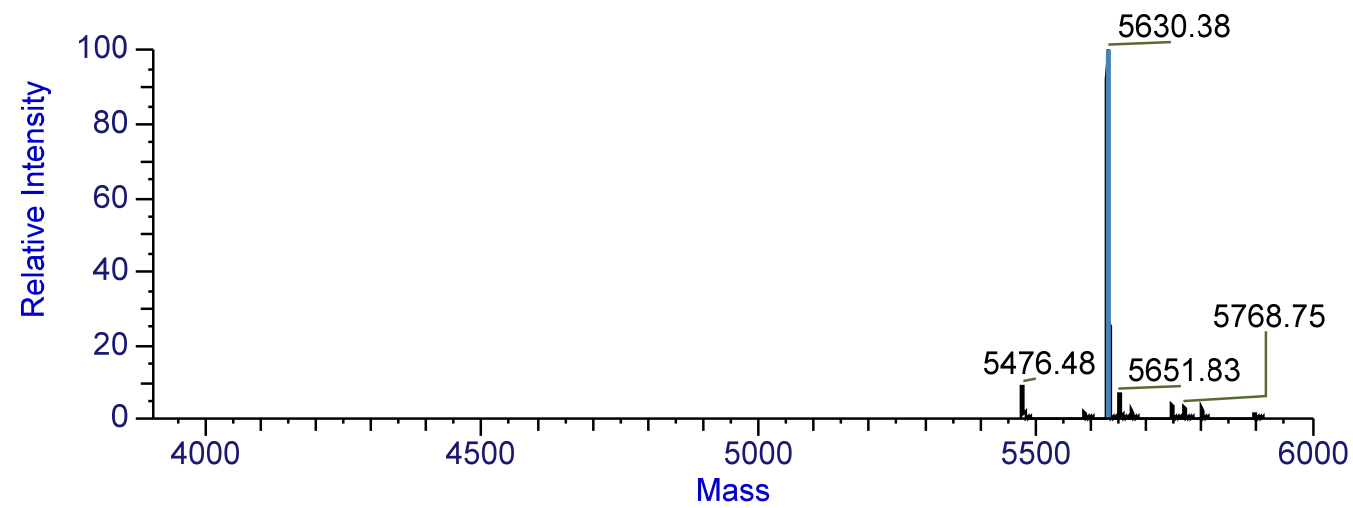

\begin{tabular}{|r|r|r|r|}
\hline Average Mass & Intensity & Relative Abundance & Fractional Abundance \\
\hline 5630.38 & $3.35 \mathrm{E}+05$ & 100.00 & 77.20 \\
\hline 5476.48 & $2.91 \mathrm{E}+04$ & 8.68 & 6.70 \\
\hline 5651.83 & $2.17 \mathrm{E}+04$ & 6.47 & 4.99 \\
\hline 5745.54 & $1.35 \mathrm{E}+04$ & 4.04 & 3.12 \\
\hline 5768.75 & $9.93 \mathrm{E}+03$ & 2.96 & 2.28 \\
\hline 5798.90 & $9.76 \mathrm{E}+03$ & 2.91 & 2.25 \\
\hline 5672.37 & $7.67 \mathrm{E}+03$ & 2.29 & 1.77 \\
\hline 5586.83 & $4.69 \mathrm{E}+03$ & 1.40 & 1.08 \\
\hline 5897.03 & $2.67 \mathrm{E}+03$ & 0.80 & 0.61 \\
\hline
\end{tabular}

31

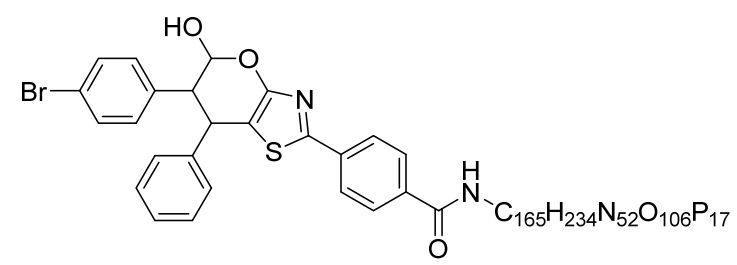

Molecular Weight: 5674.89 
wwt-0508-overnight-6

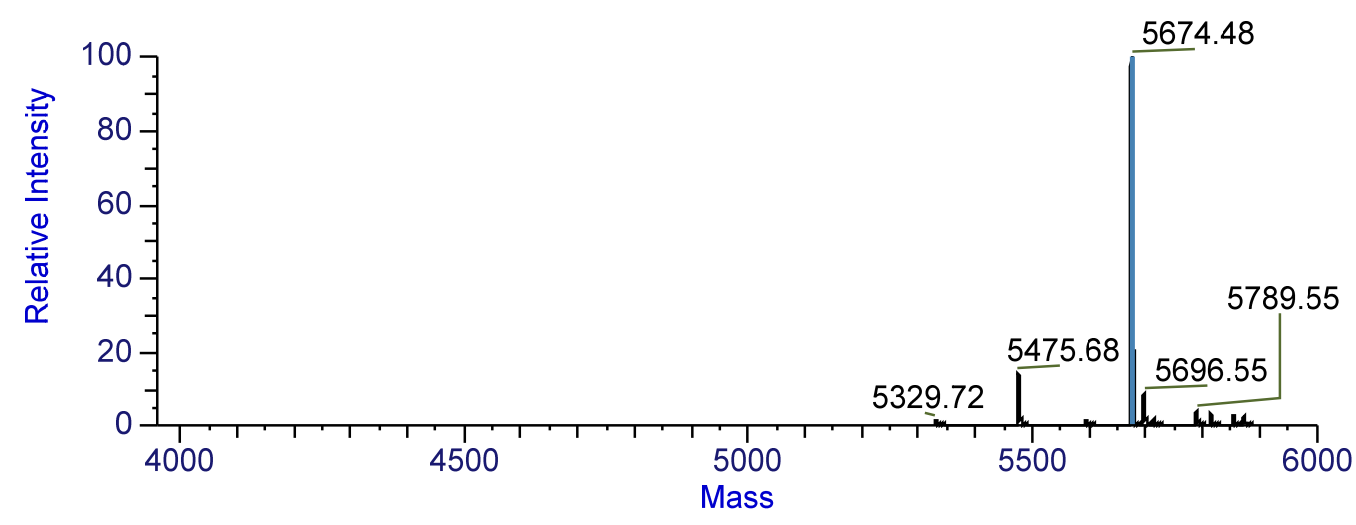

\begin{tabular}{|r|r|r|r|}
\hline Average Mass & Intensity & Relative Abundance & Fractional Abundance \\
\hline 5674.48 & $3.20 \mathrm{E}+05$ & 100.00 & 72.64 \\
\hline 5475.68 & $4.46 \mathrm{E}+04$ & 13.94 & 10.12 \\
\hline 5696.55 & $2.68 \mathrm{E}+04$ & 8.37 & 6.08 \\
\hline 5789.55 & $1.14 \mathrm{E}+04$ & 3.55 & 2.58 \\
\hline 5813.95 & $9.27 \mathrm{E}+03$ & 2.90 & 2.10 \\
\hline 5854.33 & $8.54 \mathrm{E}+03$ & 2.67 & 1.94 \\
\hline 5873.08 & $6.94 \mathrm{E}+03$ & 2.17 & 1.58 \\
\hline 5715.17 & $5.06 \mathrm{E}+03$ & 1.58 & 1.15 \\
\hline 5329.72 & $4.06 \mathrm{E}+03$ & 1.27 & 0.92 \\
\hline 5593.77 & $3.94 \mathrm{E}+03$ & 1.23 & 0.90 \\
\hline & & &
\end{tabular}

$3 m$

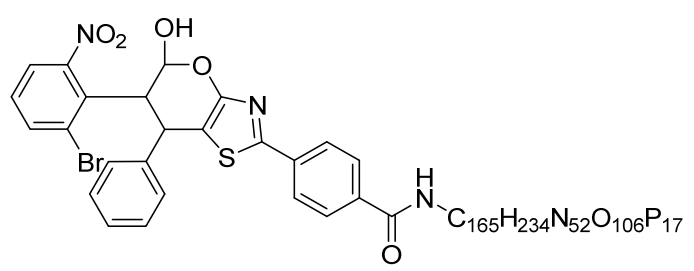

Molecular Weight: 5719.89 
wwt-8-28-24h-61

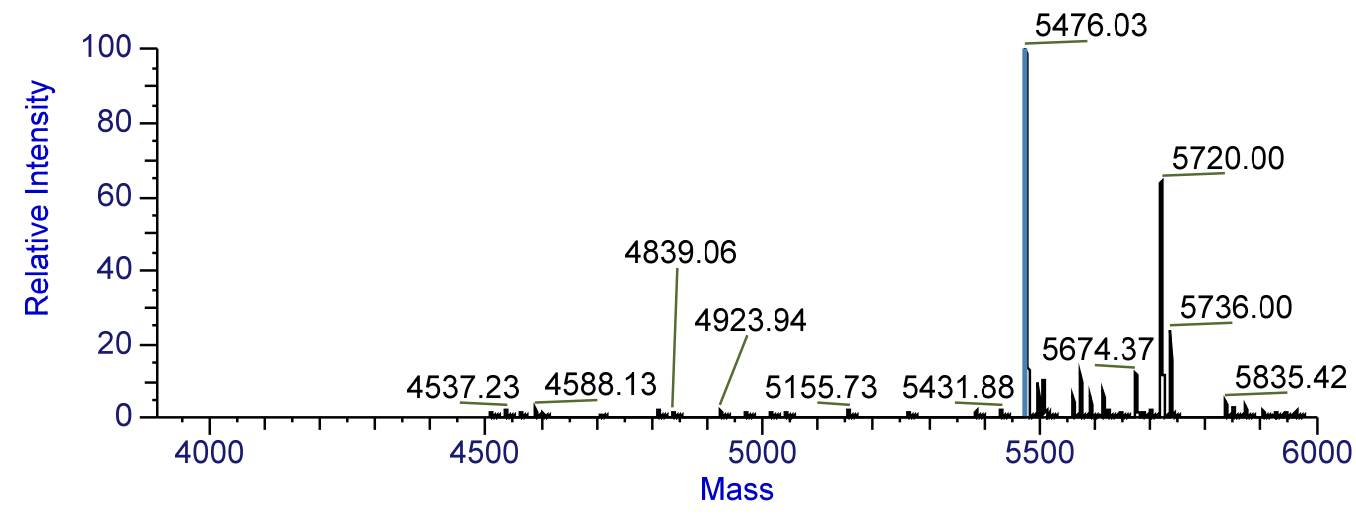

\begin{tabular}{|r|r|r|r|}
\hline Average Mass & Intensity & Relative Abundance & Fractional Abundance \\
\hline 5476.03 & $1.24 \mathrm{E}+05$ & 100.00 & 34.29 \\
\hline 5720.00 & $7.89 \mathrm{E}+04$ & 63.82 & 21.88 \\
\hline 5736.00 & $2.90 \mathrm{E}+04$ & 23.43 & 8.03 \\
\hline 5674.37 & $1.49 \mathrm{E}+04$ & 12.01 & 4.12 \\
\hline 5574.12 & $1.46 \mathrm{E}+04$ & 11.78 & 4.04 \\
\hline 5508.13 & $1.24 \mathrm{E}+04$ & 10.04 & 3.44 \\
\hline 5496.69 & $1.16 \mathrm{E}+04$ & 9.37 & 3.21 \\
\hline 5614.47 & $8.77 \mathrm{E}+03$ & 7.09 & 2.43 \\
\hline 5591.27 & $7.36 \mathrm{E}+03$ & 5.95 & 2.04 \\
\hline 5560.10 & $7.35 \mathrm{E}+03$ & 5.94 & 2.04 \\
\hline & & & \\
\hline
\end{tabular}

$3 n$

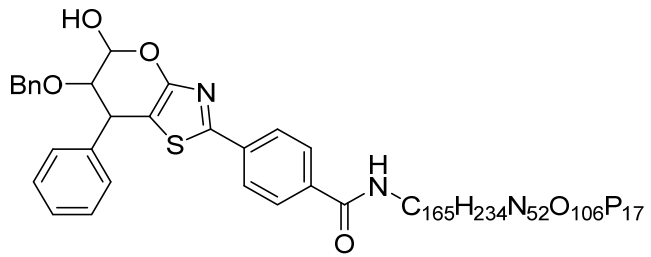

Molecular Weight: 5626.02 
wwt-0508-overnight-19

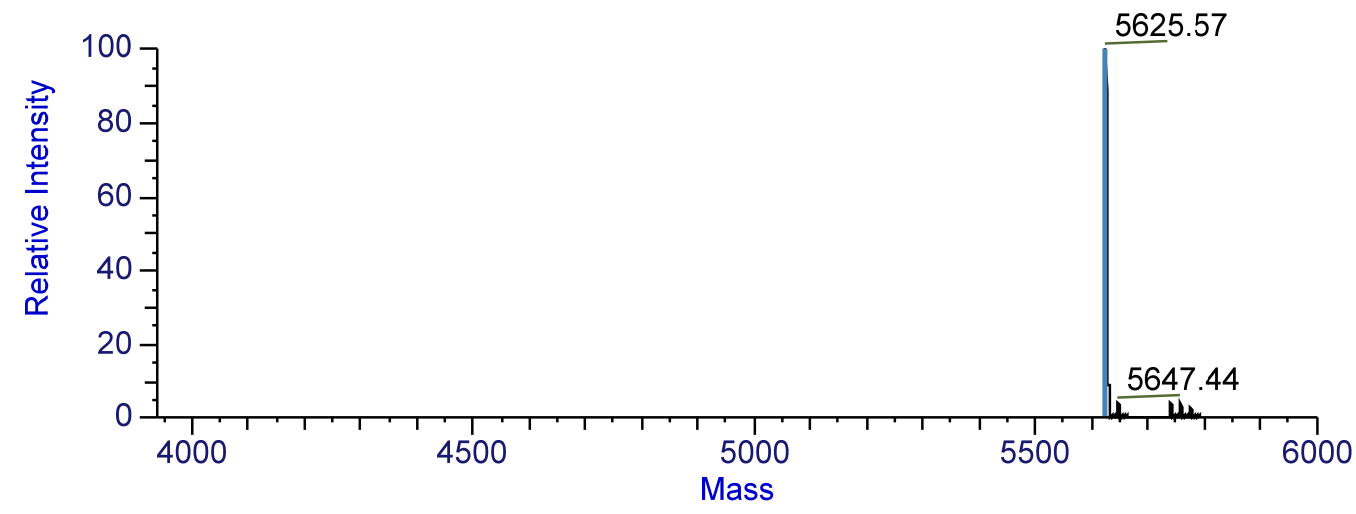

\begin{tabular}{|r|l|r|r|}
\hline Average Mass & Intensity & Relative Abundance & Fractional Abundance \\
\hline 5625.57 & $6.93 \mathrm{E}+05$ & 100.00 & 88.16 \\
\hline 5647.44 & $2.72 \mathrm{E}+04$ & 3.92 & 3.46 \\
\hline 5757.69 & $2.62 \mathrm{E}+04$ & 3.78 & 3.33 \\
\hline 5740.68 & $2.41 \mathrm{E}+04$ & 3.48 & 3.07 \\
\hline 5775.71 & $1.56 \mathrm{E}+04$ & 2.25 & 1.98 \\
\hline
\end{tabular}

30

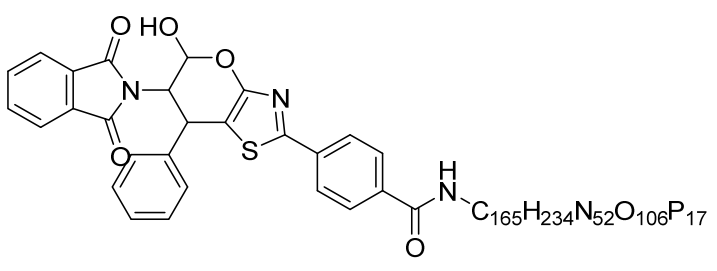

Molecular Weight: 5665.02

wwt-0508-overnight-12

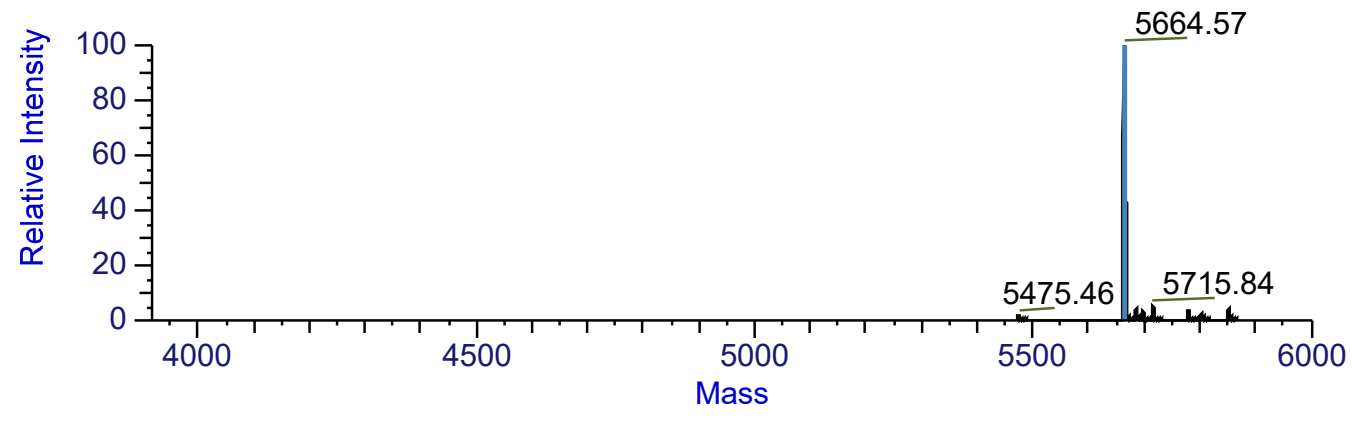

\begin{tabular}{|r|l|r|r|}
\hline Average Mass & Intensity & Relative Abundance & Fractional Abundance \\
\hline 5664.57 & $5.56 \mathrm{E}+05$ & 100.00 & 81.00 \\
\hline 5715.84 & $2.55 \mathrm{E}+04$ & 4.58 & 3.71 \\
\hline 5852.72 & $2.30 \mathrm{E}+04$ & 4.13 & 3.35 \\
\hline 5686.25 & $2.17 \mathrm{E}+04$ & 3.91 & 3.16 \\
\hline 5779.74 & $1.83 \mathrm{E}+04$ & 3.30 & 2.67 \\
\hline
\end{tabular}




\begin{tabular}{|l|l|l|l|}
\hline 5696.73 & $1.78 \mathrm{E}+04$ & 3.20 & 2.59 \\
\hline 5803.80 & $1.40 \mathrm{E}+04$ & 2.52 & 2.04 \\
\hline 5475.46 & $1.01 \mathrm{E}+04$ & 1.81 & 1.47 \\
\hline
\end{tabular}

$3 p$

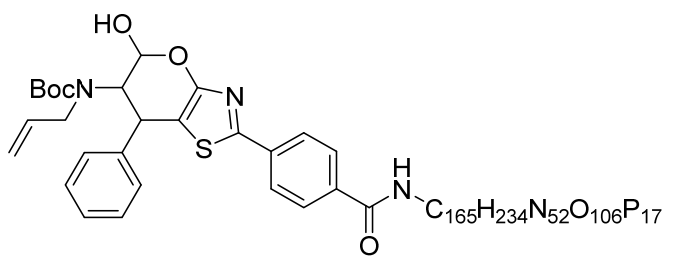

Molecular Weight: 5675.10

wwt-8-28-24h-53

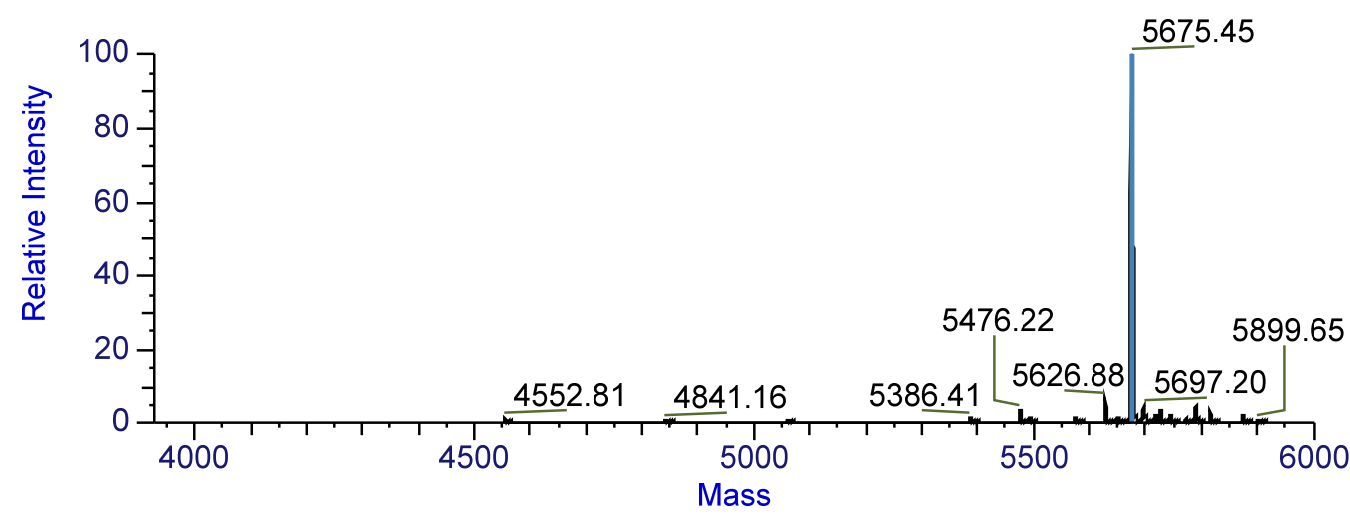

\begin{tabular}{|r|l|r|r|}
\hline Average Mass & Intensity & Relative Abundance & Fractional Abundance \\
\hline 5675.45 & $2.89 \mathrm{E}+05$ & 100.00 & 73.25 \\
\hline 5626.88 & $1.78 \mathrm{E}+04$ & 6.15 & 4.51 \\
\hline 5697.20 & $1.24 \mathrm{E}+04$ & 4.29 & 3.14 \\
\hline 5790.68 & $1.22 \mathrm{E}+04$ & 4.23 & 3.10 \\
\hline 5476.22 & $8.79 \mathrm{E}+03$ & 3.05 & 2.23 \\
\hline 5726.91 & $8.43 \mathrm{E}+03$ & 2.92 & 2.14 \\
\hline 5814.25 & $8.36 \mathrm{E}+03$ & 2.90 & 2.12 \\
\hline 5874.79 & $5.35 \mathrm{E}+03$ & 1.85 & 1.36 \\
\hline 5746.01 & $4.69 \mathrm{E}+03$ & 1.63 & 1.19 \\
\hline 5717.31 & $4.60 \mathrm{E}+03$ & 1.59 & 1.17 \\
\hline
\end{tabular}




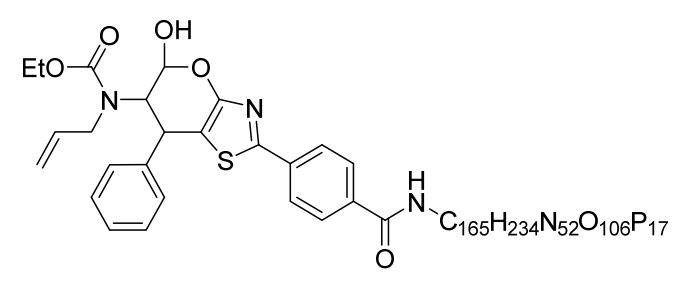

Molecular Weight: 5647.04

wwt-8-28-24h-63

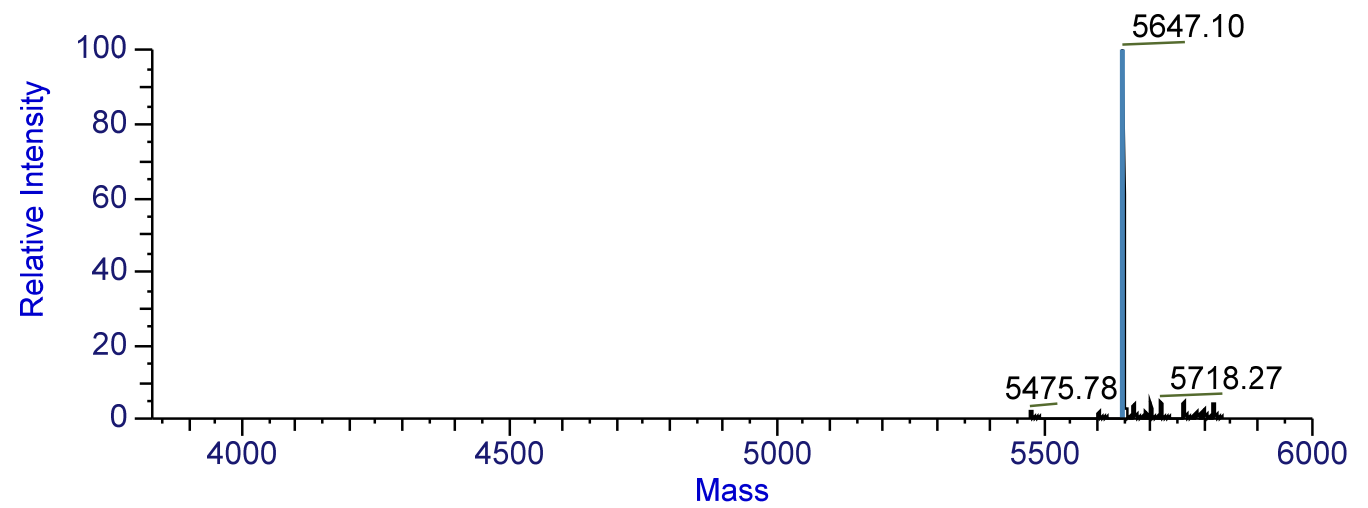

\begin{tabular}{|r|r|r|r|}
\hline Average Mass & Intensity & Relative Abundance & Fractional Abundance \\
\hline 5647.10 & $4.84 \mathrm{E}+05$ & 100.00 & 77.45 \\
\hline 5718.27 & $2.28 \mathrm{E}+04$ & 4.72 & 3.66 \\
\hline 5762.30 & $2.08 \mathrm{E}+04$ & 4.29 & 3.32 \\
\hline 5698.56 & $2.02 \mathrm{E}+04$ & 4.18 & 3.24 \\
\hline 5669.16 & $1.85 \mathrm{E}+04$ & 3.83 & 2.97 \\
\hline 5818.09 & $1.80 \mathrm{E}+04$ & 3.71 & 2.88 \\
\hline 5800.44 & $1.03 \mathrm{E}+04$ & 2.13 & 1.65 \\
\hline 5786.45 & $9.30 \mathrm{E}+03$ & 1.92 & 1.49 \\
\hline 5475.78 & $7.19 \mathrm{E}+03$ & 1.49 & 1.15 \\
\hline 5689.93 & $7.04 \mathrm{E}+03$ & 1.45 & 1.13 \\
\hline
\end{tabular}

$3 r$

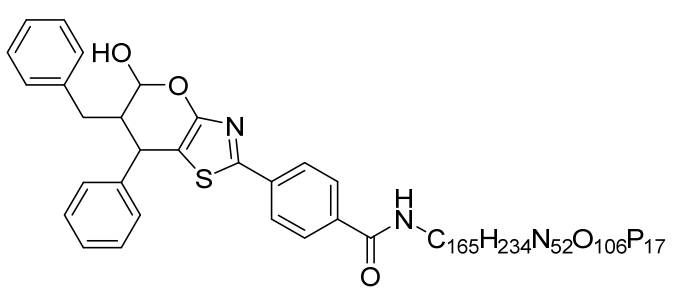

Molecular Weight: 5610.02 
wwt-0508-overnight-13

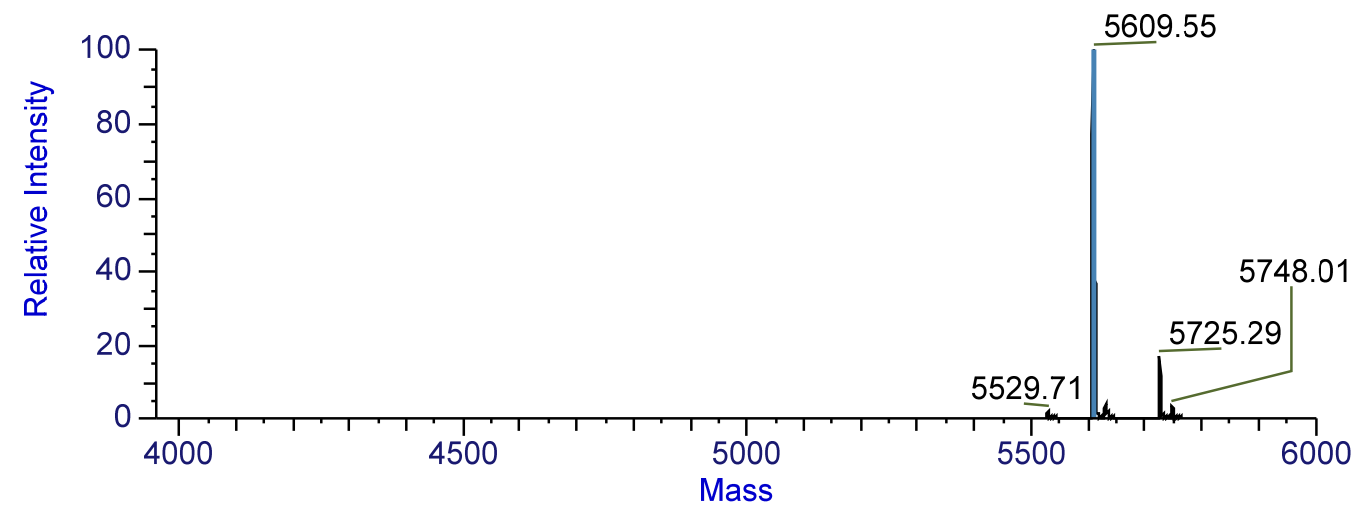

\begin{tabular}{|r|l|r|r|}
\hline Average Mass & Intensity & Relative Abundance & Fractional Abundance \\
\hline 5609.55 & $6.49 \mathrm{E}+05$ & 100.00 & 80.41 \\
\hline 5725.29 & $1.07 \mathrm{E}+05$ & 16.42 & 13.20 \\
\hline 5631.76 & $2.38 \mathrm{E}+04$ & 3.66 & 2.94 \\
\hline 5748.01 & $1.91 \mathrm{E}+04$ & 2.94 & 2.36 \\
\hline 5529.71 & $8.78 \mathrm{E}+03$ & 1.35 & 1.09 \\
\hline
\end{tabular}

3s

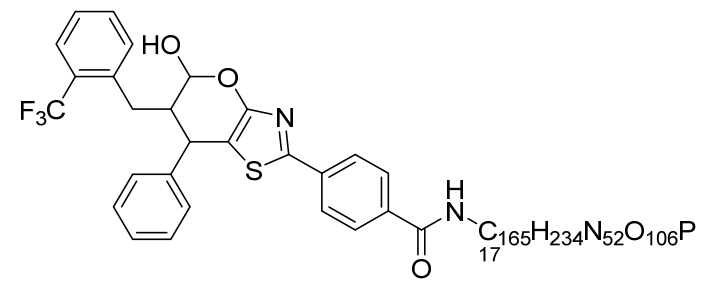

Molecular Weight: 5678.02

wwt-8-28-24h-41

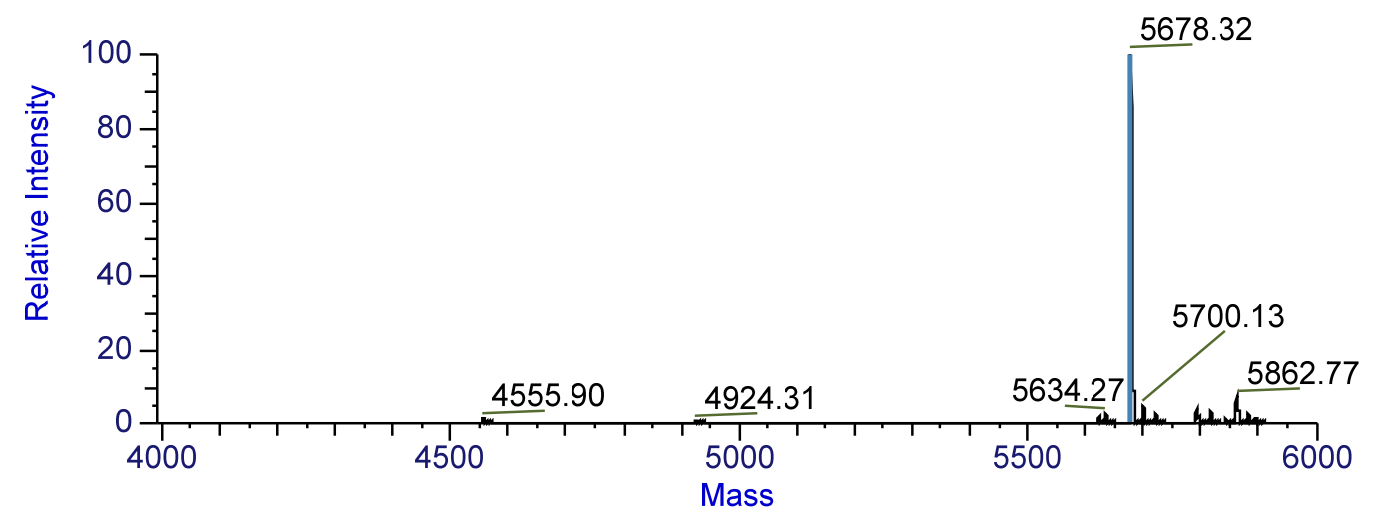

\begin{tabular}{|r|l|r|r|}
\hline Average Mass & Intensity & Relative Abundance & Fractional Abundance \\
\hline 5678.32 & $4.29 \mathrm{E}+05$ & 100.00 & 76.84 \\
\hline 5862.77 & $3.06 \mathrm{E}+04$ & 7.14 & 5.48 \\
\hline
\end{tabular}




\begin{tabular}{|r|r|r|r|}
\hline 5700.13 & $1.76 \mathrm{E}+04$ & 4.10 & 3.15 \\
\hline 5793.56 & $1.67 \mathrm{E}+04$ & 3.88 & 2.98 \\
\hline 5817.71 & $1.20 \mathrm{E}+04$ & 2.78 & 2.14 \\
\hline 5720.64 & $1.15 \mathrm{E}+04$ & 2.68 & 2.06 \\
\hline 5634.27 & $1.02 \mathrm{E}+04$ & 2.38 & 1.83 \\
\hline 5880.90 & $9.37 \mathrm{E}+03$ & 2.18 & 1.68 \\
\hline 5624.35 & $5.88 \mathrm{E}+03$ & 1.37 & 1.05 \\
\hline 4555.90 & $5.60 \mathrm{E}+03$ & 1.30 & 1.00 \\
\hline
\end{tabular}

$3 t$

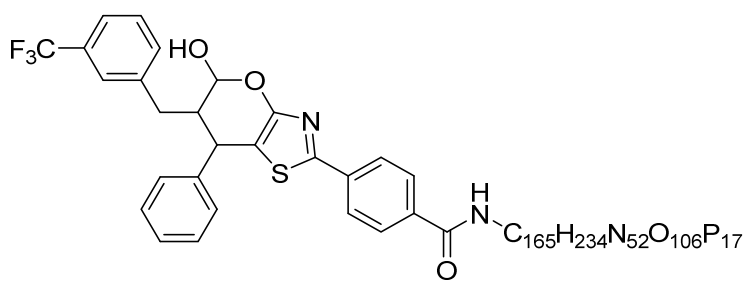

Molecular Weight: 5678.02

wwt-8-28-24h-45_190829143721

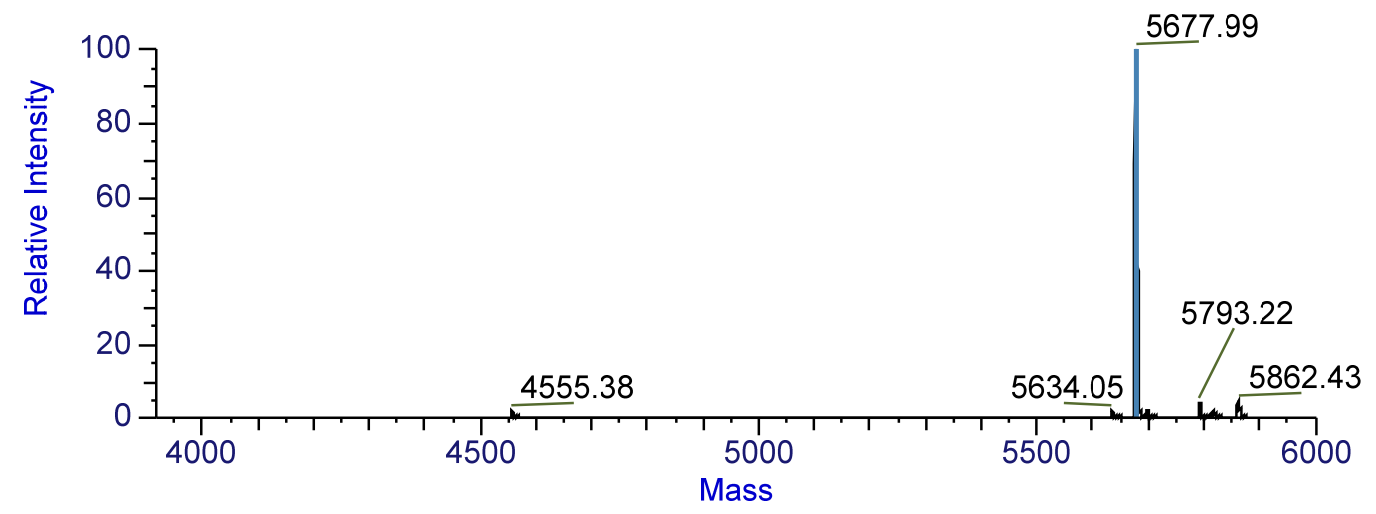

\begin{tabular}{|r|l|r|r|}
\hline Average Mass & Intensity & Relative Abundance & Fractional Abundance \\
\hline 5677.99 & $8.12 \mathrm{E}+05$ & 100.00 & 86.96 \\
\hline 5862.43 & $3.60 \mathrm{E}+04$ & 4.44 & 3.86 \\
\hline 5793.22 & $2.78 \mathrm{E}+04$ & 3.42 & 2.97 \\
\hline 5817.37 & $1.60 \mathrm{E}+04$ & 1.96 & 1.71 \\
\hline 5634.05 & $1.51 \mathrm{E}+04$ & 1.86 & 1.62 \\
\hline 5699.96 & $1.46 \mathrm{E}+04$ & 1.79 & 1.56 \\
\hline 4555.38 & $1.24 \mathrm{E}+04$ & 1.52 & 1.33 \\
\hline
\end{tabular}




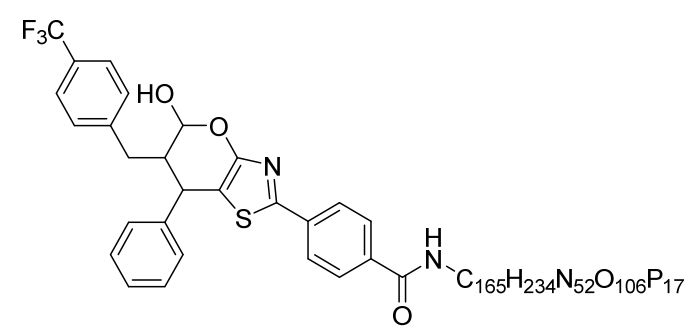

Molecular Weight: 5678.02

wwt-8-28-24h-50

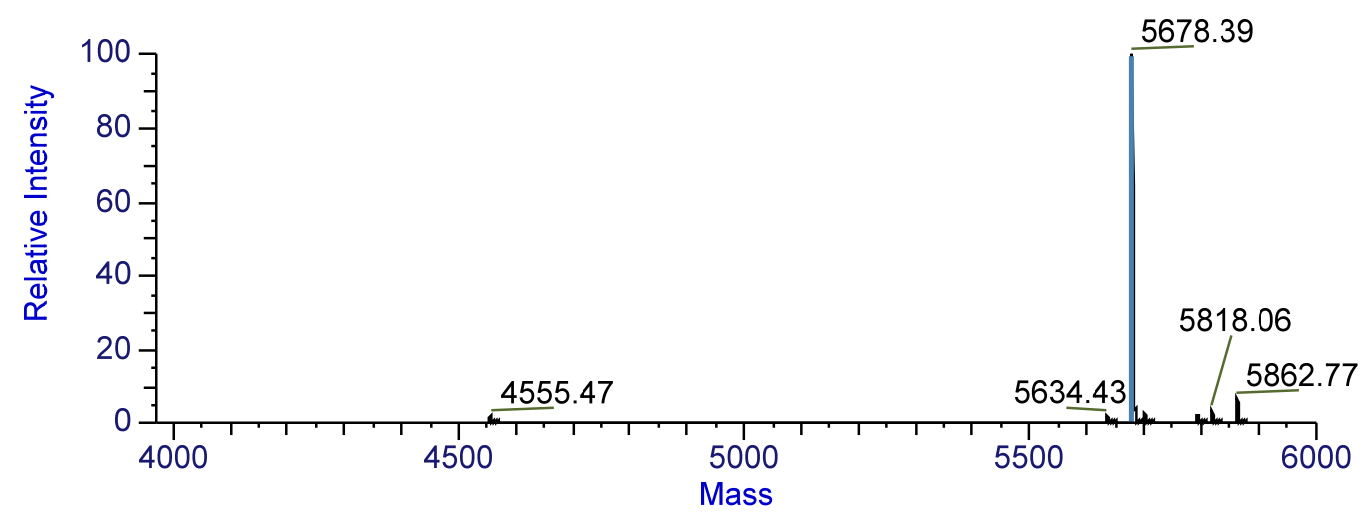

\begin{tabular}{|r|r|r|r|}
\hline Average Mass & Intensity & Relative Abundance & Fractional Abundance \\
\hline 5678.39 & $5.45 \mathrm{E}+05$ & 100.00 & 85.87 \\
\hline 5862.77 & $3.39 \mathrm{E}+04$ & 6.22 & 5.35 \\
\hline 5818.06 & $1.59 \mathrm{E}+04$ & 2.92 & 2.51 \\
\hline 5700.34 & $1.35 \mathrm{E}+04$ & 2.47 & 2.12 \\
\hline 5793.69 & $9.75 \mathrm{E}+03$ & 1.79 & 1.54 \\
\hline 5634.43 & $9.17 \mathrm{E}+03$ & 1.68 & 1.44 \\
\hline 4555.47 & $7.45 \mathrm{E}+03$ & 1.37 & 1.17 \\
\hline
\end{tabular}

3v

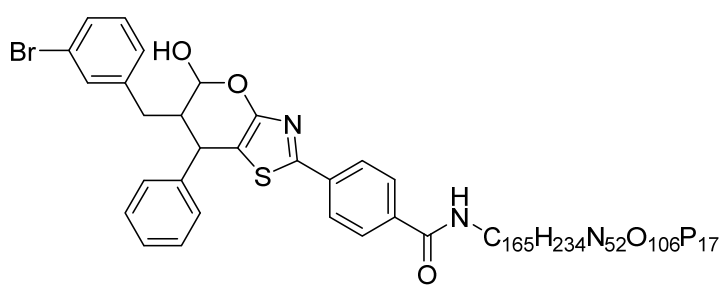

Molecular Weight: 5688.92 
wwt-8-28-24h-39

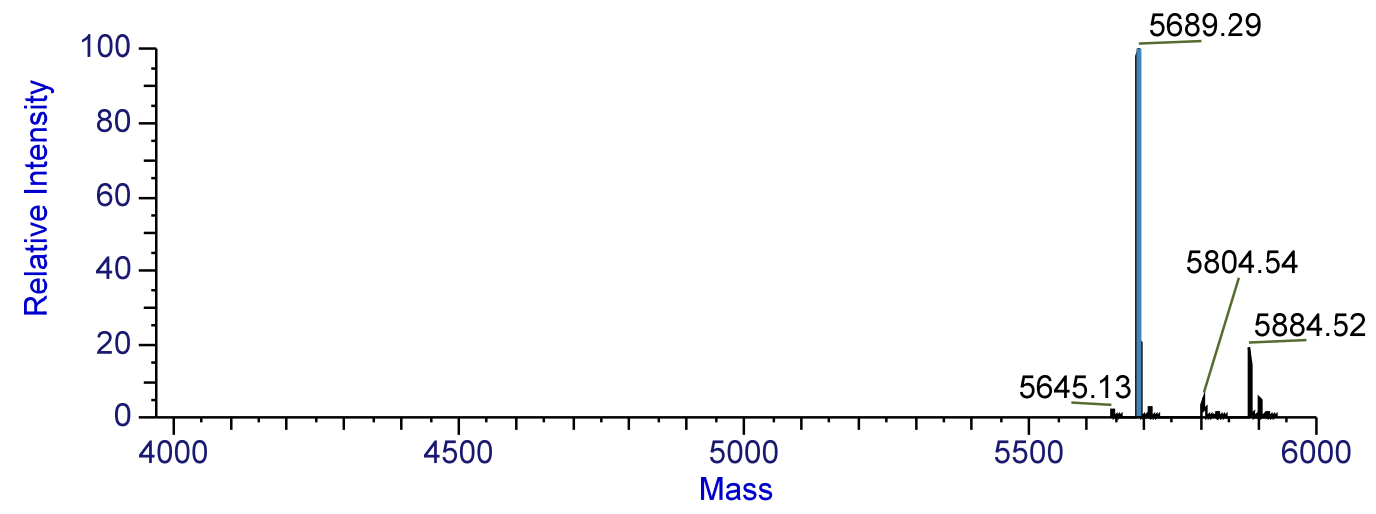

\begin{tabular}{|r|l|r|r|}
\hline Average Mass & Intensity & Relative Abundance & Fractional Abundance \\
\hline 5689.29 & $3.49 \mathrm{E}+05$ & 100.00 & 74.63 \\
\hline 5884.52 & $6.44 \mathrm{E}+04$ & 18.44 & 13.76 \\
\hline 5902.73 & $1.72 \mathrm{E}+04$ & 4.92 & 3.67 \\
\hline 5804.54 & $1.67 \mathrm{E}+04$ & 4.79 & 3.57 \\
\hline 5711.06 & $8.04 \mathrm{E}+03$ & 2.30 & 1.72 \\
\hline 5645.13 & $5.29 \mathrm{E}+03$ & 1.51 & 1.13 \\
\hline 5828.29 & $3.91 \mathrm{E}+03$ & 1.12 & 0.83 \\
\hline 5915.31 & $3.21 \mathrm{E}+03$ & 0.92 & 0.69 \\
\hline
\end{tabular}

$3 w$

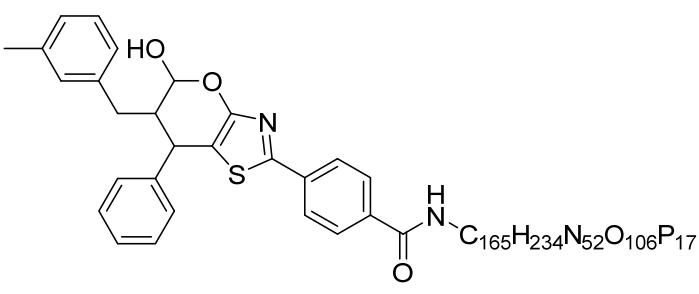

Molecular Weight: 5624.05

wwt-8-28-24h-40

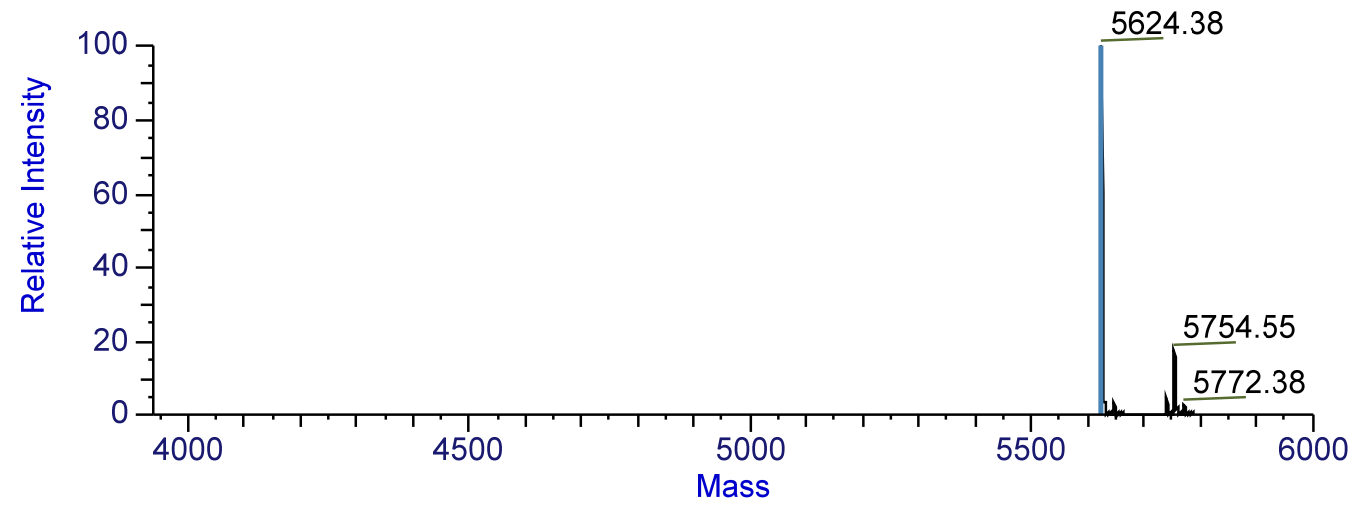




\begin{tabular}{|c|c|c|c|}
\hline Average Mass & Intensity & $\begin{array}{l}\text { Relative } \\
\text { Abundance }\end{array}$ & $\begin{array}{l}\text { Fractional } \\
\text { Abundance }\end{array}$ \\
\hline 5624.38 & $5.21 \mathrm{E}+05$ & 100.00 & 79.23 \\
\hline 5754.55 & $8.83 E+04$ & 16.95 & 13.43 \\
\hline 5739.59 & $2.13 E+04$ & 4.09 & 3.24 \\
\hline 5646.34 & $1.64 \mathrm{E}+04$ & 3.15 & 2.49 \\
\hline 5772.38 & $1.06 \mathrm{E}+04$ & 2.03 & 1.61 \\
\hline
\end{tabular}

$3 x$

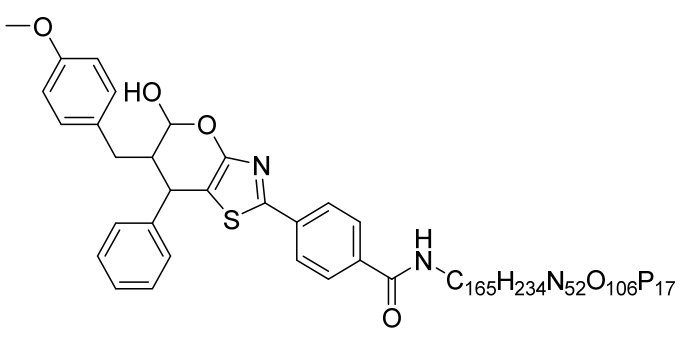

Molecular Weight: 5640.05

wwt-8-28-24h-44

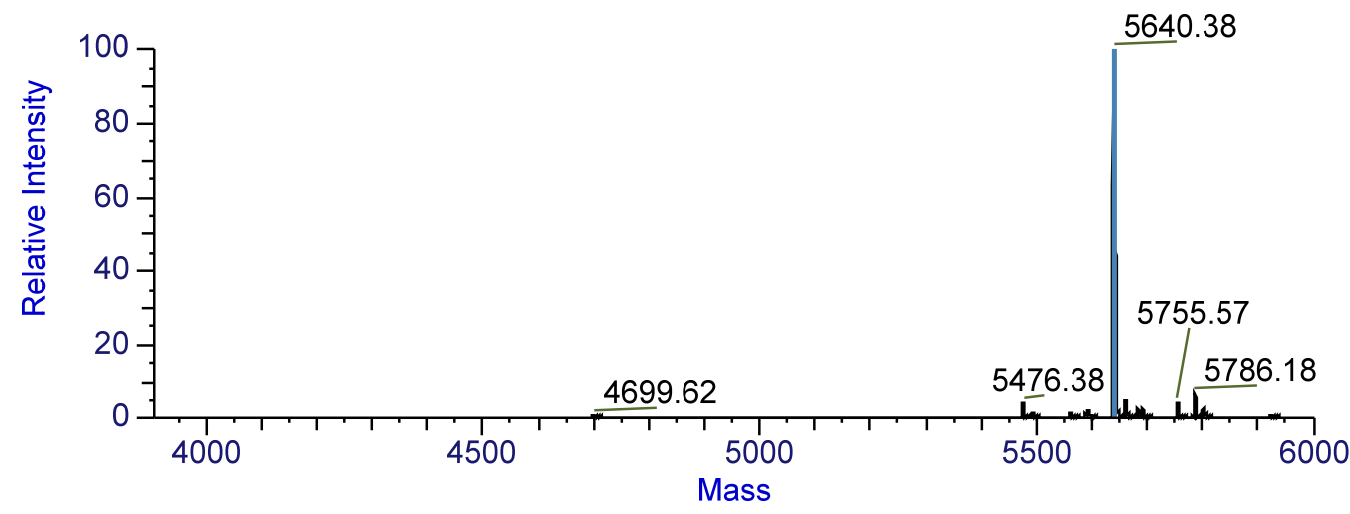

\begin{tabular}{|r|r|r|r|}
\hline Average Mass & Intensity & Relative Abundance & Fractional Abundance \\
\hline 5640.38 & $2.70 \mathrm{E}+05$ & 100.00 & 75.60 \\
\hline 5786.18 & $1.66 \mathrm{E}+04$ & 6.13 & 4.64 \\
\hline 5662.15 & $1.27 \mathrm{E}+04$ & 4.69 & 3.55 \\
\hline 5476.38 & $1.00 \mathrm{E}+04$ & 3.71 & 2.80 \\
\hline 5755.57 & $9.99 \mathrm{E}+03$ & 3.70 & 2.80 \\
\hline 5691.60 & $6.67 \mathrm{E}+03$ & 2.47 & 1.87 \\
\hline 5802.92 & $6.20 \mathrm{E}+03$ & 2.30 & 1.74 \\
\hline 5682.39 & $5.60 \mathrm{E}+03$ & 2.07 & 1.57 \\
\hline 5590.84 & $5.23 \mathrm{E}+03$ & 1.94 & 1.46 \\
\hline 5595.28 & $3.70 \mathrm{E}+03$ & 1.37 & 1.04 \\
\hline & & & \\
\hline
\end{tabular}


3y

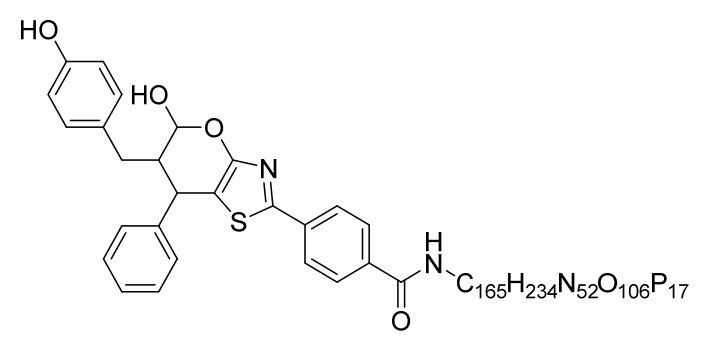

Molecular Weight: 5626.02

wwt-8-28-24h-54

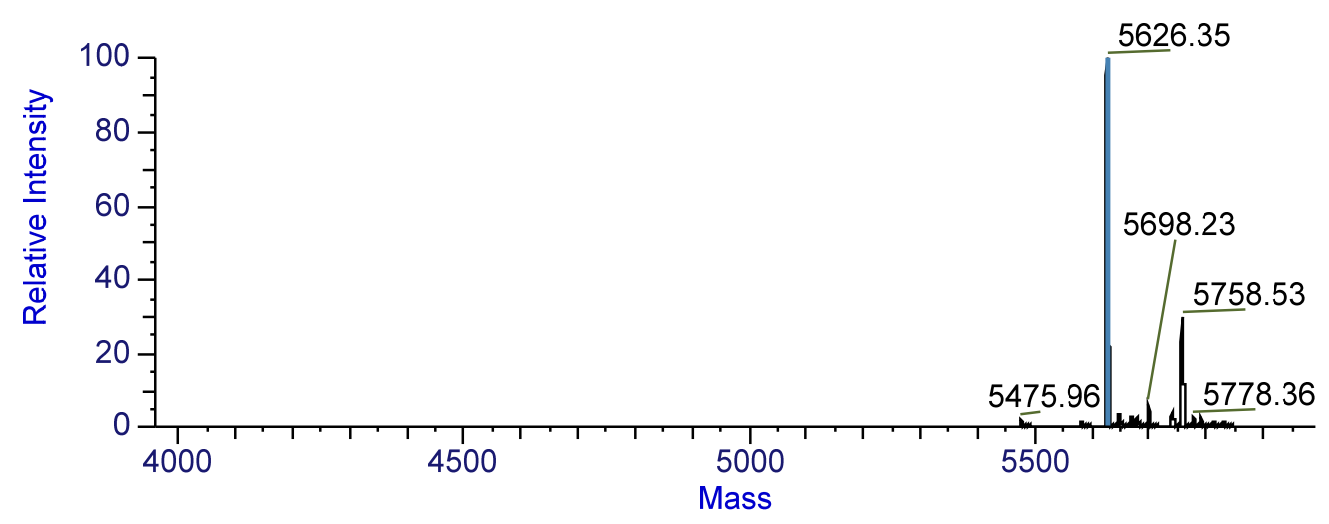

\begin{tabular}{|r|r|r|r|}
\hline Average Mass & Intensity & Relative Abundance & Fractional Abundance \\
\hline 5626.35 & $3.68 \mathrm{E}+05$ & 100.00 & 64.12 \\
\hline 5758.53 & $1.09 \mathrm{E}+05$ & 29.53 & 18.94 \\
\hline 5698.23 & $2.14 \mathrm{E}+04$ & 5.83 & 3.74 \\
\hline 5741.53 & $1.48 \mathrm{E}+04$ & 4.02 & 2.58 \\
\hline 5648.40 & $1.10 \mathrm{E}+04$ & 3.00 & 1.92 \\
\hline 5778.36 & $8.00 \mathrm{E}+03$ & 2.17 & 1.39 \\
\hline 5679.86 & $7.98 \mathrm{E}+03$ & 2.17 & 1.39 \\
\hline 5669.35 & $7.87 \mathrm{E}+03$ & 2.14 & 1.37 \\
\hline 5790.20 & $7.64 \mathrm{E}+03$ & 2.08 & 1.33 \\
\hline 5475.96 & $4.99 \mathrm{E}+03$ & 1.36 & 0.87 \\
\hline & & & \\
\hline
\end{tabular}

$3 z$

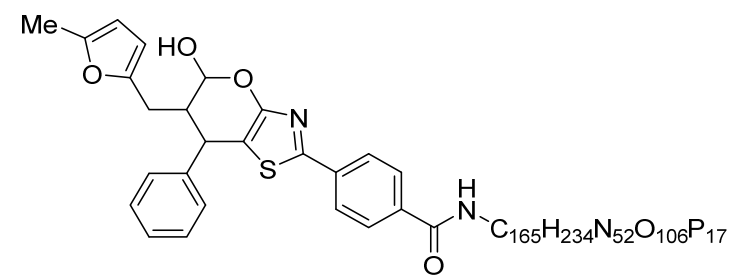

Molecular Weight: 5614.01 
wwt-8-28-24h-48

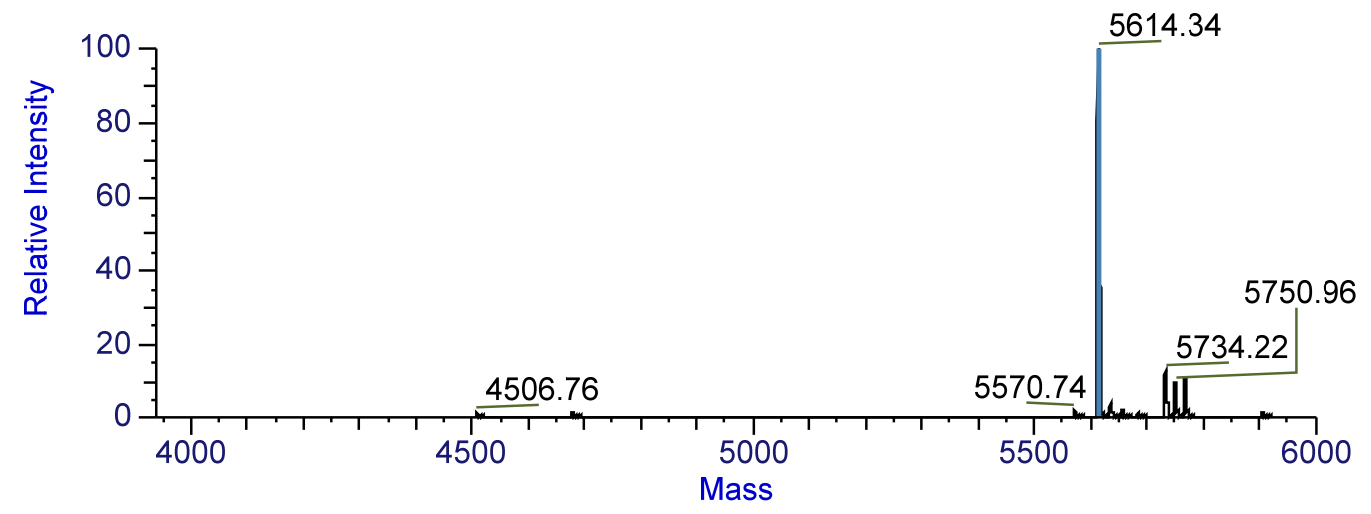

\begin{tabular}{|r|l|r|r|}
\hline Average Mass & Intensity & Relative Abundance & Fractional Abundance \\
\hline 5614.34 & $4.64 \mathrm{E}+05$ & 100.00 & 69.67 \\
\hline 5734.22 & $5.27 \mathrm{E}+04$ & 11.36 & 7.91 \\
\hline 5768.37 & $4.93 \mathrm{E}+04$ & 10.61 & 7.39 \\
\hline 5750.96 & $4.26 \mathrm{E}+04$ & 9.17 & 6.39 \\
\hline 5636.85 & $1.61 \mathrm{E}+04$ & 3.46 & 2.41 \\
\hline 5731.08 & $1.09 \mathrm{E}+04$ & 2.36 & 1.64 \\
\hline 5656.31 & $7.84 \mathrm{E}+03$ & 1.69 & 1.18 \\
\hline 5570.74 & $6.40 \mathrm{E}+03$ & 1.38 & 0.96 \\
\hline 5686.00 & $4.98 \mathrm{E}+03$ & 1.07 & 0.75 \\
\hline 4506.76 & $4.06 \mathrm{E}+03$ & 0.87 & 0.61 \\
\hline & & & \\
\hline
\end{tabular}

$3 a a$

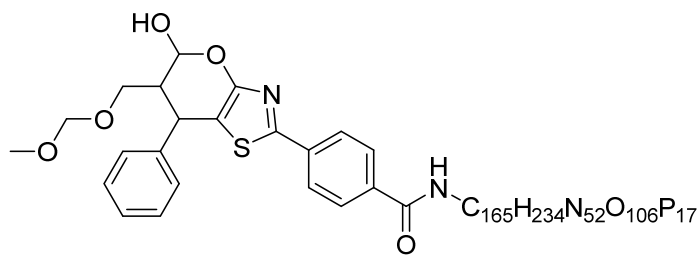

Molecular Weight: 5593.98 
wwt-8-28-24h-52

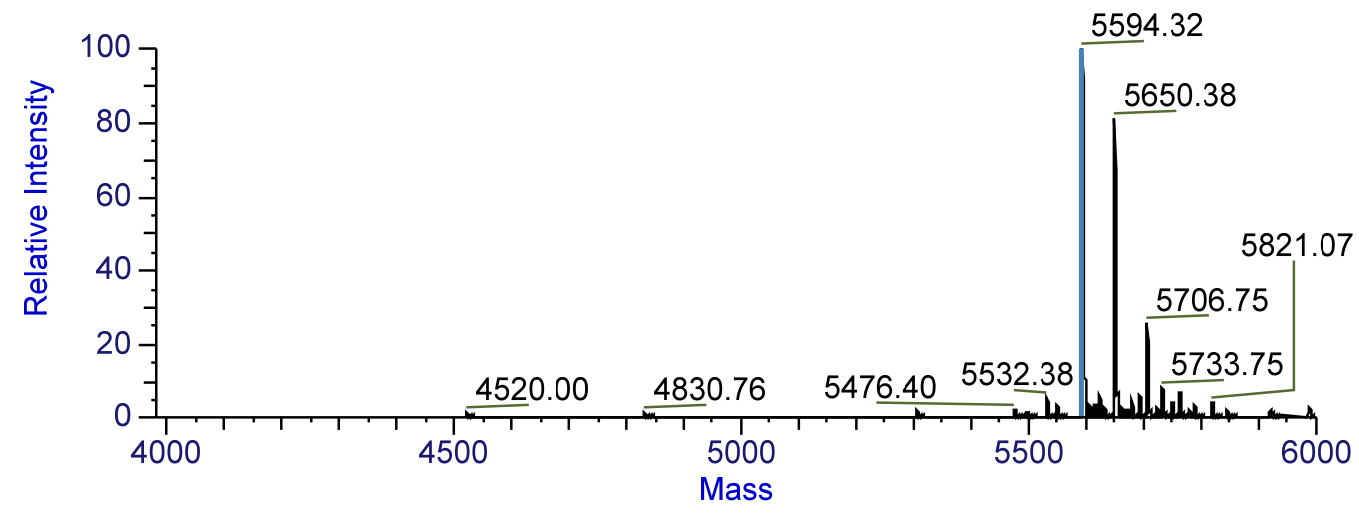

\begin{tabular}{|r|l|r|r|}
\hline Average Mass & Intensity & Relative Abundance & Fractional Abundance \\
\hline 5594.32 & $1.95 \mathrm{E}+05$ & 100.00 & 35.24 \\
\hline 5650.38 & $1.58 \mathrm{E}+05$ & 80.93 & 28.52 \\
\hline 5706.75 & $4.88 \mathrm{E}+04$ & 25.03 & 8.82 \\
\hline 5733.75 & $1.48 \mathrm{E}+04$ & 7.61 & 2.68 \\
\hline 5764.28 & $1.31 \mathrm{E}+04$ & 6.75 & 2.38 \\
\hline 5693.71 & $1.18 \mathrm{E}+04$ & 6.04 & 2.13 \\
\hline 5624.18 & $1.11 \mathrm{E}+04$ & 5.67 & 2.00 \\
\hline 5532.38 & $1.05 \mathrm{E}+04$ & 5.37 & 1.89 \\
\hline 5679.79 & $8.50 \mathrm{E}+03$ & 4.36 & 1.54 \\
\hline 5751.20 & $7.87 \mathrm{E}+03$ & 4.04 & 1.42 \\
\hline & & & \\
\hline
\end{tabular}

\section{$3 a b$}

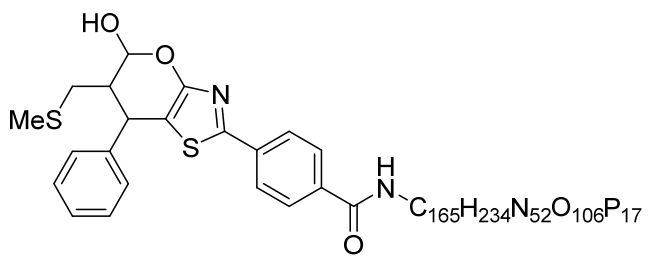

Molecular Weight: 5580.01 
wwt-0508-overnight-18

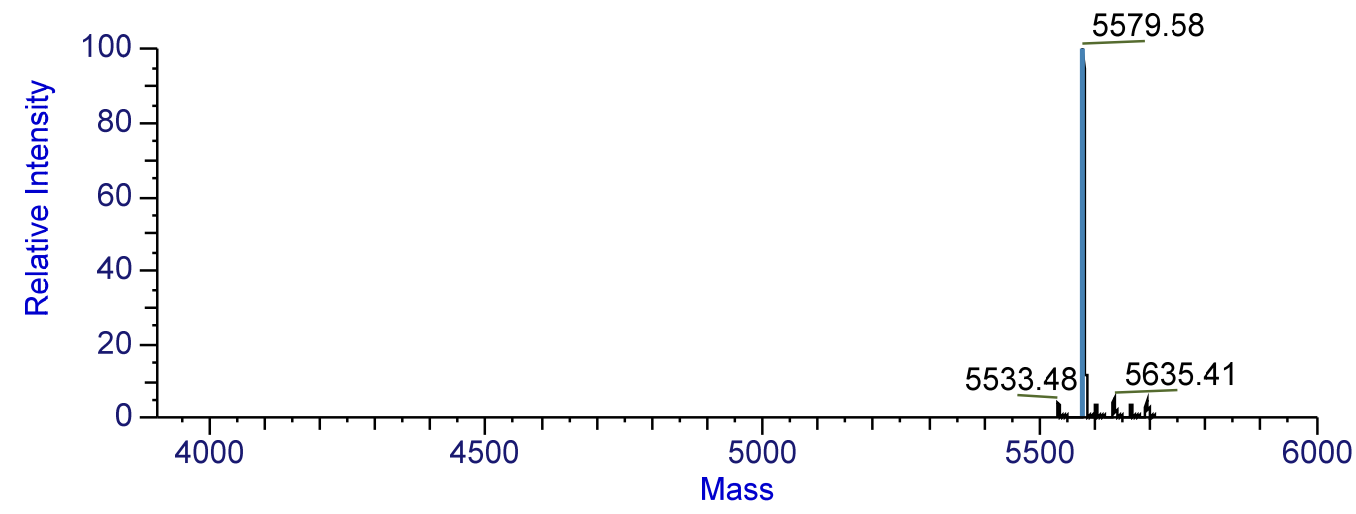

\begin{tabular}{|r|l|r|r|}
\hline Average Mass & Intensity & Relative Abundance & Fractional Abundance \\
\hline 5579.58 & $5.78 \mathrm{E}+05$ & 100.00 & 83.30 \\
\hline 5635.41 & $2.87 \mathrm{E}+04$ & 4.97 & 4.14 \\
\hline 5694.65 & $2.60 \mathrm{E}+04$ & 4.50 & 3.74 \\
\hline 5533.48 & $2.21 \mathrm{E}+04$ & 3.83 & 3.19 \\
\hline 5601.50 & $1.95 \mathrm{E}+04$ & 3.38 & 2.81 \\
\hline 5665.72 & $1.95 \mathrm{E}+04$ & 3.37 & 2.81 \\
\hline
\end{tabular}

$3 a c$

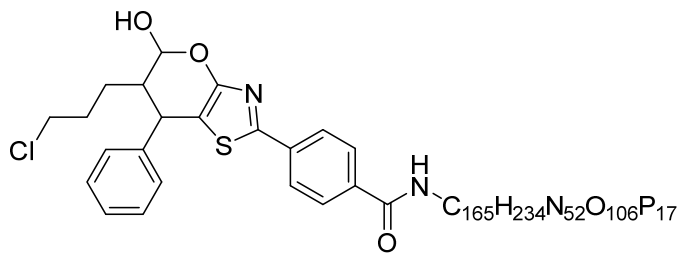

Molecular Weight: 5596.42

wwt-0508-overnight-8

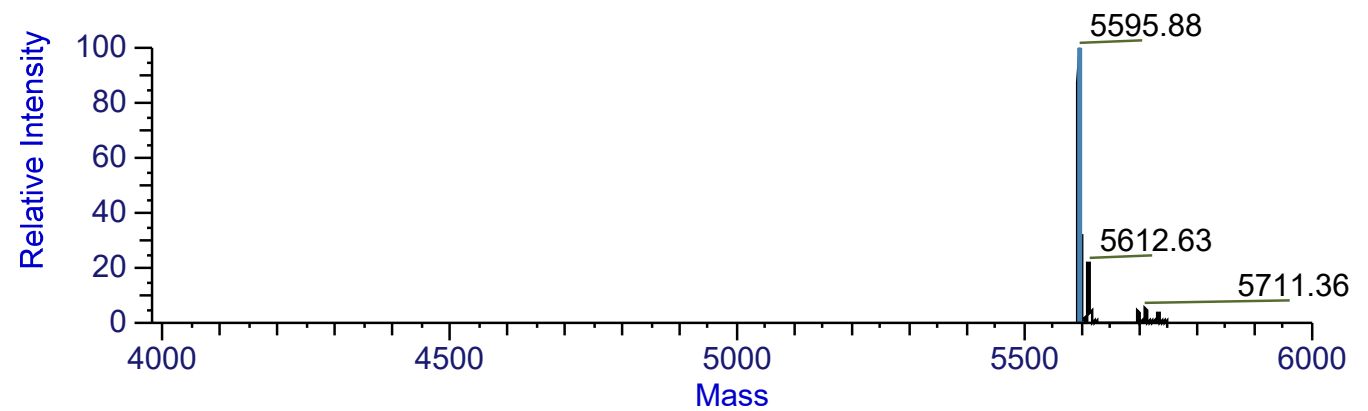

\begin{tabular}{|r|l|r|r|}
\hline Average Mass & Intensity & Relative Abundance & Fractional Abundance \\
\hline 5595.88 & $4.09 \mathrm{E}+05$ & 100.00 & 74.60 \\
\hline 5612.63 & $8.93 \mathrm{E}+04$ & 21.81 & 16.27 \\
\hline 5711.36 & $2.08 \mathrm{E}+04$ & 5.07 & 3.78 \\
\hline 5697.98 & $1.72 \mathrm{E}+04$ & 4.19 & 3.13 \\
\hline
\end{tabular}




\section{3ad}

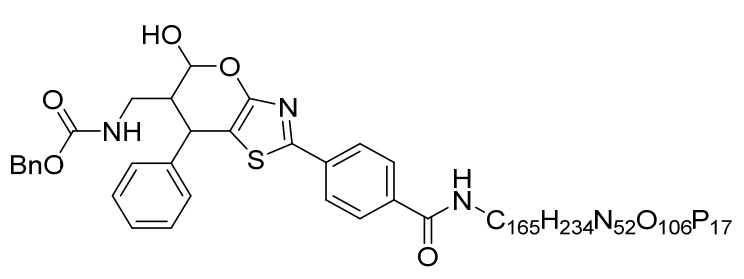

Molecular Weight: 5683.07

wwt-8-28-24h-49

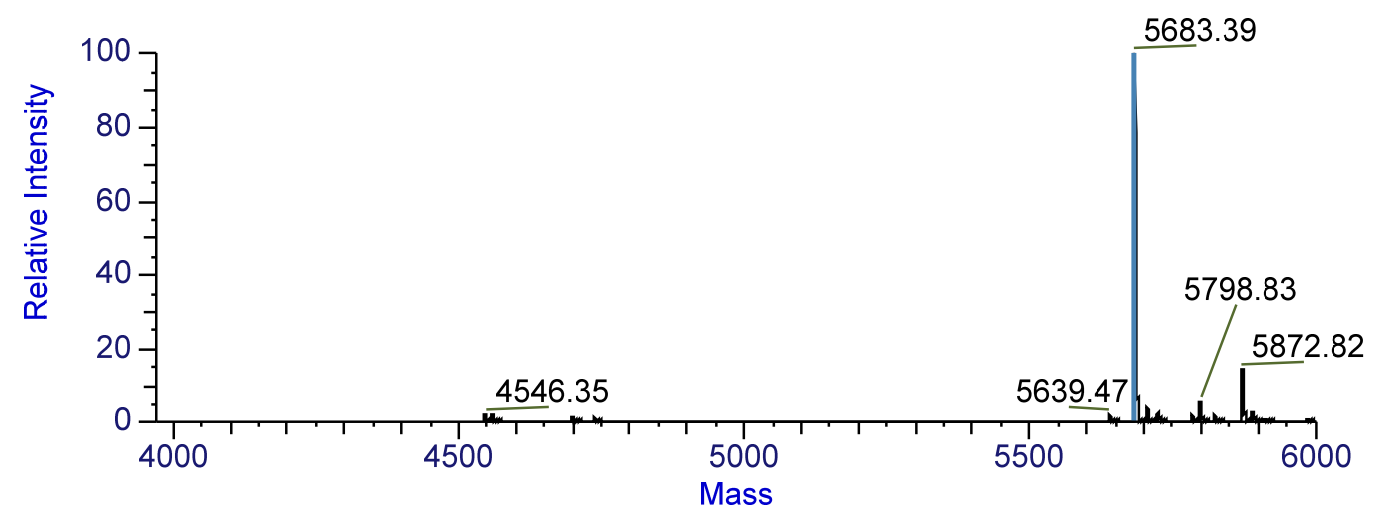

\begin{tabular}{|r|r|r|r|}
\hline Average Mass & Intensity & Relative Abundance & Fractional Abundance \\
\hline 5683.39 & $4.41 \mathrm{E}+05$ & 100.00 & 72.07 \\
\hline 5872.82 & $6.22 \mathrm{E}+04$ & 14.12 & 10.17 \\
\hline 5798.83 & $2.20 \mathrm{E}+04$ & 4.99 & 3.60 \\
\hline 5705.40 & $1.58 \mathrm{E}+04$ & 3.59 & 2.59 \\
\hline 5891.32 & $1.17 \mathrm{E}+04$ & 2.66 & 1.91 \\
\hline 5725.68 & $9.09 \mathrm{E}+03$ & 2.06 & 1.49 \\
\hline 4546.35 & $8.35 \mathrm{E}+03$ & 1.89 & 1.36 \\
\hline 5822.96 & $7.69 \mathrm{E}+03$ & 1.74 & 1.26 \\
\hline 5783.70 & $7.67 \mathrm{E}+03$ & 1.74 & 1.25 \\
\hline 5639.47 & $7.16 \mathrm{E}+03$ & 1.62 & 1.17 \\
\hline & & & \\
\hline
\end{tabular}




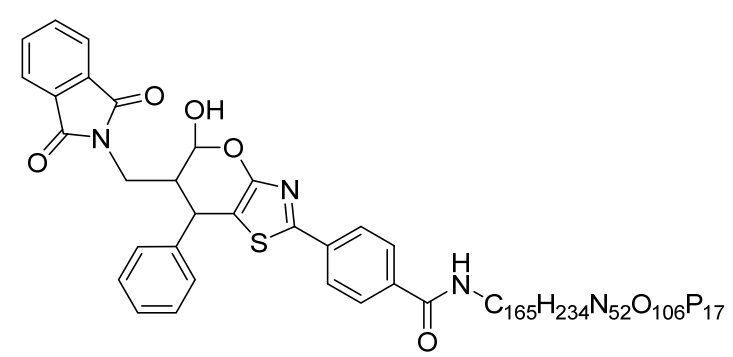

Molecular Weight: 5679.04

wwt-8-28-24h-57

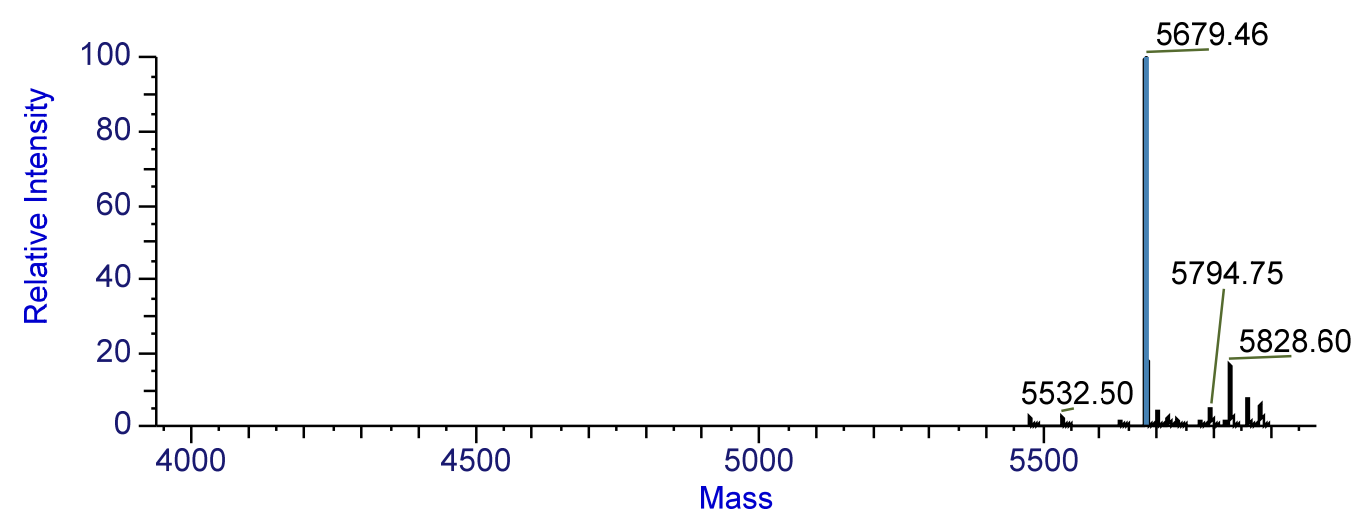

\begin{tabular}{|r|r|r|r|}
\hline Average Mass & Intensity & Relative Abundance & Fractional Abundance \\
\hline 5679.46 & $3.48 \mathrm{E}+05$ & 100.00 & 66.84 \\
\hline 5828.60 & $5.77 \mathrm{E}+04$ & 16.58 & 11.08 \\
\hline 5859.58 & $2.53 \mathrm{E}+04$ & 7.29 & 4.87 \\
\hline 5882.95 & $2.05 \mathrm{E}+04$ & 5.91 & 3.95 \\
\hline 5794.75 & $1.64 \mathrm{E}+04$ & 4.72 & 3.15 \\
\hline 5701.25 & $1.21 \mathrm{E}+04$ & 3.47 & 2.32 \\
\hline 5532.50 & $7.69 \mathrm{E}+03$ & 2.21 & 1.48 \\
\hline 5720.48 & $7.45 \mathrm{E}+03$ & 2.14 & 1.43 \\
\hline 5476.58 & $7.07 \mathrm{E}+03$ & 2.03 & 1.36 \\
\hline 5735.12 & $5.67 \mathrm{E}+03$ & 1.63 & 1.09 \\
\hline
\end{tabular}

$3 a f$

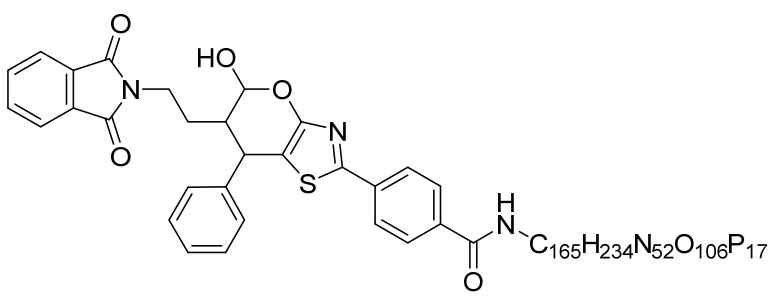

Molecular Weight: 5693.07 


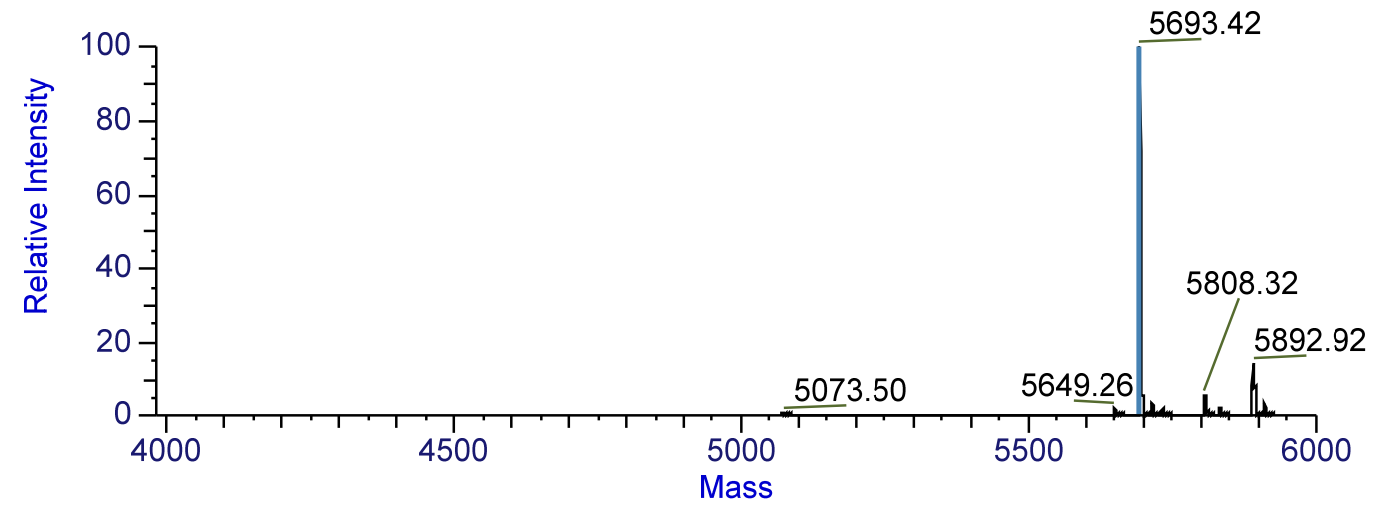

\begin{tabular}{|r|r|r|r|}
\hline Average Mass & Intensity & Relative Abundance & Fractional Abundance \\
\hline 5693.42 & $4.77 \mathrm{E}+05$ & 100.00 & 76.85 \\
\hline 5892.92 & $6.55 \mathrm{E}+04$ & 13.73 & 10.55 \\
\hline 5808.32 & $2.32 \mathrm{E}+04$ & 4.86 & 3.74 \\
\hline 5910.62 & $1.43 \mathrm{E}+04$ & 3.01 & 2.31 \\
\hline 5715.35 & $1.42 \mathrm{E}+04$ & 2.98 & 2.29 \\
\hline 5833.00 & $8.34 \mathrm{E}+03$ & 1.75 & 1.35 \\
\hline 5735.45 & $7.85 \mathrm{E}+03$ & 1.65 & 1.27 \\
\hline 5649.26 & $7.23 \mathrm{E}+03$ & 1.52 & 1.17 \\
\hline 5073.50 & $2.94 \mathrm{E}+03$ & 0.62 & 0.47 \\
\hline & & & \\
\hline
\end{tabular}

\section{3ag}

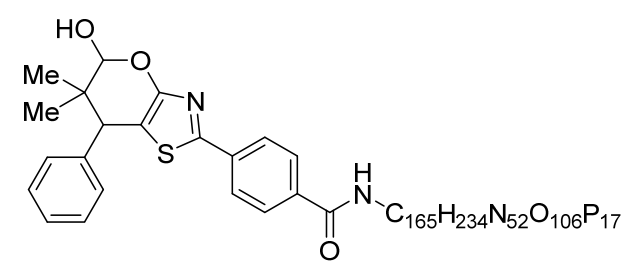

Molecular Weight: 5547.95

wwt-0514-overnight-17

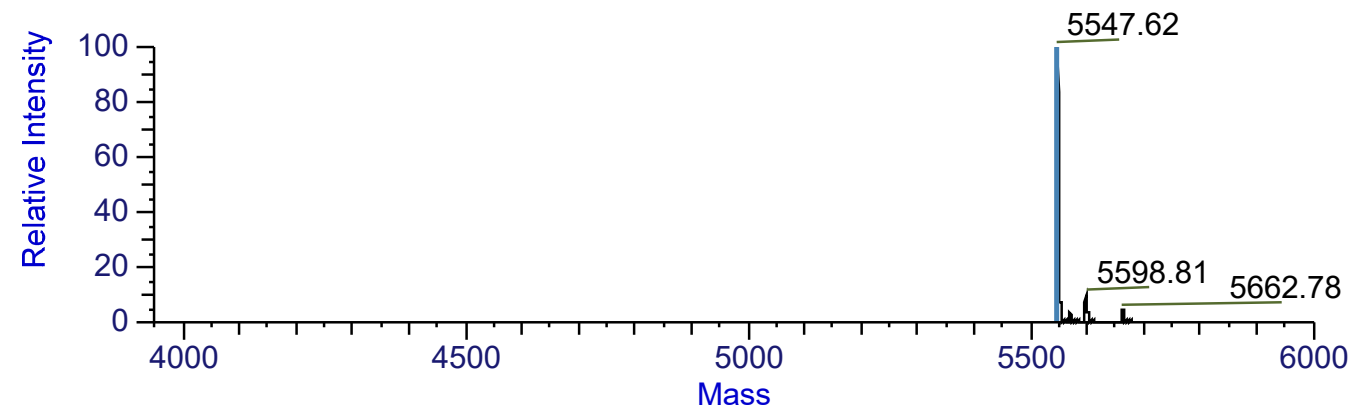

\begin{tabular}{|r|l|r|r|}
\hline Average Mass & Intensity & Relative Abundance & Fractional Abundance \\
\hline 5547.62 & $5.01 \mathrm{E}+05$ & 100.00 & 85.56 \\
\hline
\end{tabular}




\begin{tabular}{|r|r|r|r|}
\hline 5598.81 & $4.61 \mathrm{E}+04$ & 9.19 & 7.86 \\
\hline 5662.78 & $2.21 \mathrm{E}+04$ & 4.41 & 3.77 \\
\hline 5569.65 & $1.64 \mathrm{E}+04$ & 3.28 & 2.80 \\
\hline
\end{tabular}

3ah

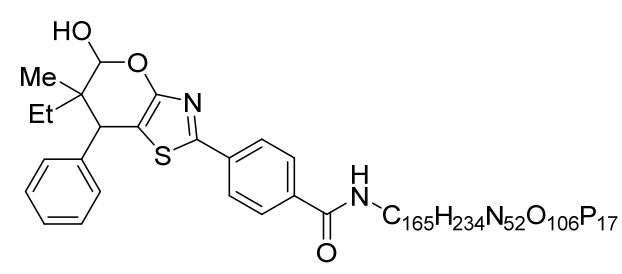

Molecular Weight: 5561.98

wwt-0523-10-overnight

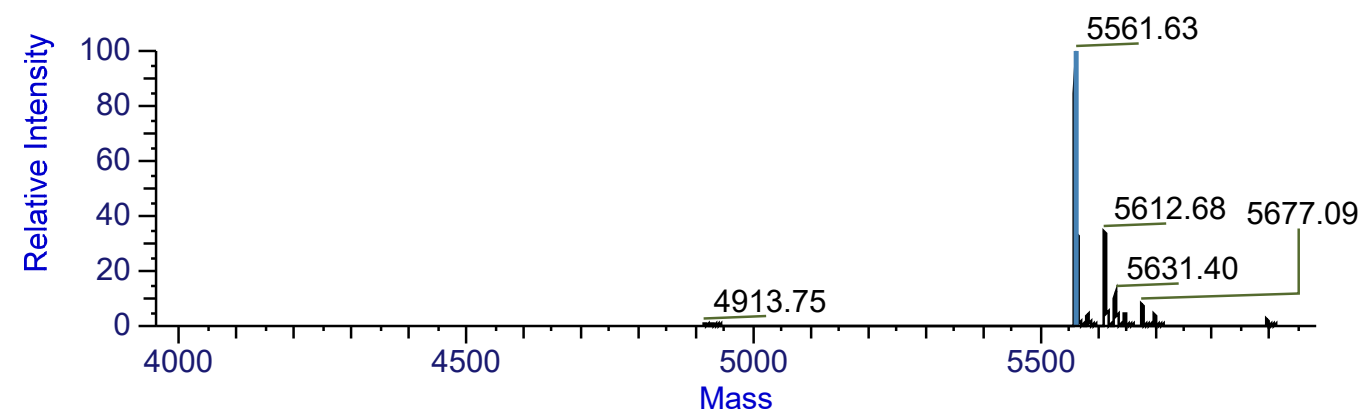

\begin{tabular}{|r|l|r|r|}
\hline Average Mass & Intensity & Relative Abundance & Fractional Abundance \\
\hline 5561.63 & $2.91 \mathrm{E}+05$ & 100.00 & 58.98 \\
\hline 5612.68 & $9.85 \mathrm{E}+04$ & 33.90 & 19.99 \\
\hline 5631.40 & $3.54 \mathrm{E}+04$ & 12.19 & 7.19 \\
\hline 5677.09 & $2.27 \mathrm{E}+04$ & 7.81 & 4.61 \\
\hline 5647.73 & $1.29 \mathrm{E}+04$ & 4.46 & 2.63 \\
\hline 5583.50 & $1.25 \mathrm{E}+04$ & 4.29 & 2.53 \\
\hline 5699.30 & $1.07 \mathrm{E}+04$ & 3.67 & 2.17 \\
\hline 5894.95 & $5.55 \mathrm{E}+03$ & 1.91 & 1.13 \\
\hline 4913.75 & $1.93 \mathrm{E}+03$ & 0.66 & 0.39 \\
\hline 4929.21 & $1.92 \mathrm{E}+03$ & 0.66 & 0.39 \\
\hline & & & \\
\hline
\end{tabular}

3ai

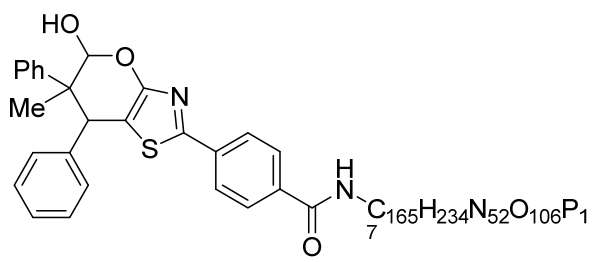

Molecular Weight: 5610.02 
wwt-0918-24h-A11

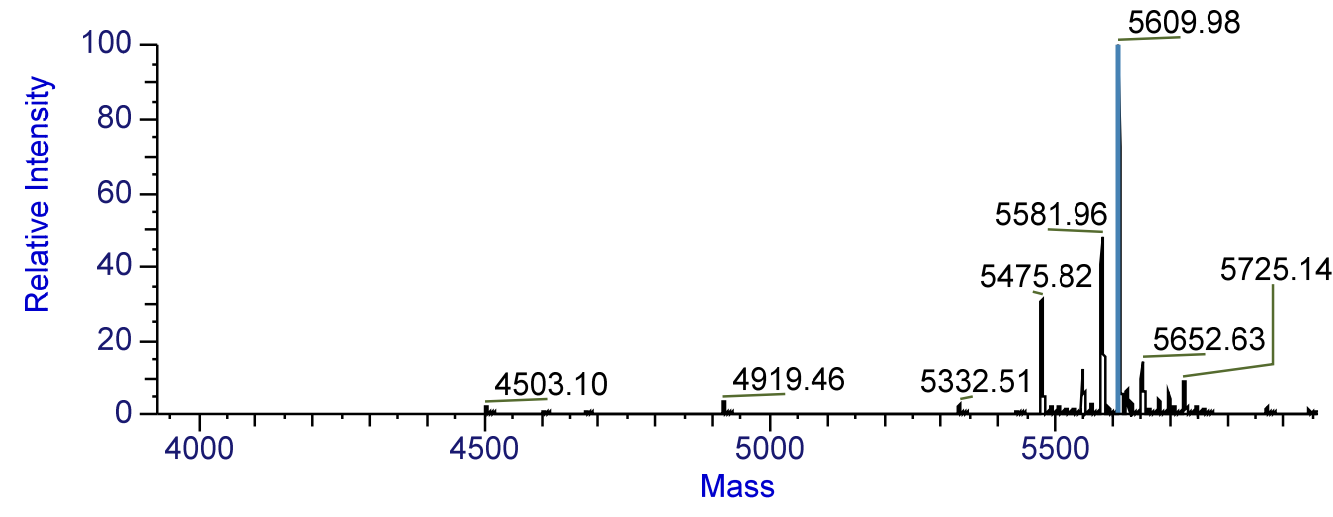

\begin{tabular}{|r|r|r|r|}
\hline Average Mass & Intensity & Relative Abundance & Fractional Abundance \\
\hline 5609.98 & $1.58 \mathrm{E}+05$ & 100.00 & 38.59 \\
\hline 5581.96 & $7.57 \mathrm{E}+04$ & 47.81 & 18.45 \\
\hline 5475.82 & $4.83 \mathrm{E}+04$ & 30.52 & 11.78 \\
\hline 5652.63 & $2.17 \mathrm{E}+04$ & 13.68 & 5.28 \\
\hline 5547.74 & $1.84 \mathrm{E}+04$ & 11.64 & 4.49 \\
\hline 5725.14 & $1.36 \mathrm{E}+04$ & 8.60 & 3.32 \\
\hline 5625.71 & $1.04 \mathrm{E}+04$ & 6.59 & 2.54 \\
\hline 5696.97 & $9.15 \mathrm{E}+03$ & 5.78 & 2.23 \\
\hline 5680.20 & $5.98 \mathrm{E}+03$ & 3.78 & 1.46 \\
\hline 4919.46 & $4.83 \mathrm{E}+03$ & 3.05 & 1.18 \\
\hline & & & \\
\hline
\end{tabular}

3aj

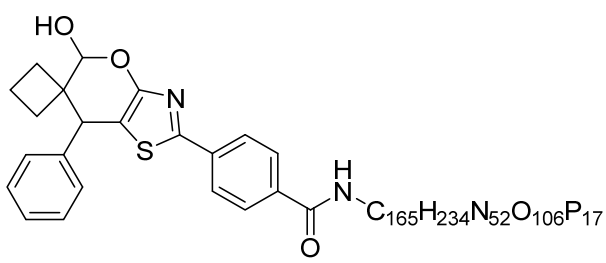

Molecular Weight: 5559.96

wwt-0514-overnight-21

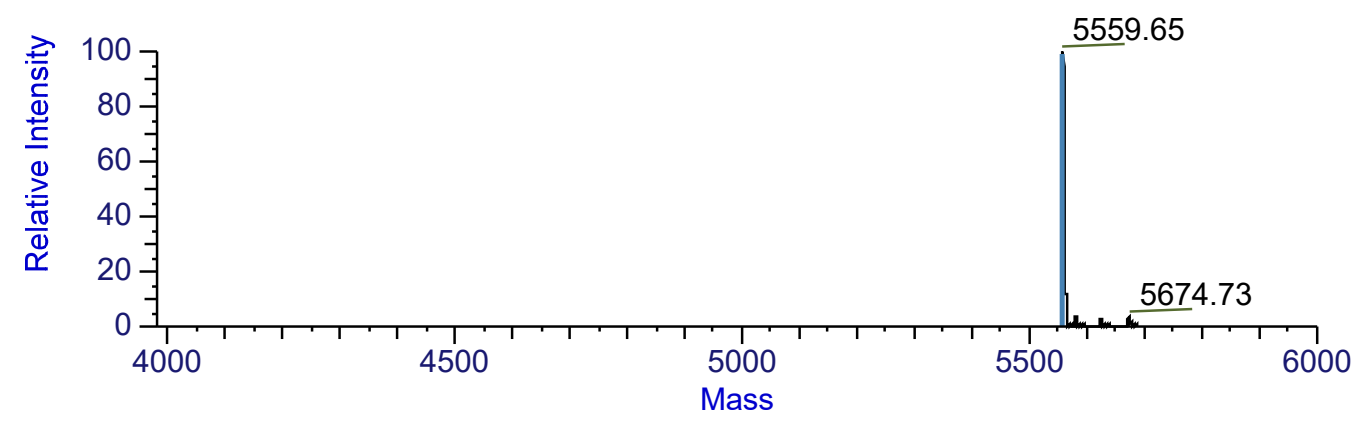

\begin{tabular}{|l|l|l|l|} 
Average Mass & Intensity & Relative Abundance & Fractional Abundance \\
\hline
\end{tabular} 


\begin{tabular}{|r|r|r|r|}
\hline 5559.65 & $6.41 \mathrm{E}+05$ & 100.00 & 92.31 \\
\hline 5674.73 & $1.92 \mathrm{E}+04$ & 3.00 & 2.77 \\
\hline 5581.47 & $1.91 \mathrm{E}+04$ & 2.99 & 2.76 \\
\hline 5625.92 & $1.50 \mathrm{E}+04$ & 2.34 & 2.16 \\
\hline
\end{tabular}

3ak

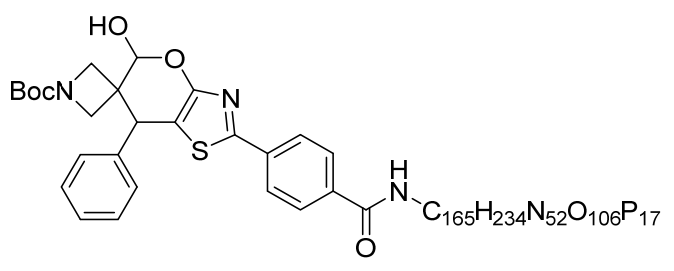

Molecular Weight: 5661.07

wwt-0816-24h-A38

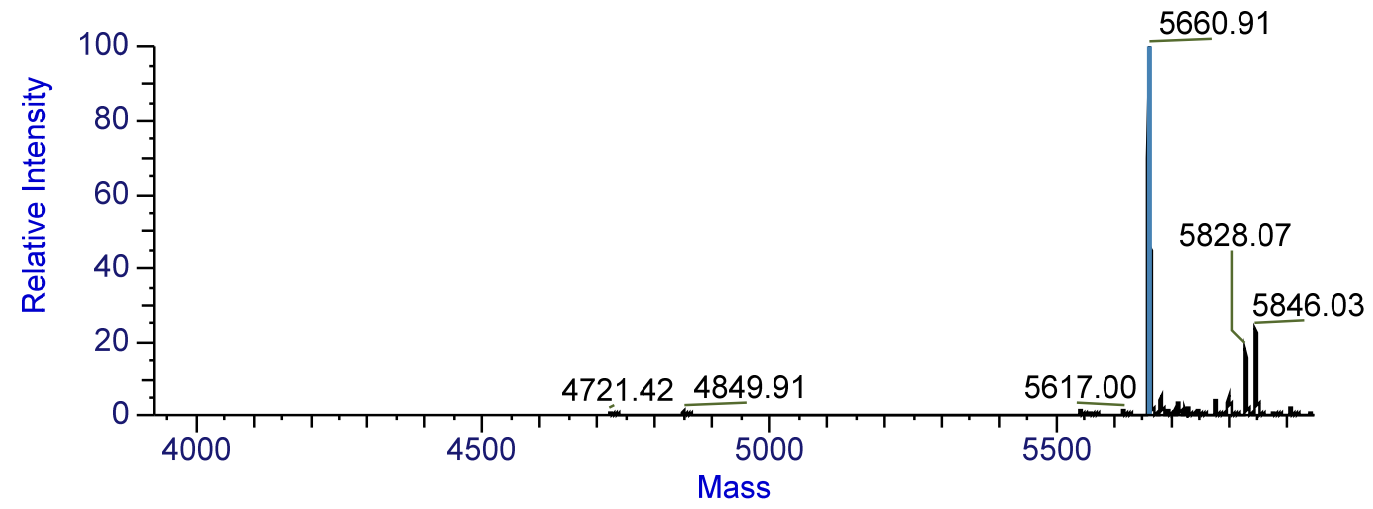

\begin{tabular}{|r|r|r|r|}
\hline Average Mass & Intensity & Relative Abundance & Fractional Abundance \\
\hline 5660.91 & $3.76 \mathrm{E}+05$ & 100.00 & 58.39 \\
\hline 5846.03 & $8.80 \mathrm{E}+04$ & 23.40 & 13.66 \\
\hline 5828.07 & $6.81 \mathrm{E}+04$ & 18.10 & 10.57 \\
\hline 5800.58 & $2.03 \mathrm{E}+04$ & 5.40 & 3.15 \\
\hline 5682.16 & $1.78 \mathrm{E}+04$ & 4.73 & 2.76 \\
\hline 5776.25 & $1.38 \mathrm{E}+04$ & 3.68 & 2.15 \\
\hline 5711.99 & $1.18 \mathrm{E}+04$ & 3.12 & 1.82 \\
\hline 5729.55 & $5.67 \mathrm{E}+03$ & 1.51 & 0.88 \\
\hline 5723.62 & $5.58 \mathrm{E}+03$ & 1.48 & 0.87 \\
\hline 5908.09 & $5.54 \mathrm{E}+03$ & 1.47 & 0.86 \\
\hline
\end{tabular}


3al

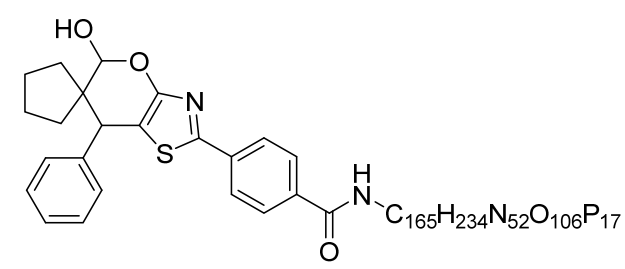

Molecular Weight: 5573.99

wwt-0514-overnight-20

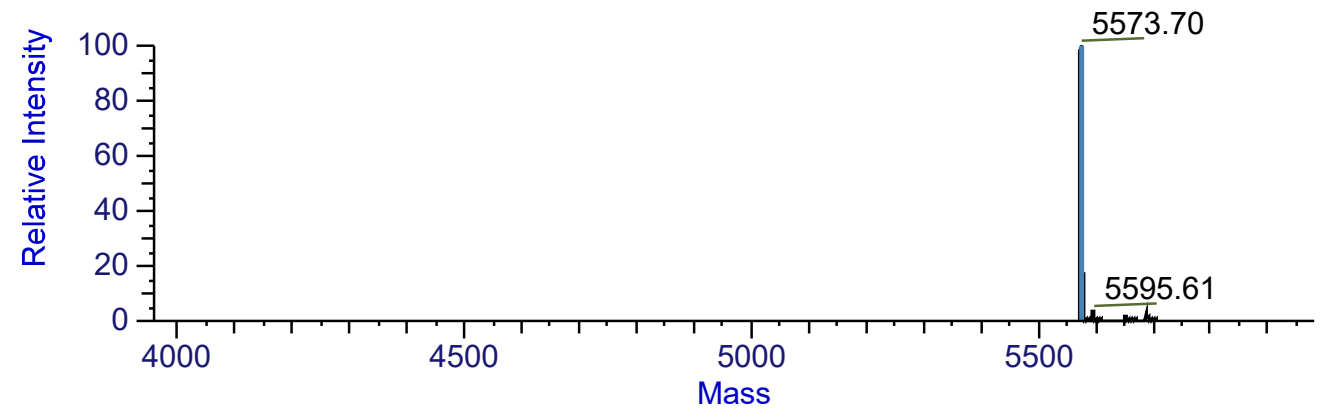

\begin{tabular}{|r|l|r|r|}
\hline Average Mass & Intensity & Relative Abundance & Fractional Abundance \\
\hline 5573.70 & $7.07 \mathrm{E}+05$ & 100.00 & 92.63 \\
\hline 5595.61 & $2.39 \mathrm{E}+04$ & 3.38 & 3.13 \\
\hline 5688.83 & $2.04 \mathrm{E}+04$ & 2.88 & 2.67 \\
\hline 5653.80 & $1.19 \mathrm{E}+04$ & 1.69 & 1.56 \\
\hline
\end{tabular}

3am

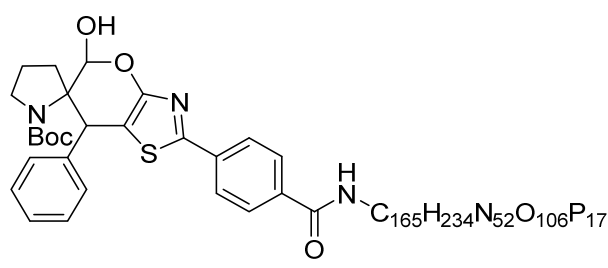

Molecular Weight: 5675.10

wwt-0514-overnight-26

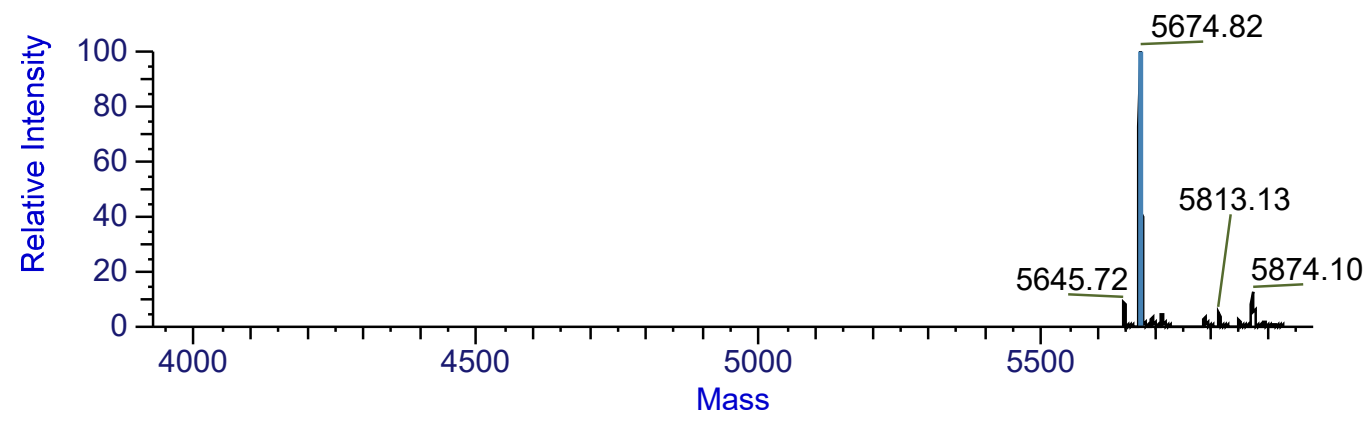




\begin{tabular}{|r|l|r|r|}
\hline Average Mass & Intensity & Relative Abundance & Fractional Abundance \\
\hline 5674.82 & $3.92 \mathrm{E}+05$ & 100.00 & 70.69 \\
\hline 5874.10 & $4.67 \mathrm{E}+04$ & 11.93 & 8.43 \\
\hline 5645.72 & $3.48 \mathrm{E}+04$ & 8.89 & 6.28 \\
\hline 5813.13 & $1.82 \mathrm{E}+04$ & 4.64 & 3.28 \\
\hline 5713.80 & $1.53 \mathrm{E}+04$ & 3.91 & 2.77 \\
\hline 5790.01 & $1.42 \mathrm{E}+04$ & 3.63 & 2.56 \\
\hline 5696.74 & $1.34 \mathrm{E}+04$ & 3.41 & 2.41 \\
\hline 5848.10 & $1.06 \mathrm{E}+04$ & 2.72 & 1.92 \\
\hline 5892.78 & $6.38 \mathrm{E}+03$ & 1.63 & 1.15 \\
\hline 5911.35 & $2.74 \mathrm{E}+03$ & 0.70 & 0.49 \\
\hline & & & \\
\hline
\end{tabular}

\section{3an}

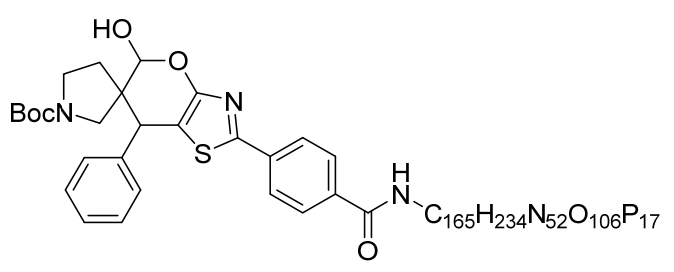

Molecular Weight: 5675.10

wwt-0816-24h-A37

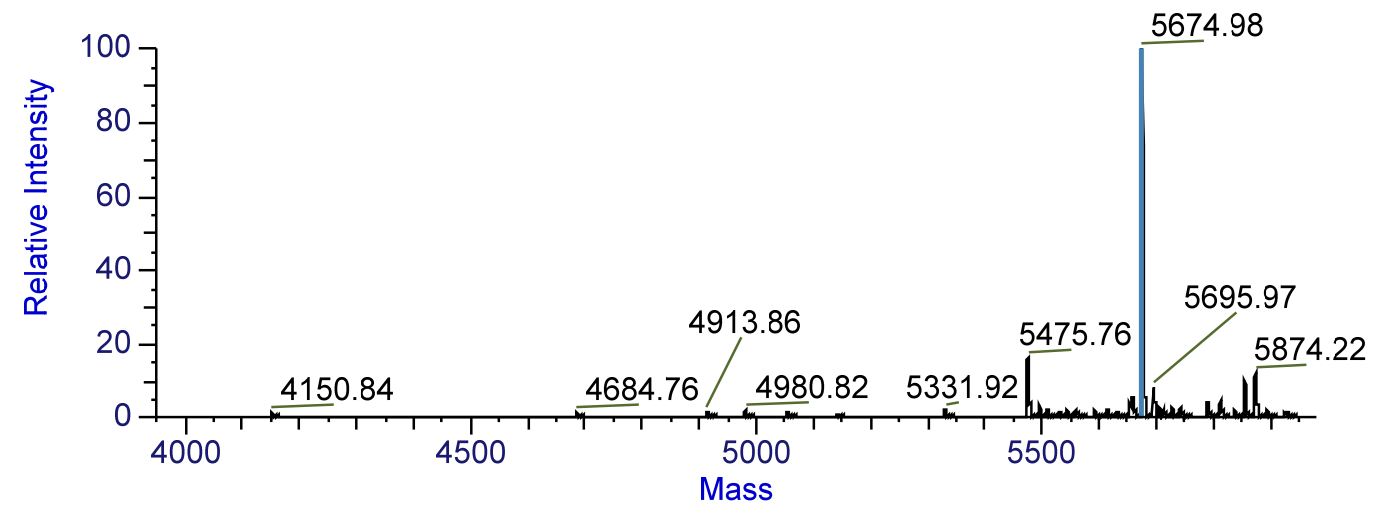

\begin{tabular}{|r|r|r|r|}
\hline Average Mass & Intensity & Relative Abundance & Fractional Abundance \\
\hline 5674.98 & $1.86 \mathrm{E}+05$ & 100.00 & 50.73 \\
\hline 5475.76 & $3.01 \mathrm{E}+04$ & 16.15 & 8.19 \\
\hline 5874.22 & $2.19 \mathrm{E}+04$ & 11.74 & 5.96 \\
\hline 5855.02 & $1.85 \mathrm{E}+04$ & 9.92 & 5.03 \\
\hline 5695.97 & $1.43 \mathrm{E}+04$ & 7.65 & 3.88 \\
\hline 5656.20 & $9.81 \mathrm{E}+03$ & 5.27 & 2.67 \\
\hline 5813.85 & $7.67 \mathrm{E}+03$ & 4.11 & 2.09 \\
\hline 5790.33 & $7.52 \mathrm{E}+03$ & 4.04 & 2.05 \\
\hline 5660.31 & $7.13 \mathrm{E}+03$ & 3.82 & 1.94 \\
\hline
\end{tabular}




\begin{tabular}{|l|r|r|r|}
\hline 5494.66 & $5.07 \mathrm{E}+03$ & 2.72 & 1.38 \\
\hline
\end{tabular}

\section{3 ao}

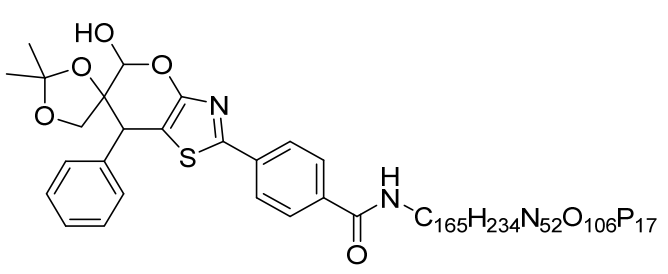

Molecular Weight: 5605.99

wwt-0816-24h-A36

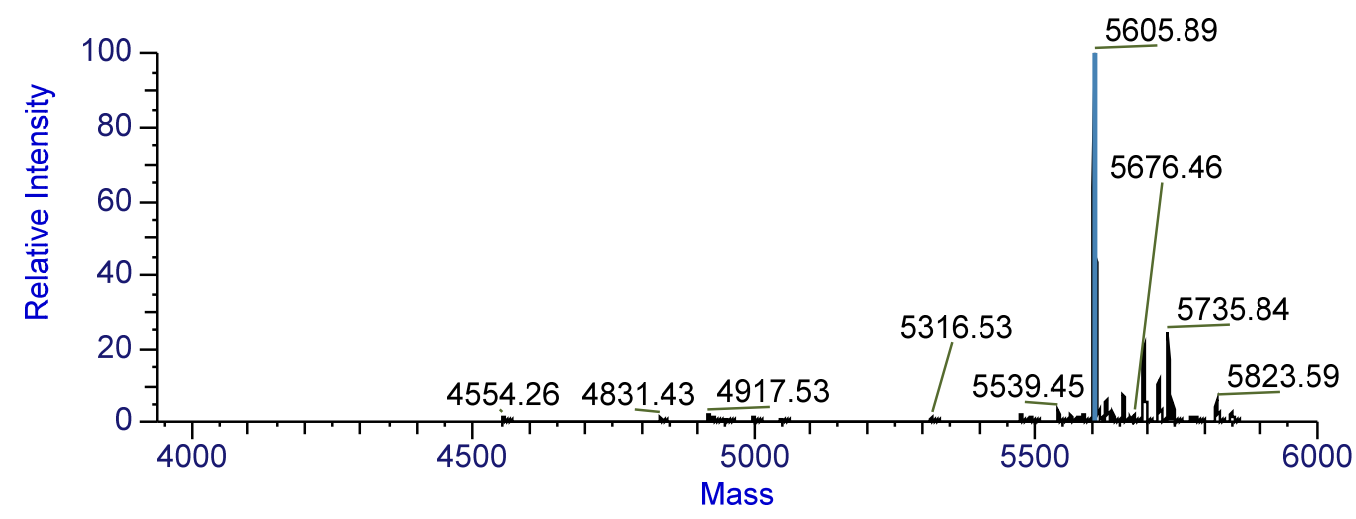

\begin{tabular}{|r|r|r|r|}
\hline Average Mass & Intensity & Relative Abundance & Fractional Abundance \\
\hline 5605.89 & $1.73 \mathrm{E}+05$ & 100.00 & 48.15 \\
\hline 5735.84 & $4.17 \mathrm{E}+04$ & 24.13 & 11.62 \\
\hline 5693.81 & $3.53 \mathrm{E}+04$ & 20.43 & 9.84 \\
\hline 5720.54 & $1.93 \mathrm{E}+04$ & 11.17 & 5.38 \\
\hline 5656.69 & $1.21 \mathrm{E}+04$ & 7.02 & 3.38 \\
\hline 5627.68 & $1.04 \mathrm{E}+04$ & 6.00 & 2.89 \\
\hline 5823.59 & $9.67 \mathrm{E}+03$ & 5.59 & 2.69 \\
\hline 5744.44 & $8.28 \mathrm{E}+03$ & 4.79 & 2.31 \\
\hline 5539.45 & $5.12 \mathrm{E}+03$ & 2.96 & 1.43 \\
\hline 5850.54 & $4.51 \mathrm{E}+03$ & 2.61 & 1.26 \\
\hline & & & \\
\hline
\end{tabular}

3ap

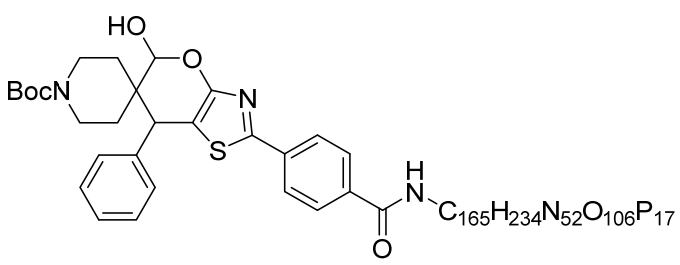

Molecular Weight: 5689.12 
wwt-0514-overnight-24

5671.06

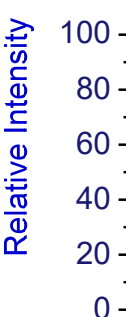

5688.74

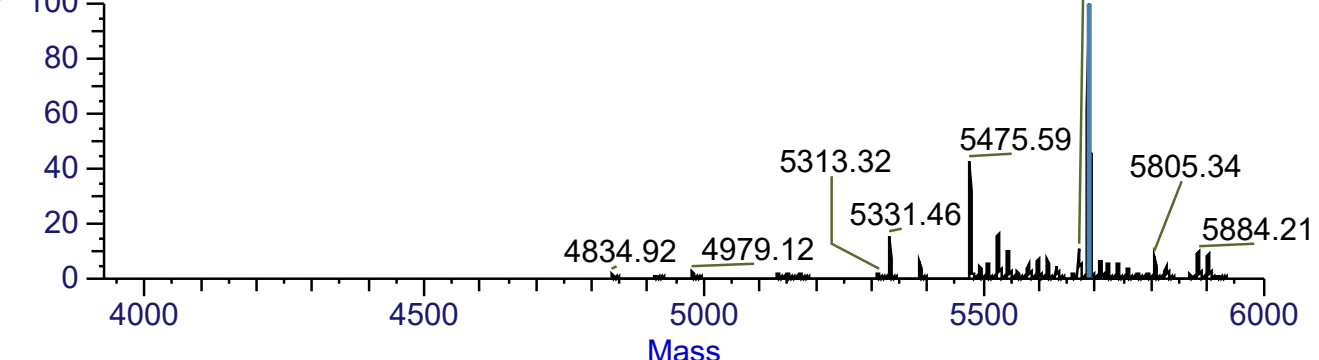

\begin{tabular}{|r|r|r|r|}
\hline Average Mass & Intensity & Relative Abundance & Fractional Abundance \\
\hline 5688.74 & $1.06 \mathrm{E}+05$ & 100.00 & 33.64 \\
\hline 5475.59 & $4.47 \mathrm{E}+04$ & 42.35 & 14.25 \\
\hline 5526.72 & $1.68 \mathrm{E}+04$ & 15.87 & 5.34 \\
\hline 5331.46 & $1.59 \mathrm{E}+04$ & 15.05 & 5.06 \\
\hline 5671.06 & $1.09 \mathrm{E}+04$ & 10.33 & 3.48 \\
\hline 5544.62 & $1.04 \mathrm{E}+04$ & 9.84 & 3.31 \\
\hline 5884.21 & $9.65 \mathrm{E}+03$ & 9.14 & 3.07 \\
\hline 5902.09 & $9.14 \mathrm{E}+03$ & 8.65 & 2.91 \\
\hline 5805.34 & $8.24 \mathrm{E}+03$ & 7.80 & 2.62 \\
\hline 5614.14 & $7.39 \mathrm{E}+03$ & 7.00 & 2.35 \\
\hline & & & \\
\hline
\end{tabular}

$3 a q$

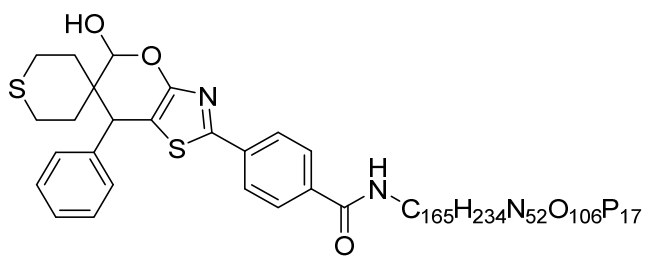

Molecular Weight: 5606.05

wwt-0514-overnight-25

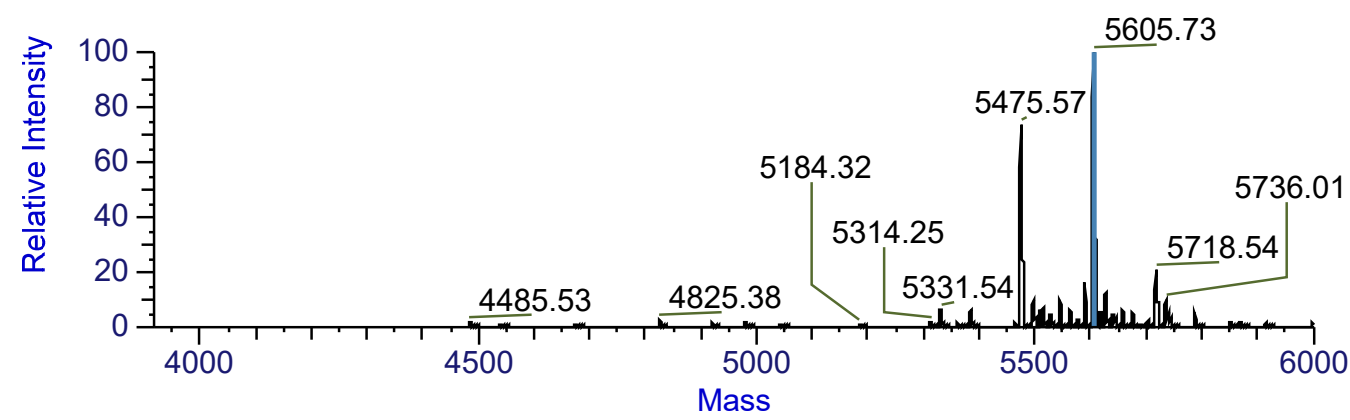

\begin{tabular}{|r|l|r|r|}
\hline Average Mass & Intensity & Relative Abundance & Fractional Abundance \\
\hline 5605.73 & $1.02 \mathrm{E}+05$ & 100.00 & 29.41 \\
\hline 5475.57 & $7.49 \mathrm{E}+04$ & 73.44 & 21.60 \\
\hline
\end{tabular}




\begin{tabular}{|r|r|r|r|}
\hline 5718.54 & $2.04 \mathrm{E}+04$ & 20.03 & 5.89 \\
\hline 5588.67 & $1.63 \mathrm{E}+04$ & 15.95 & 4.69 \\
\hline 5627.46 & $1.24 \mathrm{E}+04$ & 12.11 & 3.56 \\
\hline 5736.01 & $1.01 \mathrm{E}+04$ & 9.88 & 2.90 \\
\hline 5497.76 & $9.67 \mathrm{E}+03$ & 9.48 & 2.79 \\
\hline 5545.10 & $9.37 \mathrm{E}+03$ & 9.19 & 2.70 \\
\hline 5515.44 & $6.50 \mathrm{E}+03$ & 6.37 & 1.87 \\
\hline 5331.54 & $6.33 \mathrm{E}+03$ & 6.20 & 1.82 \\
\hline
\end{tabular}

3ar<smiles></smiles>

Molecular Weight: 5545.94

wwt-0508-overnight-31_190509174832

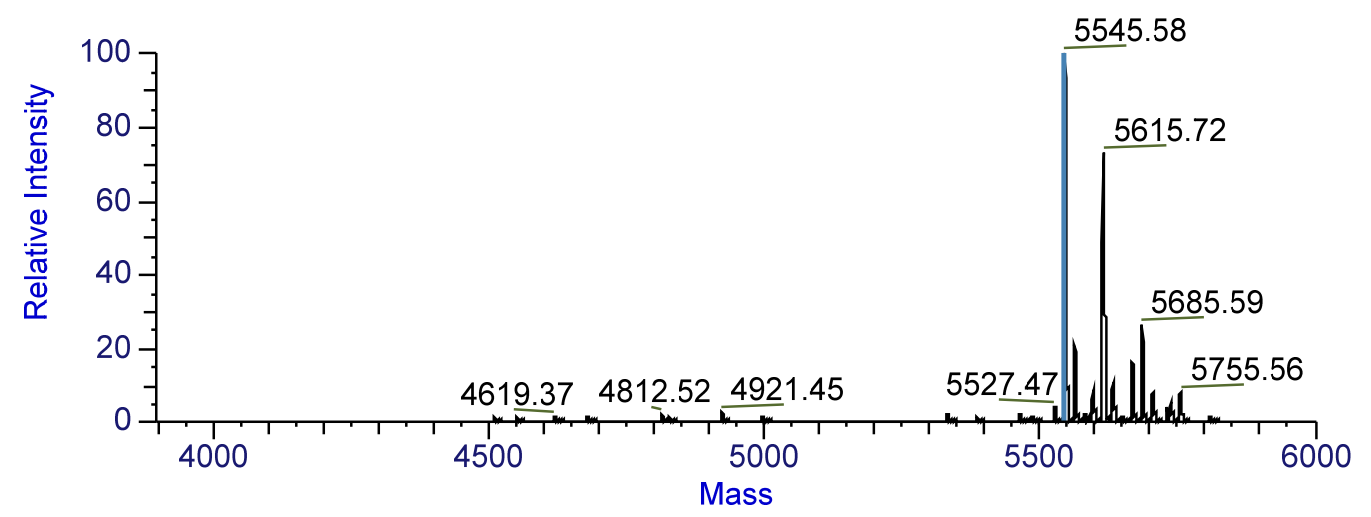

\begin{tabular}{|r|l|r|r|}
\hline Average Mass & Intensity & Relative Abundance & Fractional Abundance \\
\hline 5545.58 & $1.56 \mathrm{E}+05$ & 100.00 & 32.84 \\
\hline 5615.72 & $1.13 \mathrm{E}+05$ & 72.47 & 23.80 \\
\hline 5685.59 & $4.07 \mathrm{E}+04$ & 26.08 & 8.56 \\
\hline 5563.70 & $3.22 \mathrm{E}+04$ & 20.61 & 6.77 \\
\hline 5668.08 & $2.51 \mathrm{E}+04$ & 16.08 & 5.28 \\
\hline 5633.61 & $1.67 \mathrm{E}+04$ & 10.68 & 3.51 \\
\hline 5597.58 & $1.30 \mathrm{E}+04$ & 8.30 & 2.73 \\
\hline 5755.56 & $1.20 \mathrm{E}+04$ & 7.71 & 2.53 \\
\hline 5738.46 & $7.71 \mathrm{E}+03$ & 4.94 & 1.62 \\
\hline 5706.42 & $7.18 \mathrm{E}+03$ & 4.60 & 1.51 \\
\hline & & & \\
\hline
\end{tabular}


3as

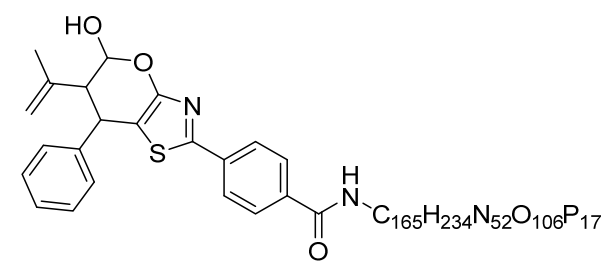

Molecular Weight: 5559.96

wwt-0508-overnight-28

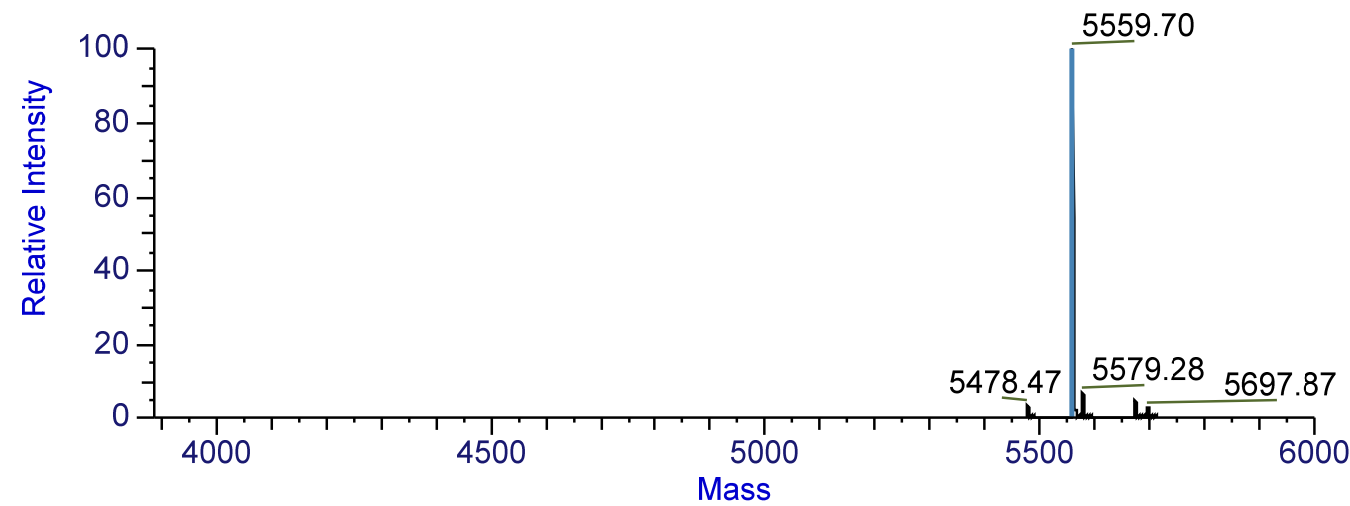

\begin{tabular}{|r|r|r|r|}
\hline Average Mass & Intensity & Relative Abundance & Fractional Abundance \\
\hline 5559.70 & $6.27 \mathrm{E}+05$ & 100.00 & 85.87 \\
\hline 5579.28 & $4.08 \mathrm{E}+04$ & 6.50 & 5.58 \\
\hline 5674.96 & $2.76 \mathrm{E}+04$ & 4.41 & 3.78 \\
\hline 5478.47 & $1.90 \mathrm{E}+04$ & 3.03 & 2.60 \\
\hline 5697.87 & $1.58 \mathrm{E}+04$ & 2.53 & 2.17 \\
\hline
\end{tabular}

3at

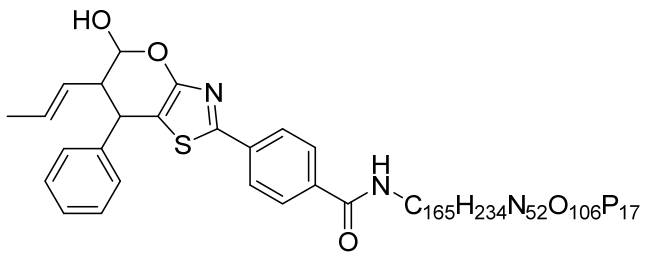

Molecular Weight: 5559.96 
wwt-8-28-24h-46

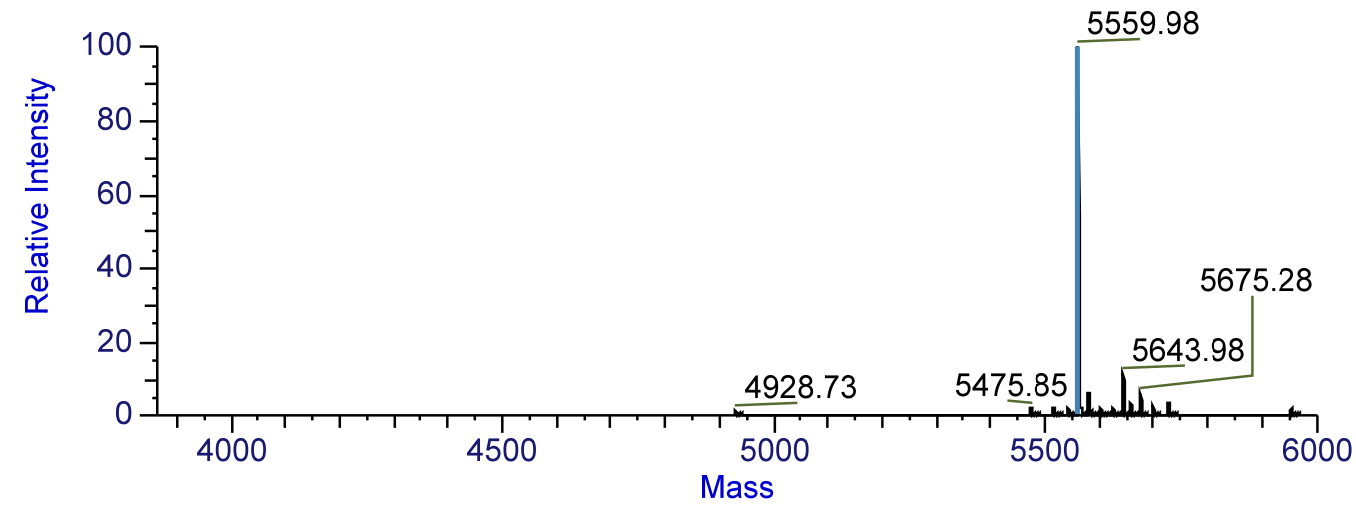

\begin{tabular}{|r|r|r|r|}
\hline Average Mass & Intensity & Relative Abundance & Fractional Abundance \\
\hline 5559.98 & $3.71 \mathrm{E}+05$ & 100.00 & 70.40 \\
\hline 5643.98 & $4.21 \mathrm{E}+04$ & 11.33 & 7.98 \\
\hline 5675.28 & $2.24 \mathrm{E}+04$ & 6.03 & 4.24 \\
\hline 5580.86 & $2.14 \mathrm{E}+04$ & 5.75 & 4.05 \\
\hline 5727.68 & $1.14 \mathrm{E}+04$ & 3.06 & 2.16 \\
\hline 5658.54 & $1.07 \mathrm{E}+04$ & 2.87 & 2.02 \\
\hline 5697.95 & $9.33 \mathrm{E}+03$ & 2.51 & 1.77 \\
\hline 5602.24 & $6.38 \mathrm{E}+03$ & 1.72 & 1.21 \\
\hline 5475.85 & $6.27 \mathrm{E}+03$ & 1.69 & 1.19 \\
\hline 5516.06 & $6.18 \mathrm{E}+03$ & 1.66 & 1.17 \\
\hline & & & \\
\hline
\end{tabular}

\section{3au}

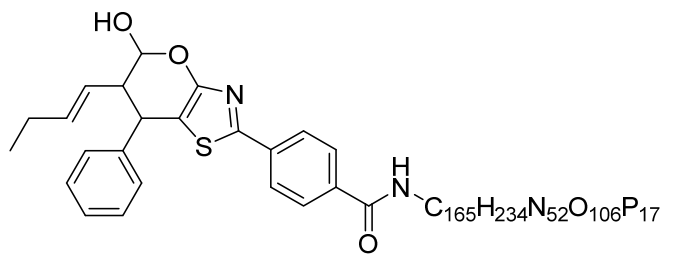

Molecular Weight: 5573.99 


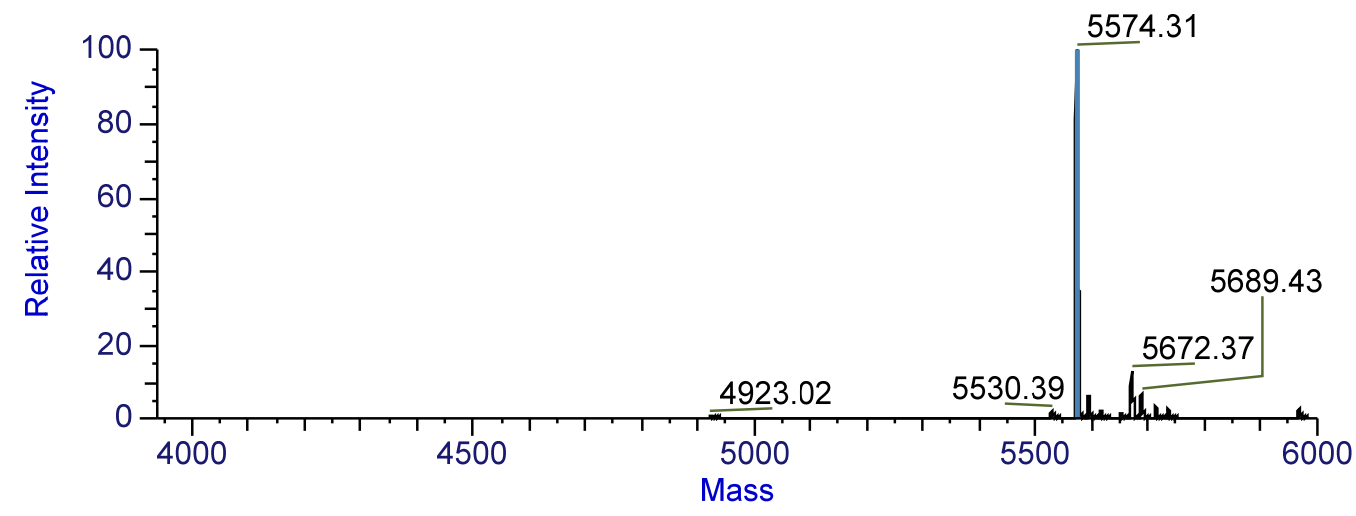

\begin{tabular}{|r|r|r|r|}
\hline Average Mass & Intensity & Relative Abundance & Fractional Abundance \\
\hline 5574.31 & $4.06 \mathrm{E}+05$ & 100.00 & 72.81 \\
\hline 5672.37 & $5.16 \mathrm{E}+04$ & 12.71 & 9.26 \\
\hline 5689.43 & $2.56 \mathrm{E}+04$ & 6.31 & 4.59 \\
\hline 5595.38 & $2.36 \mathrm{E}+04$ & 5.80 & 4.22 \\
\hline 5713.39 & $1.32 \mathrm{E}+04$ & 3.26 & 2.37 \\
\hline 5736.15 & $8.79 \mathrm{E}+03$ & 2.16 & 1.57 \\
\hline 5969.69 & $8.50 \mathrm{E}+03$ & 2.09 & 1.52 \\
\hline 5616.65 & $7.02 \mathrm{E}+03$ & 1.73 & 1.26 \\
\hline 5530.39 & $6.43 \mathrm{E}+03$ & 1.58 & 1.15 \\
\hline 5653.11 & $4.77 \mathrm{E}+03$ & 1.17 & 0.86 \\
\hline
\end{tabular}

\subsection{General procedure for ketones in formal [4+2] cycloaddition reaction on DNA}

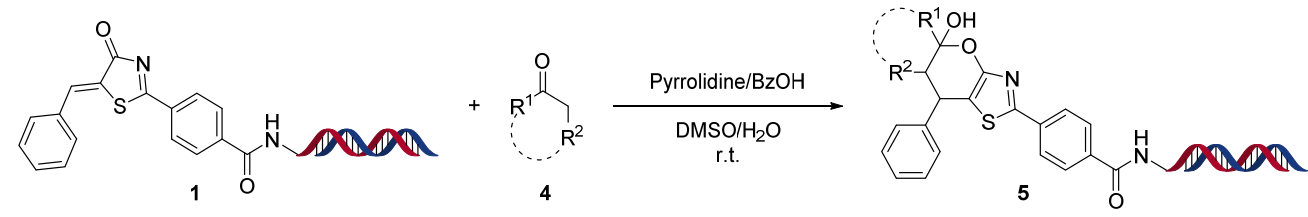

To a solution of DNA-linked 1 (5 nmol, 1 equiv) in water $(5 \mu \mathrm{L})$ was added a solution of aldehyde 4 (5000 nmol, 1000 equiv, 200 mM in DMSO, 5 uL), pyrrolidine (1000 nmol, 200 equiv, $200 \mathrm{mM}$ in DMSO, $1 \mathrm{uL}$ ), and benzoic acid (BzOH) (1000 nmol, 200 equiv, $200 \mathrm{mM}$ in DMSO, $1 \mathrm{uL}$ ). The resultant mixture was vortexed and stood at room temperature for overnight. When LTQ-LCMS showed that reaction was completed, aqueous $\mathrm{NaCl}(2.0 \mu \mathrm{L}, 5.0 \mathrm{M})$ and cold ethanol $(60 \mu \mathrm{L})$ were sequentially added and the resultant mixture was stored at $-80^{\circ} \mathrm{C}$ for $2 \mathrm{~h}$. The mixture was centrifuged at $4{ }^{\circ} \mathrm{C}$ for $30 \mathrm{~min}$ at $10000 \mathrm{rpm}$ before the resultant supernatant was removed. The pellet was dissolved in deionized water and analyzed by fractional abundance LTQ-LCMS to determine the yield of the formal [4+2] cycloaddition reaction. 


\subsection{Mass spectra of 5}

$5 a$

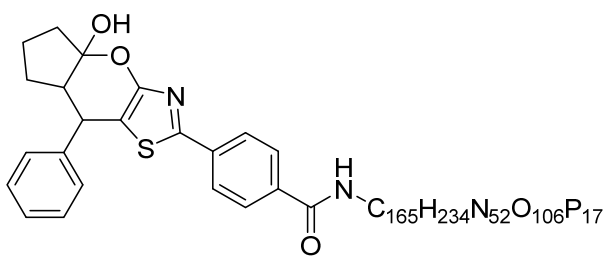

Molecular Weight: 5559.96

wwt-0520-overnight-k1

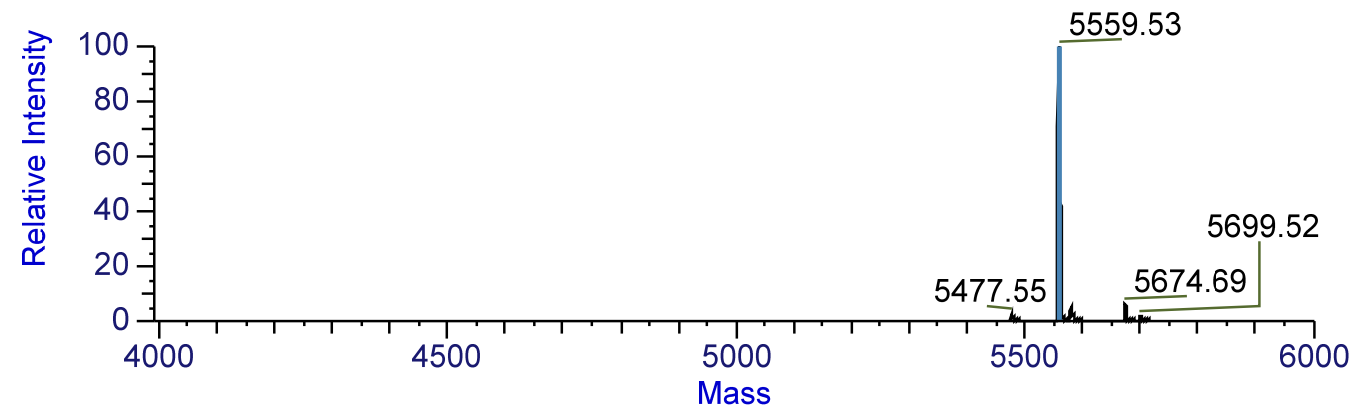

\begin{tabular}{|r|l|r|r|}
\hline Average Mass & Intensity & Relative Abundance & Fractional Abundance \\
\hline 5559.53 & $5.40 \mathrm{E}+05$ & 100.00 & 87.36 \\
\hline 5674.69 & $3.02 \mathrm{E}+04$ & 5.60 & 4.89 \\
\hline 5581.18 & $2.71 \mathrm{E}+04$ & 5.02 & 4.39 \\
\hline 5477.55 & $1.18 \mathrm{E}+04$ & 2.18 & 1.91 \\
\hline 5699.52 & $9.00 \mathrm{E}+03$ & 1.67 & 1.46 \\
\hline
\end{tabular}

$5 b$

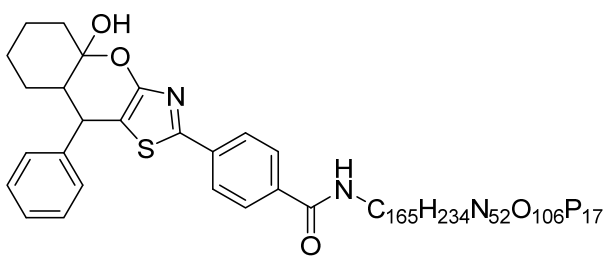

Molecular Weight: 5573.99 
wwt-0520-overnight-k2

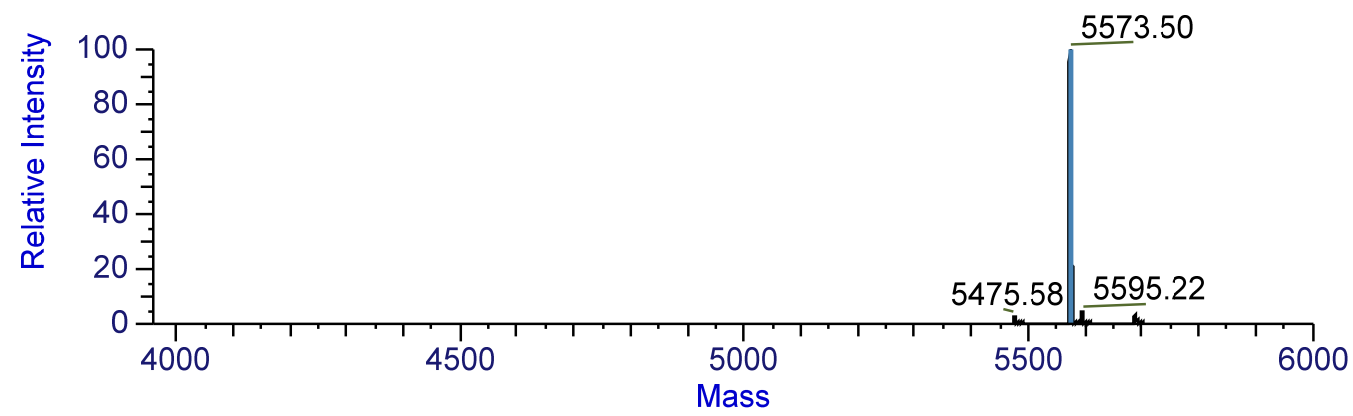

\begin{tabular}{|r|l|r|r|}
\hline Average Mass & Intensity & Relative Abundance & Fractional Abundance \\
\hline 5573.50 & $4.53 \mathrm{E}+05$ & 100.00 & 90.95 \\
\hline 5595.22 & $1.86 \mathrm{E}+04$ & 4.11 & 3.74 \\
\hline 5688.68 & $1.50 \mathrm{E}+04$ & 3.31 & 3.01 \\
\hline 5475.58 & $1.15 \mathrm{E}+04$ & 2.53 & 2.30 \\
\hline
\end{tabular}

5c

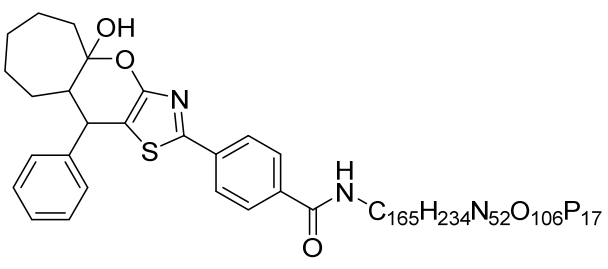

Molecular Weight: 5588.02

wwt-0520-overnight-k3

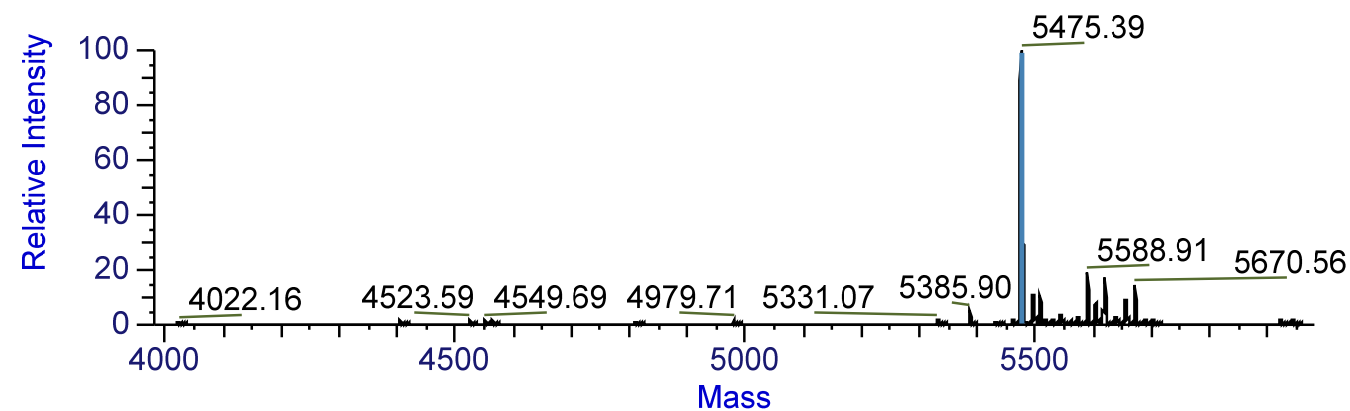

\begin{tabular}{|r|r|r|r|}
\hline Average Mass & Intensity & Relative Abundance & Fractional Abundance \\
\hline 5475.39 & $2.04 \mathrm{E}+05$ & 100.00 & 44.56 \\
\hline 5588.91 & $3.82 \mathrm{E}+04$ & 18.68 & 8.32 \\
\hline 5670.56 & $2.93 \mathrm{E}+04$ & 14.31 & 6.38 \\
\hline 5618.98 & $2.88 \mathrm{E}+04$ & 14.10 & 6.28 \\
\hline 5507.49 & $2.18 \mathrm{E}+04$ & 10.65 & 4.75 \\
\hline 5496.27 & $2.13 \mathrm{E}+04$ & 10.42 & 4.64 \\
\hline 5656.05 & $1.81 \mathrm{E}+04$ & 8.84 & 3.94 \\
\hline 5604.13 & $1.55 \mathrm{E}+04$ & 7.57 & 3.37 \\
\hline
\end{tabular}




\begin{tabular}{|r|r|r|r|}
\hline 5616.51 & $1.04 \mathrm{E}+04$ & 5.09 & 2.27 \\
\hline 5385.90 & $1.00 \mathrm{E}+04$ & 4.90 & 2.18 \\
\hline
\end{tabular}

$5 d$

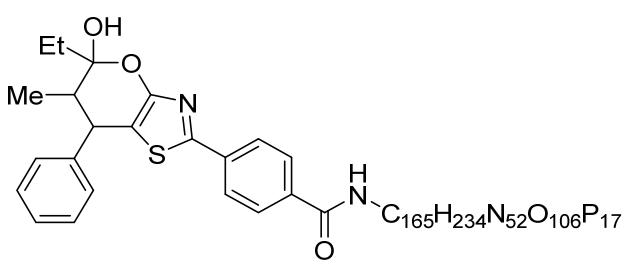

Molecular Weight: 5561.98

wwt-0520-overnight-k6

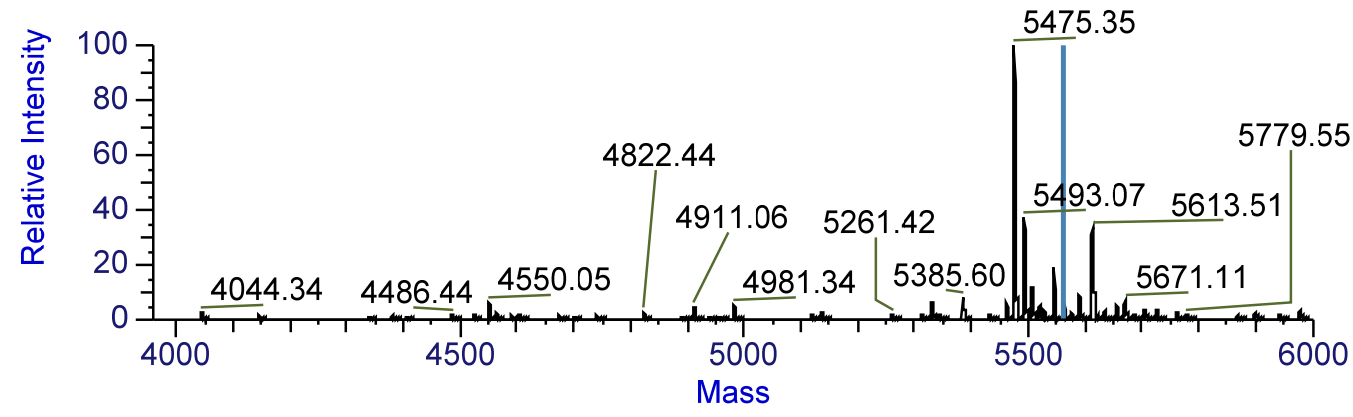

\begin{tabular}{|r|l|r|r|}
\hline Average Mass & Intensity & Relative Abundance & Fractional Abundance \\
\hline 5475.35 & $1.27 \mathrm{E}+05$ & 100.00 & 30.72 \\
\hline 5493.07 & $4.63 \mathrm{E}+04$ & 36.54 & 11.22 \\
\hline 5613.51 & $4.22 \mathrm{E}+04$ & 33.36 & 10.25 \\
\hline 5544.40 & $2.41 \mathrm{E}+04$ & 19.03 & 5.85 \\
\hline 5507.34 & $1.49 \mathrm{E}+04$ & 11.80 & 3.62 \\
\hline 5590.39 & $1.04 \mathrm{E}+04$ & 8.24 & 2.53 \\
\hline 5385.60 & $9.72 \mathrm{E}+03$ & 7.68 & 2.36 \\
\hline 5561.92 & $8.46 \mathrm{E}+03$ & 6.69 & 2.05 \\
\hline 5671.11 & $8.36 \mathrm{E}+03$ & 6.60 & 2.03 \\
\hline 5461.17 & $8.00 \mathrm{E}+03$ & 6.32 & 1.94 \\
\hline & & &
\end{tabular}

$5 e$

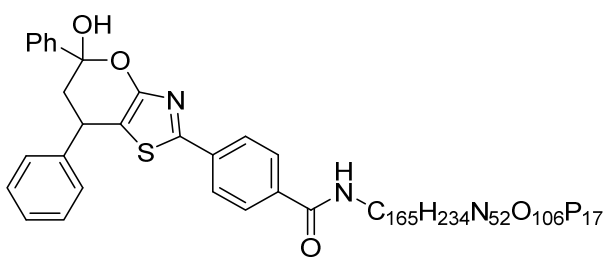

Molecular Weight: 5596.00 
wwt-0520-overnight-k10

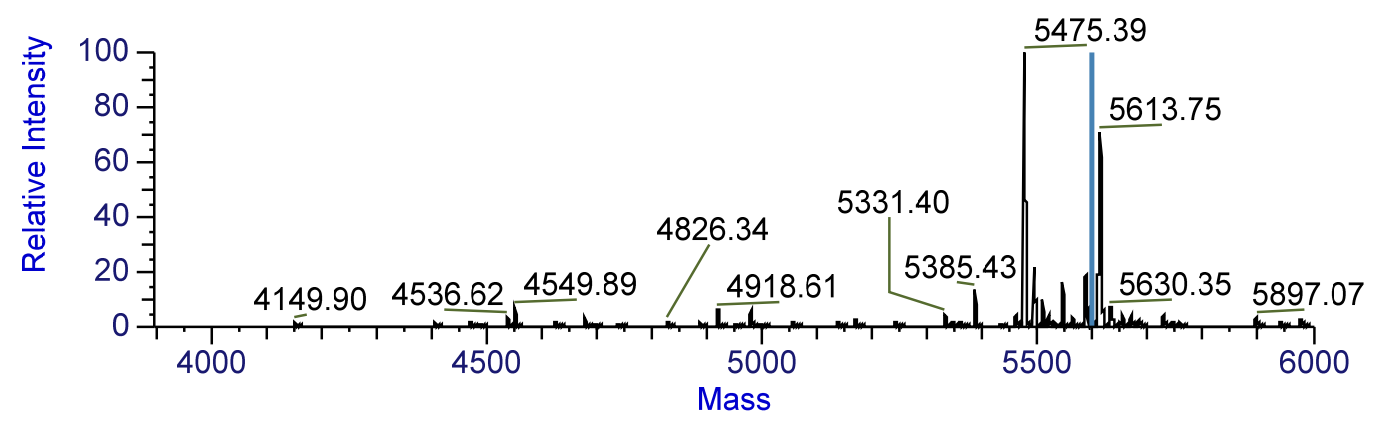

\begin{tabular}{|r|r|r|r|}
\hline Average Mass & Intensity & Relative Abundance & Fractional Abundance \\
\hline 5475.39 & $6.85 \mathrm{E}+04$ & 100.00 & 27.10 \\
\hline 5613.75 & $3.52 \mathrm{E}+04$ & 51.32 & 13.91 \\
\hline 5611.37 & $2.09 \mathrm{E}+04$ & 30.56 & 8.28 \\
\hline 5493.47 & $1.49 \mathrm{E}+04$ & 21.71 & 5.88 \\
\hline 5587.46 & $1.29 \mathrm{E}+04$ & 18.76 & 5.09 \\
\hline 5544.49 & $1.11 \mathrm{E}+04$ & 16.14 & 4.37 \\
\hline 5385.43 & $8.83 \mathrm{E}+03$ & 12.88 & 3.49 \\
\hline 5507.41 & $6.62 \mathrm{E}+03$ & 9.66 & 2.62 \\
\hline 5596.39 & $5.15 \mathrm{E}+03$ & 7.51 & 2.04 \\
\hline 5630.35 & $4.71 \mathrm{E}+03$ & 6.88 & 1.86 \\
\hline
\end{tabular}

$5 f$

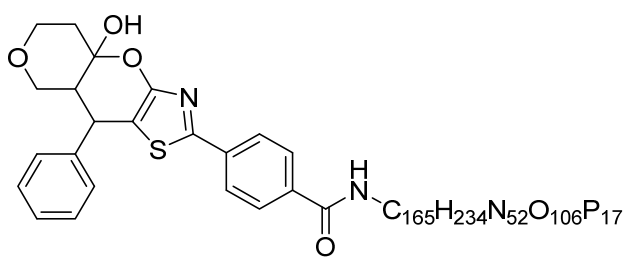

Molecular Weight: 5575.96

wwt-0520-overnight-k7

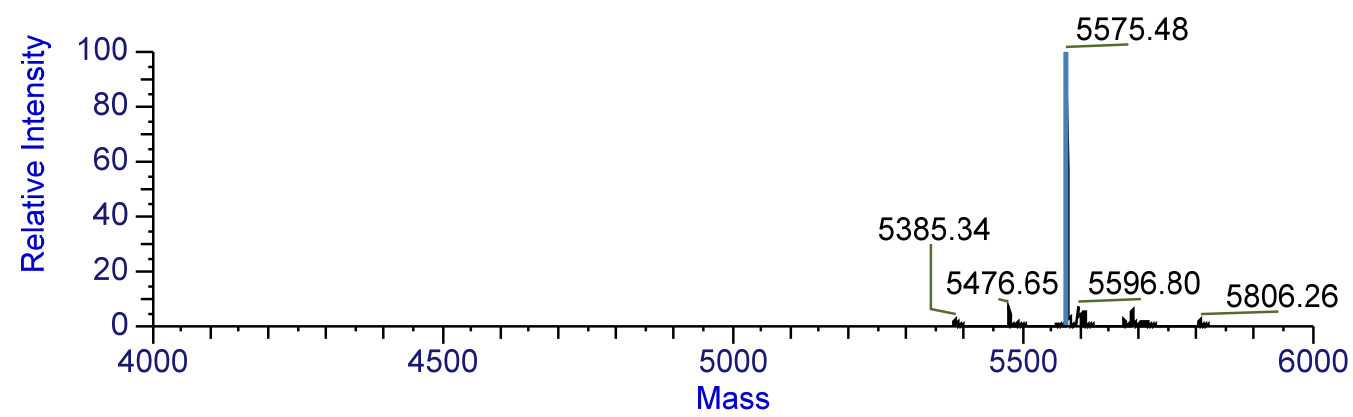

\begin{tabular}{|r|l|r|r|}
\hline Average Mass & Intensity & Relative Abundance & Fractional Abundance \\
\hline 5575.48 & $3.34 \mathrm{E}+05$ & 100.00 & 73.46 \\
\hline 5596.80 & $2.37 \mathrm{E}+04$ & 7.09 & 5.21 \\
\hline
\end{tabular}




\begin{tabular}{|r|r|r|r|}
\hline 5476.65 & $2.35 \mathrm{E}+04$ & 7.02 & 5.16 \\
\hline 5690.46 & $1.92 \mathrm{E}+04$ & 5.74 & 4.22 \\
\hline 5607.59 & $1.67 \mathrm{E}+04$ & 4.99 & 3.66 \\
\hline 5385.34 & $8.68 \mathrm{E}+03$ & 2.60 & 1.91 \\
\hline 5675.22 & $6.99 \mathrm{E}+03$ & 2.09 & 1.54 \\
\hline 5806.26 & $6.19 \mathrm{E}+03$ & 1.85 & 1.36 \\
\hline 5715.00 & $5.72 \mathrm{E}+03$ & 1.71 & 1.26 \\
\hline 5493.12 & $4.29 \mathrm{E}+03$ & 1.28 & 0.94 \\
\hline
\end{tabular}

$5 g$

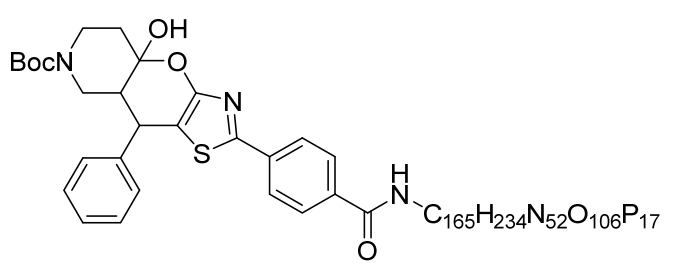

Molecular Weight: 5675.10

wwt-0520-overnight-k4

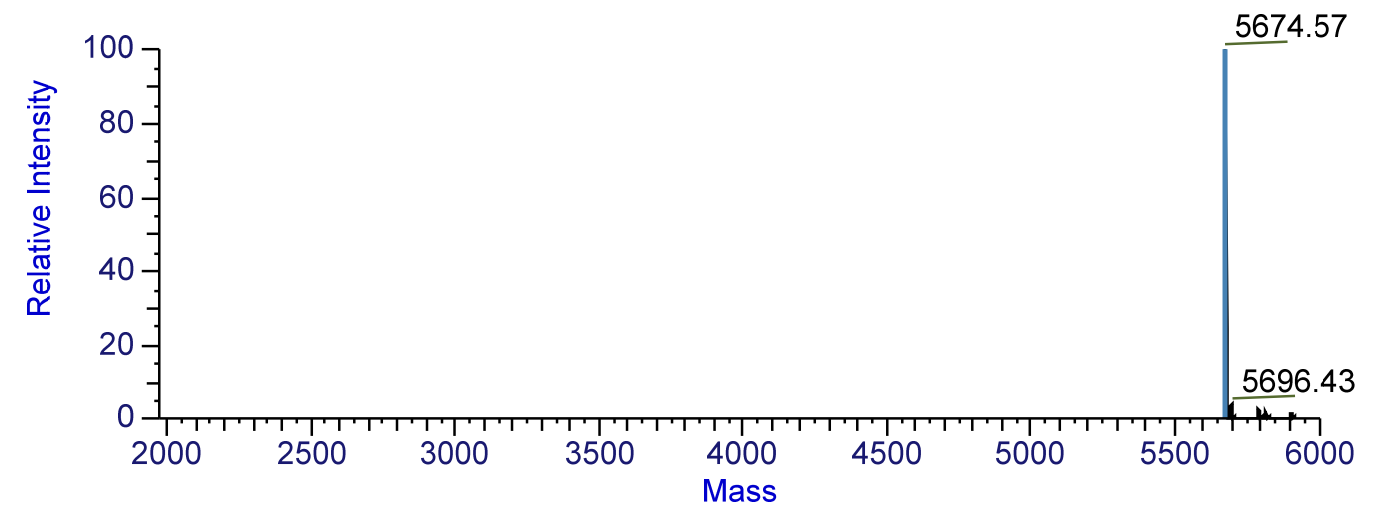

\begin{tabular}{|r|c|r|r|}
\hline Average Mass & Intensity & Relative Abundance & Fractional Abundance \\
\hline 5674.57 & $7.20 \mathrm{E}+05$ & 100.00 & 91.50 \\
\hline 5696.43 & $2.53 \mathrm{E}+04$ & 3.52 & 3.22 \\
\hline 5789.73 & $1.92 \mathrm{E}+04$ & 2.66 & 2.44 \\
\hline 5814.16 & $1.35 \mathrm{E}+04$ & 1.87 & 1.71 \\
\hline 5905.02 & $8.92 \mathrm{E}+03$ & 1.24 & 1.13 \\
\hline
\end{tabular}




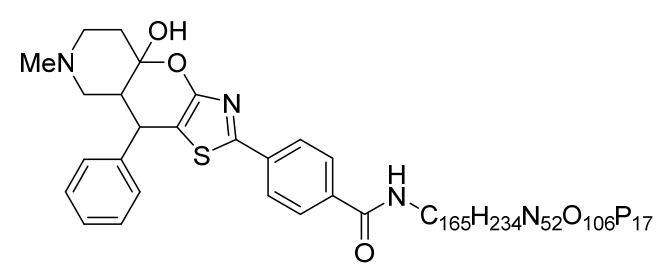

Molecular Weight: 5589.01

wwt-0520-overnight-k5

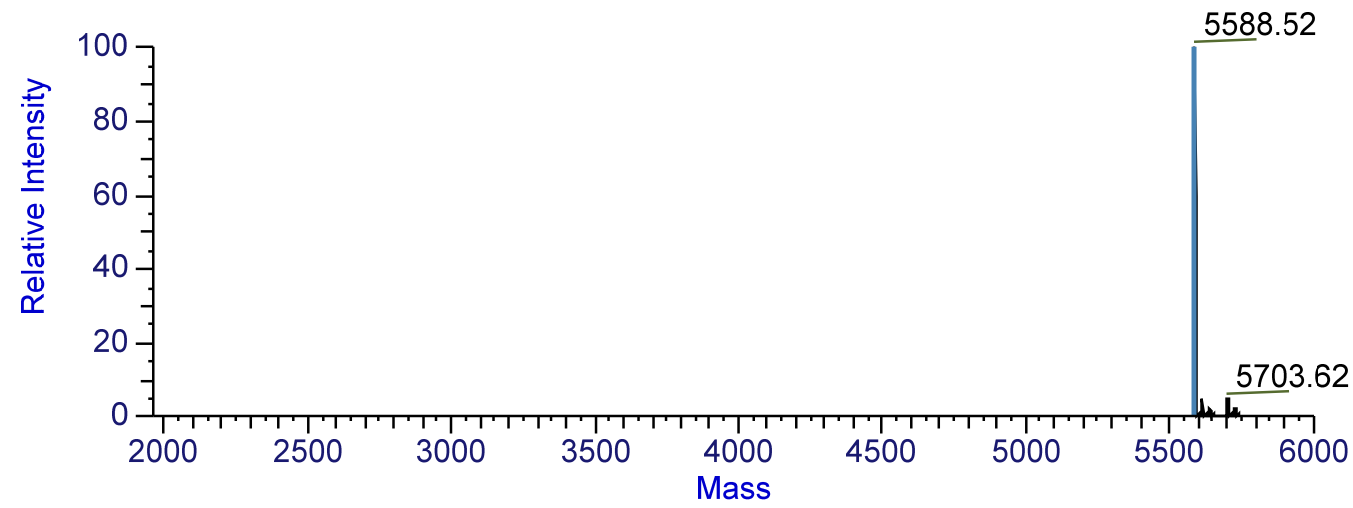

\begin{tabular}{|r|r|r|r|}
\hline Average Mass & Intensity & Relative Abundance & Fractional Abundance \\
\hline 5588.52 & $6.77 \mathrm{E}+05$ & 100.00 & 88.84 \\
\hline 5703.62 & $3.08 \mathrm{E}+04$ & 4.55 & 4.04 \\
\hline 5610.33 & $2.81 \mathrm{E}+04$ & 4.15 & 3.69 \\
\hline 5728.79 & $1.37 \mathrm{E}+04$ & 2.02 & 1.79 \\
\hline 5640.76 & $1.25 \mathrm{E}+04$ & 1.84 & 1.64 \\
\hline
\end{tabular}

$5 \mathbf{i}$

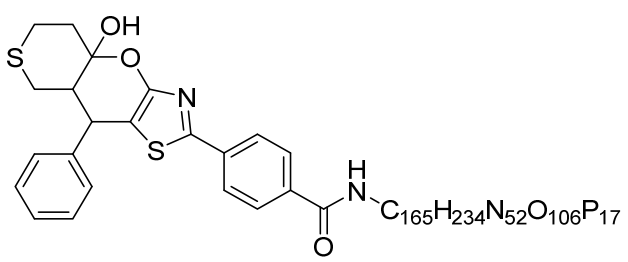

Molecular Weight: 5592.02 
wwt-0520-overnight-k9

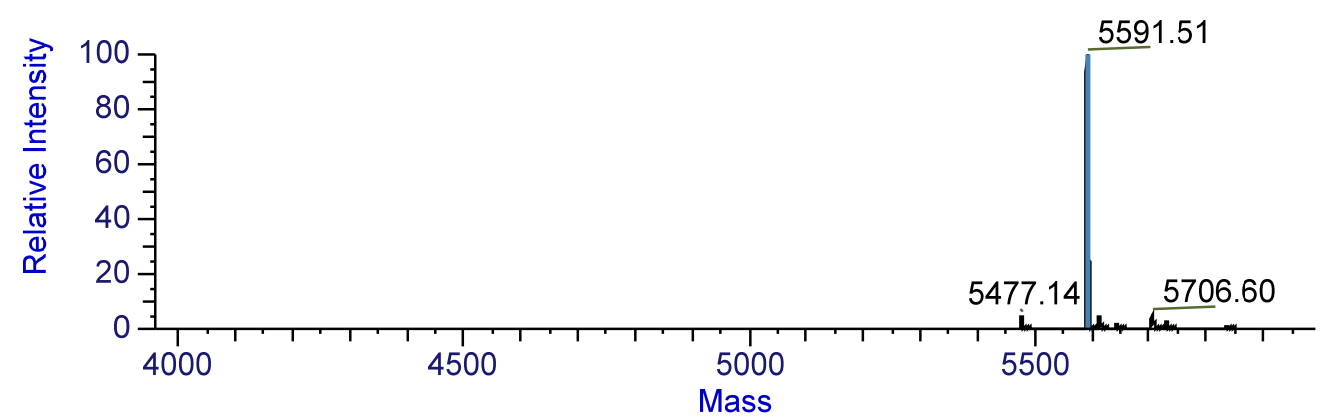

\begin{tabular}{|r|r|r|r|}
\hline Average Mass & Intensity & Relative Abundance & Fractional Abundance \\
\hline 5591.51 & $5.42 \mathrm{E}+05$ & 100.00 & 84.52 \\
\hline 5706.60 & $2.72 \mathrm{E}+04$ & 5.02 & 4.24 \\
\hline 5613.47 & $2.41 \mathrm{E}+04$ & 4.45 & 3.76 \\
\hline 5477.14 & $2.40 \mathrm{E}+04$ & 4.42 & 3.74 \\
\hline 5730.95 & $1.10 \mathrm{E}+04$ & 2.02 & 1.71 \\
\hline 5643.86 & $8.73 \mathrm{E}+03$ & 1.61 & 1.36 \\
\hline 5837.06 & $4.28 \mathrm{E}+03$ & 0.79 & 0.67 \\
\hline
\end{tabular}

$5 j$

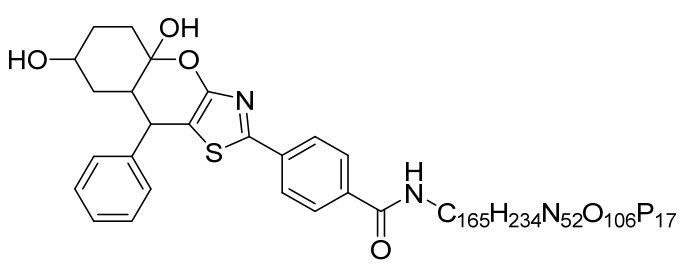

Molecular Weight: 5589.99

wwt-0816-24h-k17

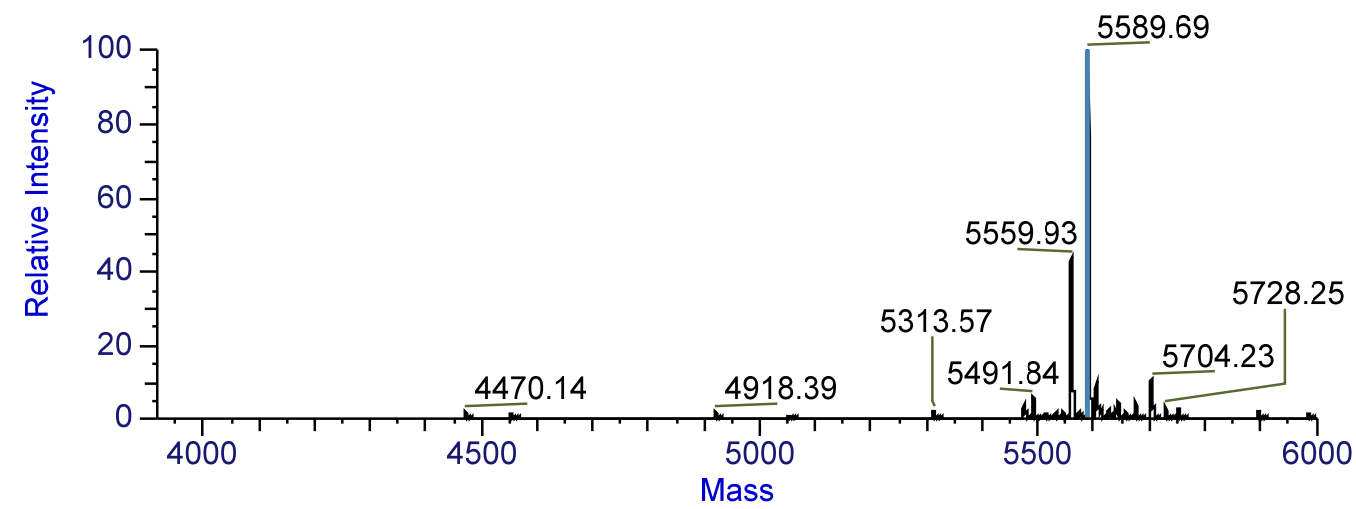

\begin{tabular}{|r|l|r|r|}
\hline Average Mass & Intensity & Relative Abundance & Fractional Abundance \\
\hline 5589.69 & $1.44 \mathrm{E}+05$ & 100.00 & 47.44 \\
\hline 5559.93 & $6.29 \mathrm{E}+04$ & 43.76 & 20.76 \\
\hline 5704.23 & $1.52 \mathrm{E}+04$ & 10.58 & 5.02 \\
\hline
\end{tabular}




\begin{tabular}{|r|r|r|r|}
\hline 5605.83 & $1.39 \mathrm{E}+04$ & 9.65 & 4.58 \\
\hline 5491.84 & $8.17 \mathrm{E}+03$ & 5.68 & 2.70 \\
\hline 5674.34 & $6.68 \mathrm{E}+03$ & 4.64 & 2.20 \\
\hline 5476.06 & $5.36 \mathrm{E}+03$ & 3.72 & 1.77 \\
\hline 5643.92 & $5.08 \mathrm{E}+03$ & 3.53 & 1.67 \\
\hline 5728.25 & $4.14 \mathrm{E}+03$ & 2.88 & 1.36 \\
\hline 5612.39 & $3.94 \mathrm{E}+03$ & 2.74 & 1.30 \\
\hline
\end{tabular}

$5 k$<smiles>CCCCN[C@@H](CCCCNC(=O)c1ccc(-c2nc3c(s2)C(c2ccccc2)C2CC(CC)CCC2(O)O3)cc1)OOCCC</smiles>

Molecular Weight: 5602.04

wwt-0816-24h-k16

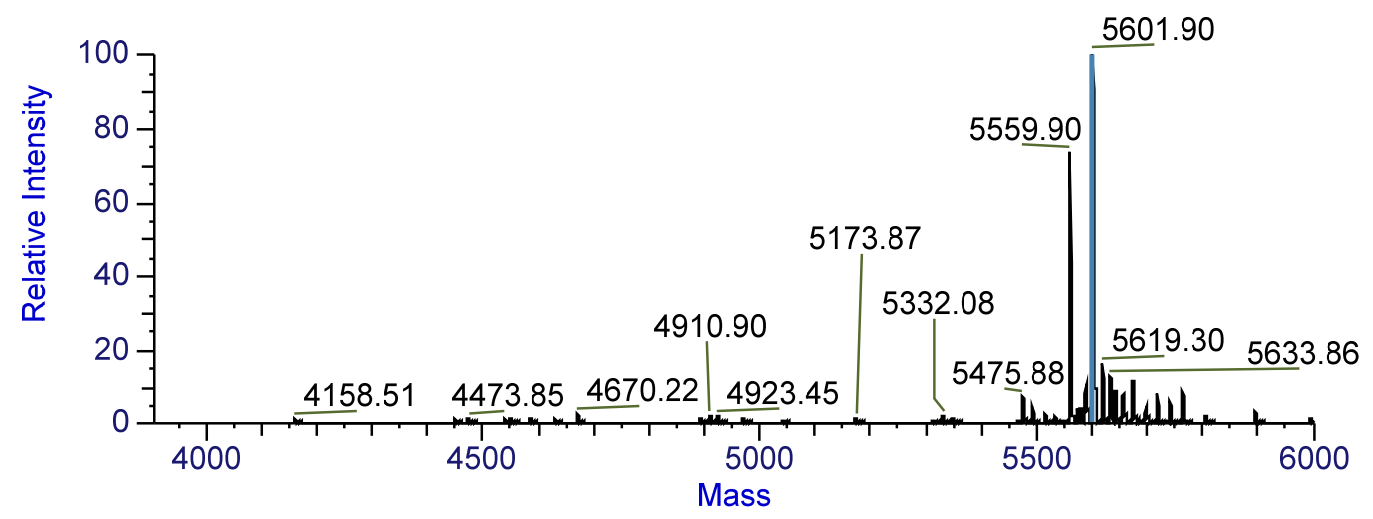

\begin{tabular}{|r|l|r|r|}
\hline Average Mass & Intensity & Relative Abundance & Fractional Abundance \\
\hline 5601.90 & $1.09 \mathrm{E}+05$ & 100.00 & 31.72 \\
\hline 5559.90 & $8.00 \mathrm{E}+04$ & 73.18 & 23.21 \\
\hline 5619.30 & $1.70 \mathrm{E}+04$ & 15.57 & 4.94 \\
\hline 5633.86 & $1.38 \mathrm{E}+04$ & 12.65 & 4.01 \\
\hline 5674.66 & $1.24 \mathrm{E}+04$ & 11.37 & 3.61 \\
\hline 5590.50 & $1.14 \mathrm{E}+04$ & 10.41 & 3.30 \\
\hline 5643.04 & $9.30 \mathrm{E}+03$ & 8.51 & 2.70 \\
\hline 5764.04 & $9.20 \mathrm{E}+03$ & 8.41 & 2.67 \\
\hline 5657.56 & $8.56 \mathrm{E}+03$ & 7.82 & 2.48 \\
\hline 5717.63 & $8.26 \mathrm{E}+03$ & 7.55 & 2.40 \\
\hline
\end{tabular}




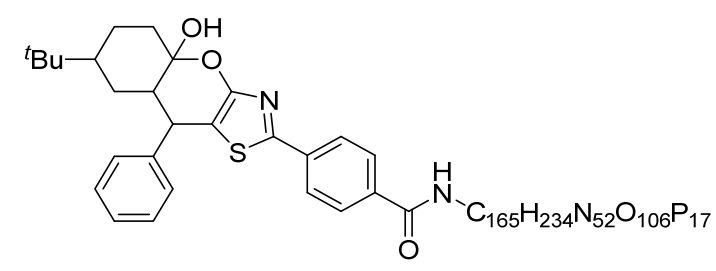

Molecular Weight: 5630.10

wwt-0816-24h-k13

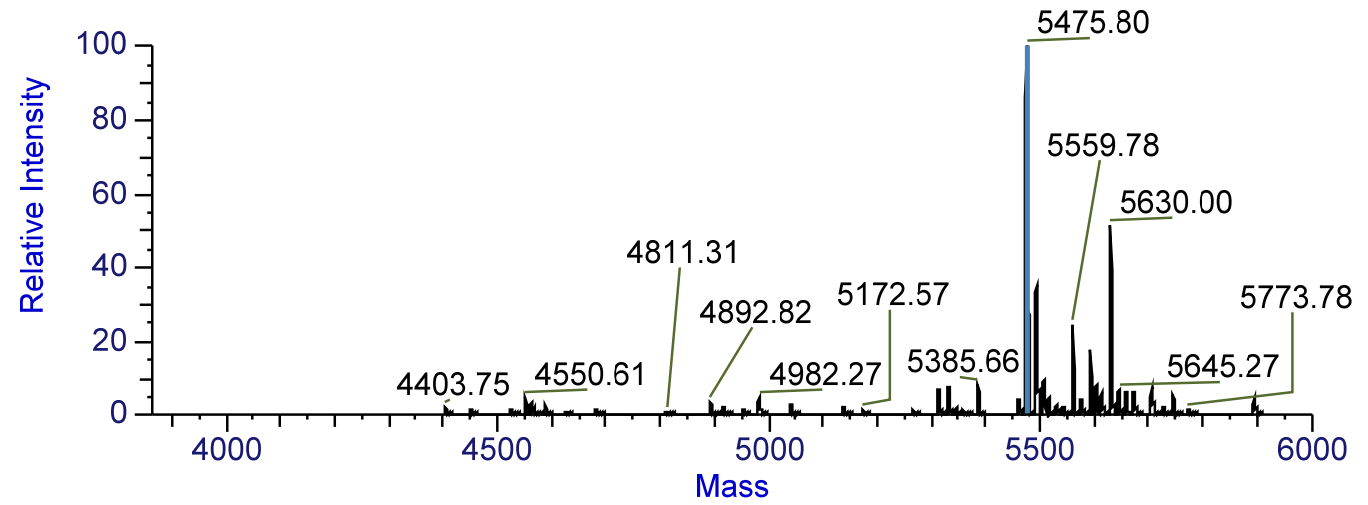

\begin{tabular}{|r|r|r|r|}
\hline Average Mass & Intensity & Relative Abundance & Fractional Abundance \\
\hline 5475.80 & $7.09 \mathrm{E}+04$ & 100.00 & 27.84 \\
\hline 5630.00 & $3.60 \mathrm{E}+04$ & 50.74 & 14.13 \\
\hline 5493.61 & $2.46 \mathrm{E}+04$ & 34.66 & 9.65 \\
\hline 5559.78 & $1.68 \mathrm{E}+04$ & 23.65 & 6.59 \\
\hline 5592.35 & $1.24 \mathrm{E}+04$ & 17.54 & 4.88 \\
\hline 5507.79 & $6.28 \mathrm{E}+03$ & 8.86 & 2.47 \\
\hline 5385.66 & $5.62 \mathrm{E}+03$ & 7.93 & 2.21 \\
\hline 5603.88 & $5.28 \mathrm{E}+03$ & 7.45 & 2.07 \\
\hline 5331.83 & $4.91 \mathrm{E}+03$ & 6.93 & 1.93 \\
\hline 5313.46 & $4.49 \mathrm{E}+03$ & 6.33 & 1.76 \\
\hline
\end{tabular}

$5 m$

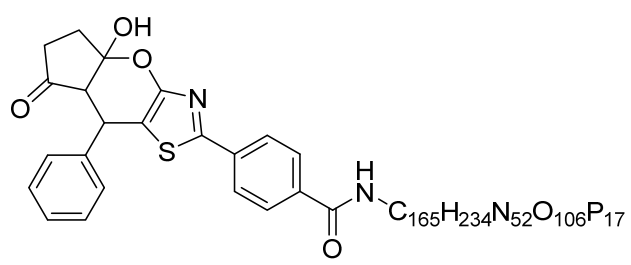

Molecular Weight: 5573.95 


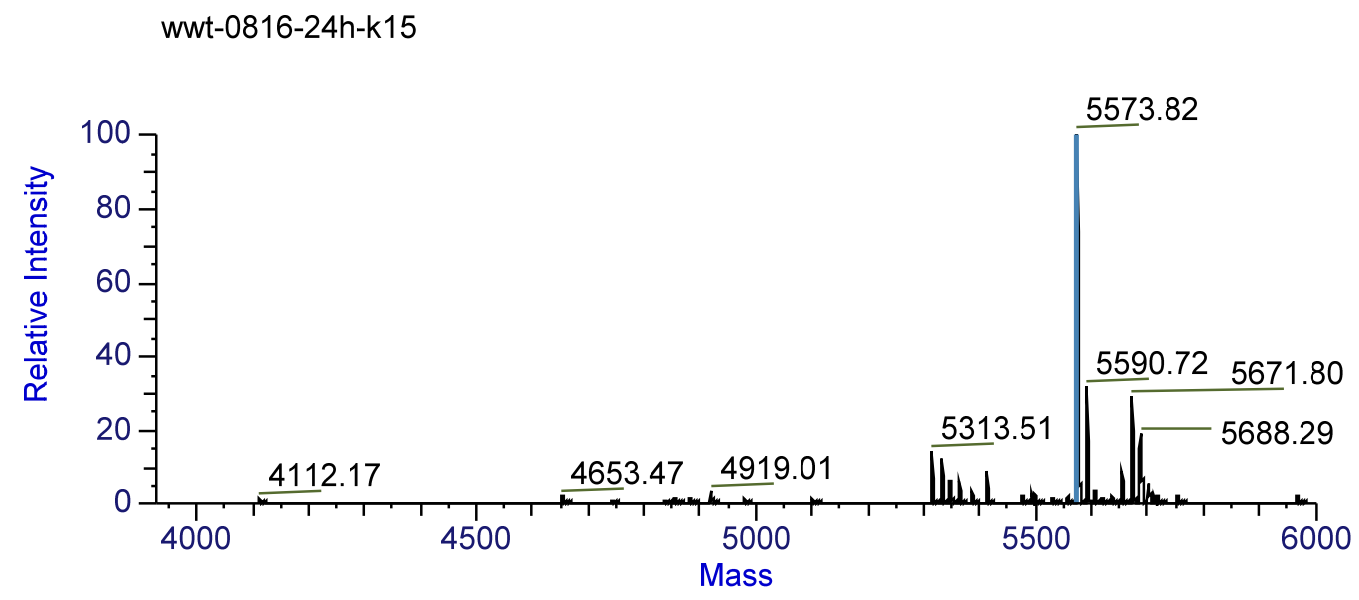

\begin{tabular}{|c|c|c|c|}
\hline Average Mass & Intensity & $\begin{array}{l}\text { Relative } \\
\text { Abundance }\end{array}$ & $\begin{array}{l}\text { Fractional } \\
\text { Abundance }\end{array}$ \\
\hline 5573.82 & $2.08 \mathrm{E}+05$ & 100.00 & 36.54 \\
\hline 5590.72 & $6.52 \mathrm{E}+04$ & 31.27 & 11.42 \\
\hline 5671.80 & $6.00 E+04$ & 28.79 & 10.52 \\
\hline 5688.29 & $3.83 E+04$ & 18.35 & 6.70 \\
\hline 5313.51 & $2.87 E+04$ & 13.75 & 5.02 \\
\hline 5331.89 & $2.53 \mathrm{E}+04$ & 12.13 & 4.43 \\
\hline 5654.06 & 1.77E+04 & 8.51 & 3.11 \\
\hline 5411.82 & $1.75 \mathrm{E}+04$ & 8.39 & 3.06 \\
\hline 5347.58 & $1.26 \mathrm{E}+04$ & 6.04 & 2.21 \\
\hline 5363.31 & $1.15 \mathrm{E}+04$ & 5.53 & 2.02 \\
\hline
\end{tabular}

$5 n$

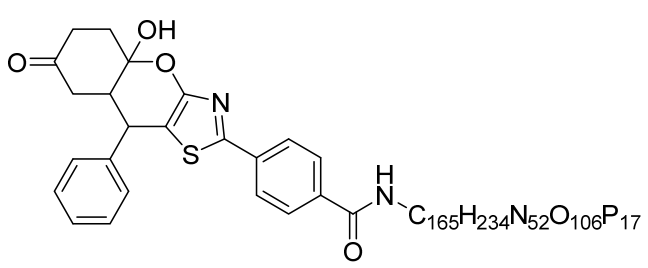

Molecular Weight: 5587.97 
wwt-0816-24h-k11

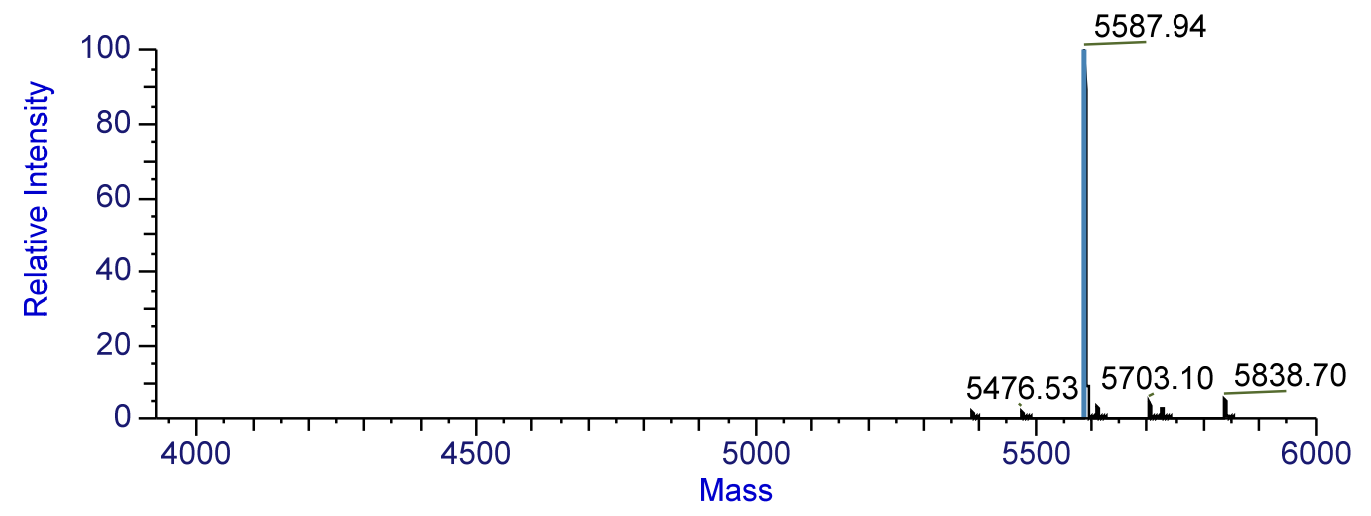

\begin{tabular}{|r|r|r|r|}
\hline Average Mass & Intensity & Relative Abundance & Fractional Abundance \\
\hline 5587.94 & $5.42 \mathrm{E}+05$ & 100.00 & 84.55 \\
\hline 5838.70 & $2.59 \mathrm{E}+04$ & 4.77 & 4.03 \\
\hline 5703.10 & $2.55 \mathrm{E}+04$ & 4.70 & 3.97 \\
\hline 5609.62 & $1.82 \mathrm{E}+04$ & 3.36 & 2.84 \\
\hline 5727.35 & $1.42 \mathrm{E}+04$ & 2.62 & 2.22 \\
\hline 5476.53 & $7.75 \mathrm{E}+03$ & 1.43 & 1.21 \\
\hline 5385.92 & $7.52 \mathrm{E}+03$ & 1.39 & 1.17 \\
\hline
\end{tabular}

50

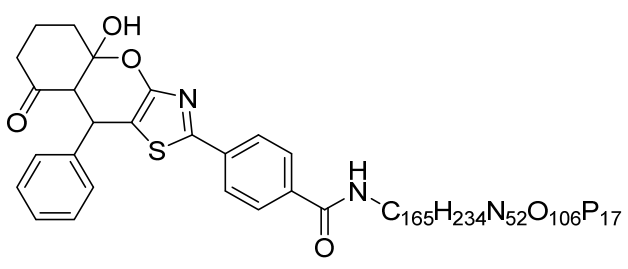

Molecular Weight: 5587.97

wwt-0816-24h-k12

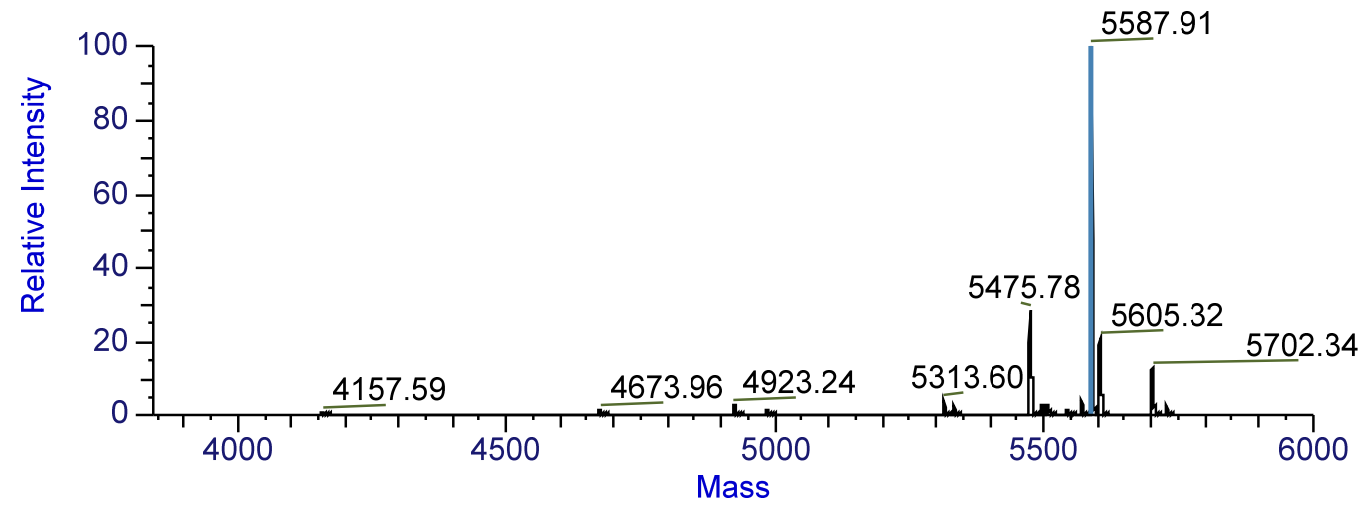

\begin{tabular}{|r|l|r|r|}
\hline Average Mass & Intensity & Relative Abundance & Fractional Abundance \\
\hline 5587.91 & $3.09 \mathrm{E}+05$ & 100.00 & 54.43 \\
\hline
\end{tabular}




\begin{tabular}{|r|r|r|r|}
\hline 5475.78 & $8.71 \mathrm{E}+04$ & 28.20 & 15.35 \\
\hline 5605.32 & $6.35 \mathrm{E}+04$ & 20.53 & 11.18 \\
\hline 5702.34 & $3.87 \mathrm{E}+04$ & 12.51 & 6.81 \\
\hline 5313.60 & $1.09 \mathrm{E}+04$ & 3.52 & 1.92 \\
\hline 5570.10 & $1.07 \mathrm{E}+04$ & 3.46 & 1.88 \\
\hline 5507.90 & $8.18 \mathrm{E}+03$ & 2.65 & 1.44 \\
\hline 4923.24 & $7.64 \mathrm{E}+03$ & 2.47 & 1.35 \\
\hline 5496.46 & $7.32 \mathrm{E}+03$ & 2.37 & 1.29 \\
\hline 5727.59 & $7.13 \mathrm{E}+03$ & 2.31 & 1.26 \\
\hline
\end{tabular}

\subsection{Procedures for enzymatic ligation}

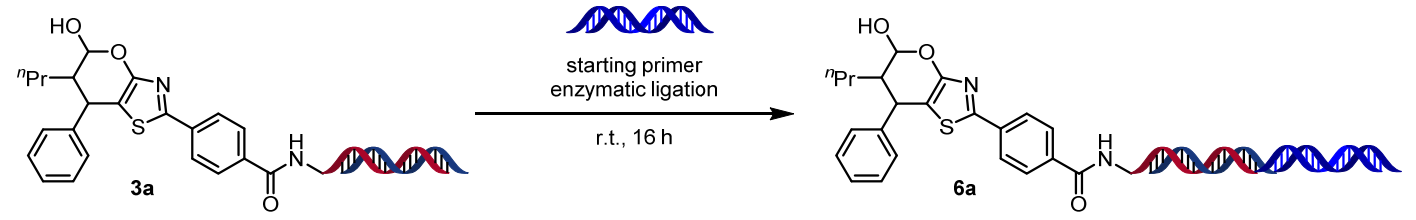

The above pellet 3a ( $5 \mathrm{nmol}, \mathrm{MW}$ : 5562 ) was dissolved in $5 \mathrm{uL} \mathrm{dd} \mathrm{H}_{2} \mathrm{O}$. To the tube was added the Primer (LGC Biosearch Technologies, $1 \mathrm{mM}$ in dd $\mathrm{d}_{2} \mathrm{O}, 6 \mathrm{uL}$, Primer 1 and Primer 2 were freshly annealed at $95{ }^{\circ} \mathrm{C}$ for $5 \mathrm{~min}$, then stored at $4{ }^{\circ} \mathrm{C}$ for $15 \mathrm{~min}$ ), Ligation buffer (Thermo Scientific, 10 $\mathrm{X}, 3 \mathrm{uL}), \mathrm{ddH}_{2} \mathrm{O}(15.7 \mathrm{uL}), \mathrm{T} 4$ ligase $(30 \mathrm{U} / \mu \mathrm{L}, 0.3 \mathrm{uL})$. The tube was mixed, eddied and centrifuged, stood at r.t. for overnight. Analyze the sample by LTQ-LCMS. Mass spectrum showed only the desired product 6a (Target Molecular weight: 17984).

Sequence of primer (MW: 12458):

Primer 1: 5'-AAATCGATGTGGTCAGGAAG-3'

Primer 2: 3'-GGTTTAGCTACACCAGTCCT-5'

\section{Mass spectra of $6 a$}

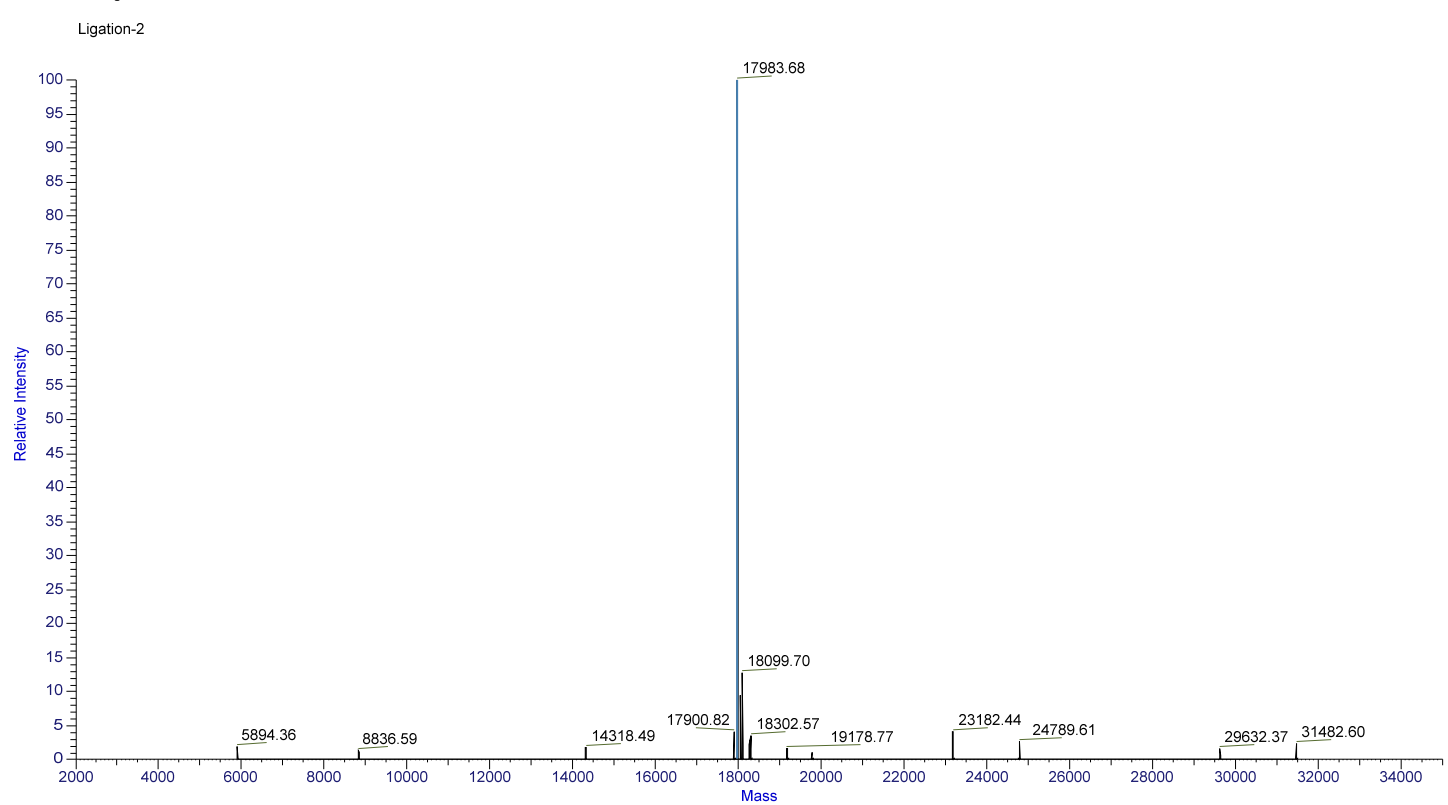




\section{References}

(1) Kennedy, A. J.; Mathews, T. P.; Kharel, Y.; Field, S. D.; Moyer, M. L.; East, J. E.; Houck, J. D.; Lynch, K. R.; MacDonald, T. L., Development of Amidine-Based Sphingosine Kinase 1 Nanomolar Inhibitors and Reduction of Sphingosine 1-Phosphate in Human Leukemia Cells. J. Med. Chem. 2011, 54, 3524.

(2) Lin, L.; Yang, Y.; Wang, M.; Lai, L.; Guo, Y.; Wang, R., Oxidative N-heterocyclic carbene catalyzed stereoselective annulation of simple aldehydes and 5-alkenyl thiazolones. Chem. Commun. 2015, 51,8134 . 


\section{Copies of NMR spectra}

${ }^{1} \mathrm{H}$ NMR spectrum of $\mathbf{3 a}\left(400 \mathrm{MHz}, \mathrm{CDCl}_{3}\right)$

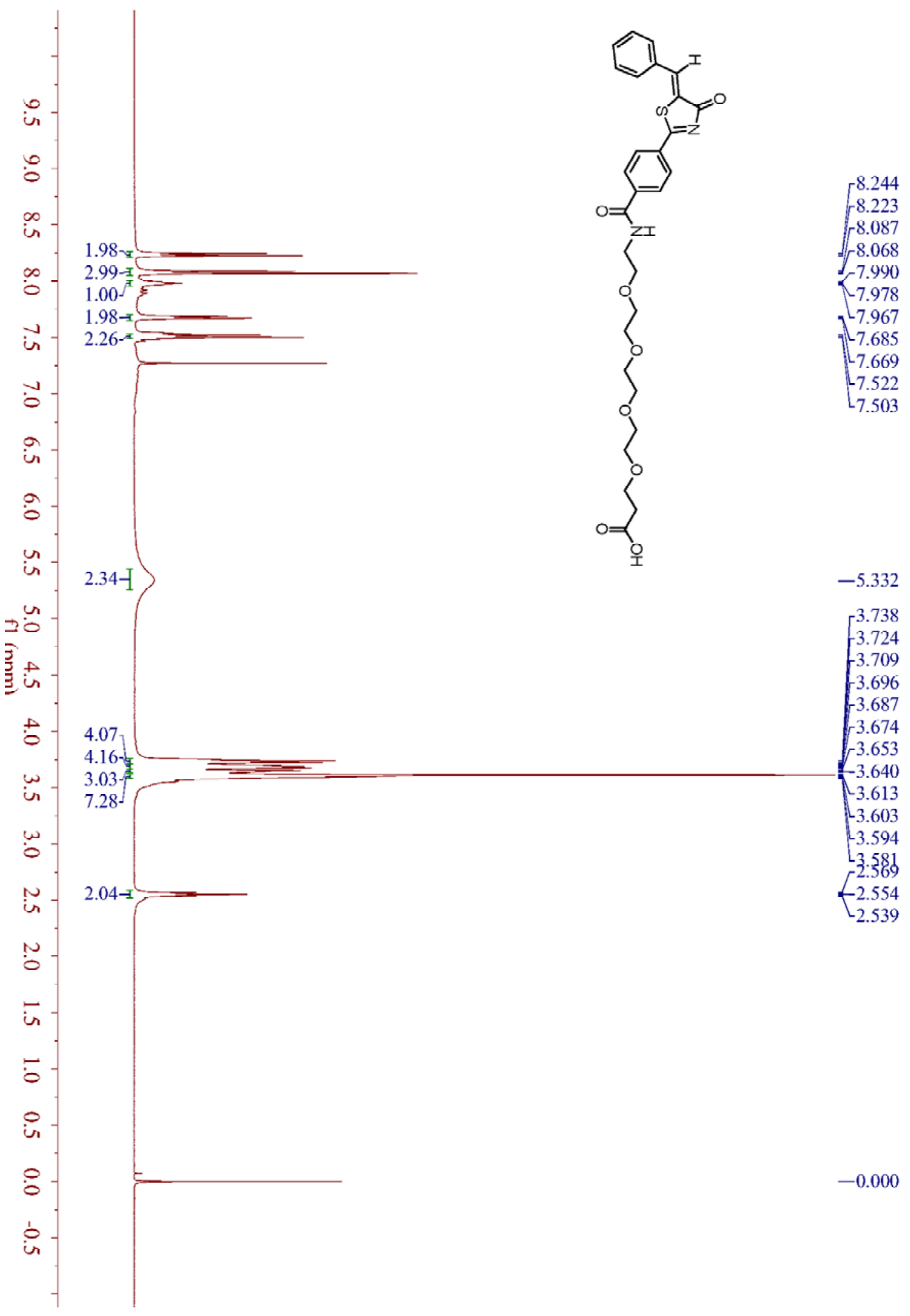


${ }^{13} \mathrm{C}$ NMR spectrum of $\mathbf{3 a}\left(100 \mathrm{MHz}, \mathrm{CDCl}_{3}\right)$

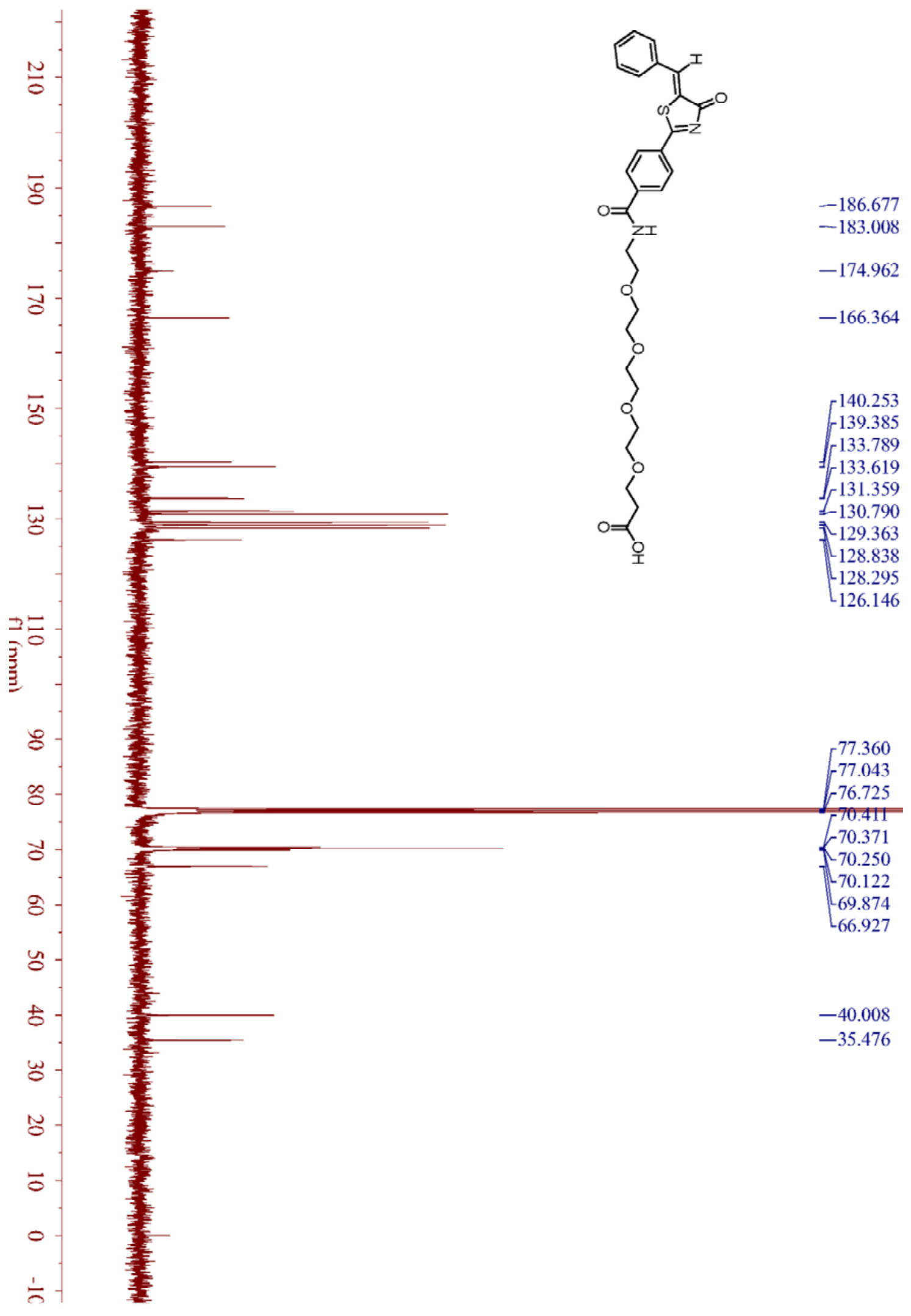

